\title{
The Role of Aldol Condensation and Hydrogen Transfer Reactions in the Guerbet Coupling Reaction of Ethanol over Acid-Base Catalysts
}

\section{A Dissertation \\ Presented to}

the faculty of the School of Engineering and Applied Science

University of Virginia

\author{
in partial fulfillment \\ of the requirements for the degree \\ Doctor of Philosophy \\ by \\ Zachary Donald Young
}

August 2017 


\begin{abstract}
Guerbet coupling is a well-known reaction that couples two short chain alcohols into a longer chain alcohol. Guerbet coupling is believed to consist of many reactions including dehydrogenation, aldol condensation, dehydration, and hydrogenation. Recently, the calcium phosphate hydroxyapatite (HAP) has been shown to have a higher activity and selectivity towards butanol when compared to a more traditional Guerbet coupling catalyst such as $\mathrm{MgO}$. In an attempt to study the overall Guerbet coupling reaction network in more detail, as well as to understand what makes HAP such an effective catalyst, the constituent reactions of the Guerbet coupling reaction network were investigated. Specifically, aldol condensation of acetaldehyde, dehydrogenation of benzyl alcohol, and hydrogenation of ethene and acetone using both $\mathrm{H}_{2}$ and ethanol were studied. The aldol condensation reaction was tested over anatase titania $\left(\mathrm{TiO}_{2}\right)$, hydroxyapatite $(\mathrm{HAP})$, and magnesia $(\mathrm{MgO})$ in an attempt to determine the mechanism of aldol condensation over these catalysts. Conclusions based on reaction kinetics and isotope studies indicated enolate formation was fast while both adsorption of acetaldehyde and product desorption were kinetically relevant. The role that hydrogen plays in the coupling network was also studied in detail over HAP and $\mathrm{MgO}$. Guerbet coupling in the presence of $\mathrm{D}_{2}$ revealed that deuterium was incorporated into the product butanol formed over $\mathrm{MgO}$ but not over HAP. Reactions involving $\mathrm{H}_{2}$ with ethene and acetone showed that $\mathrm{H}_{2}$ was unable to hydrogenate $\mathrm{C}=\mathrm{C}$ or $\mathrm{C}=\mathrm{O}$ bonds. The main route for hydrogenation reactions instead occurs through a Meerwein-Ponndorf-Verley-like (MPV-like) mechanism. The lack of $\mathrm{C}=\mathrm{C}$ bond
\end{abstract}


hydrogenation with either $\mathrm{H}_{2}$ or ethanol indicates that crotonaldehyde hydrogenation proceeds through the MPV-like hydrogenation to crotyl alcohol, followed by rapid double bond isomerization and keto/enol tautomerization to butanal. Butanal will then be hydrogenated by an MPV-like reaction with ethanol. In this way, the acetaldehyde that was consumed during aldol condensation is regenerated in the hydrogenation steps. The initial alcohol dehydrogenation reaction that must occur in the Guerbet reaction network was probed by measuring benzyl alcohol dehydrogenation. This reaction occurred over both $\mathrm{MgO}$ and $\mathrm{HAP}$, but required much higher temperatures when compared to aldol condensation and hydrogenation. The efficiency with which the rapid aldol condensation/crotonaldehyde hydrogenation cycle takes place seems to control the overall activity and selectivity of the Guerbet coupling of ethanol. 


\section{Acknowledgments}

There are a few people I would like to acknowledge. First, my parents Ronda and Charlie. Without your constant love and support, I would never have been able to make it this far. I would also like to thank my adviser Robert J. Davis for guiding me through my PhD. A special thank you goes to Dr. Sabra Hanspal for being my friend and mentor throughout. Many long nights in the lab would have felt empty without your advice and, more importantly, your friendship. I would be remiss if I did not take this time to mention all of my other labmates and friends. A PhD is never easy, but without all of you I am sure it would have been impossible.

Finally, I would like to acknowledge the funding source for this project. This work was supported by the Chemical Sciences, Geosciences and Biosciences Division, Office of Basic Energy Sciences, Office of Science, U.S. Department of Energy, grant no. DE-FG02-95ER14549. 


\section{Contents}

1 Introduction $\quad 1$

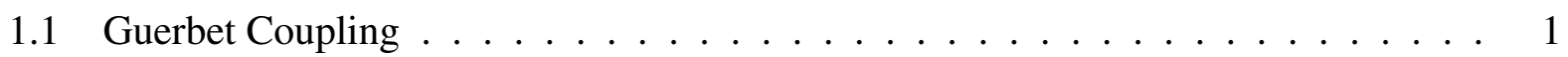

1.1.1 Catalysts used for Guerbet Coupling . . . . . . . . . . . . . . 2

1.1.2 Guerbet Coupling Mechanism . . . . . . . . . . . . . . . 4

1.2 Surface Characterization ...................... 8

1.2.1 Adsorption Microcalorimetry _. . . . . . . . . . . . . 9

1.2.2 Diffuse Reflectance Infrared Fourier Transform Spectroscopy (DRIFTS) . . 13

1.3 Steady State Isotopic Transient Kinetic Analysis . . . . . . . . . . . . . . . . . 14

1.4 Outline of Completed Work . . . . . . . . . . . . . . . . . . . 18

2 Aldol Condensation of Acetaldehyde over Titania, Hydroxyapatite, and Magnesia 19

2.1 Introduction . . . . . . . . . . . . . . . 20

2.2 Materials and Methods . . . . . . . . . . . . . . . . . 22

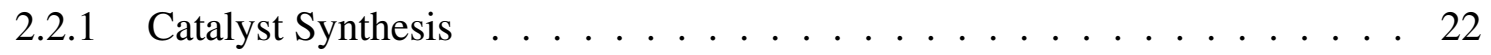

2.2.2 Catalyst Characterization . . . . . . . . . . . . . 23

2.2.3 Aldol Condensation of Acetaldehyde . . . . . . . . . . . . 23

2.2.4 Adsorption Microcalorimetry . . . . . . . . . . . . . . . 24

2.2.5 Diffuse Reflectance Infrared Fourier Transform Spectroscopy (DRIFTS) . . 25

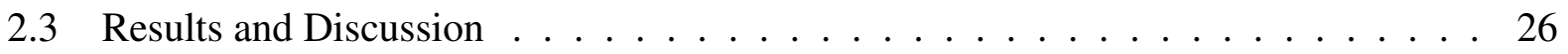


2.3 .1 Catalyst Characterization . . . . . . . . . . . . . . 26

2.3.2 Aldol Condensation Kinetics . . . . . . . . . . . . . . . . . . . . 27

2.3.3 Aldol Condensation in the Presence of Ethanol . . . . . . . . . . . . 34

2.3.4 Ethanol Conversion . . . . . . . . . . . . . . . . . . 37

2.3.5 Adsorption Microcalorimetry . . . . . . . . . . . . . . . . 39

$2.3 .6 \quad$ DRIFTS . . . . . . . . . . . . . . . . . . 43

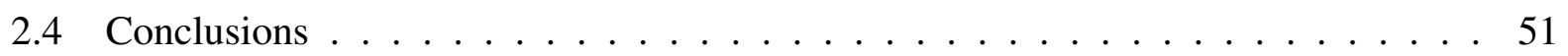

3 Hydrogen Transfer Reactions Relevant to Guerbet Coupling of Alcohols over Hydroxyapatite and Magnesium Oxide Catalysts $\quad 53$

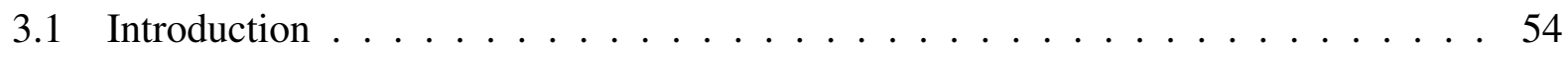

3.2 Materials and Methods . . . . . . . . . . . . . . . . . . . 59

$3.2 .1 \quad$ Catalyst Synthesis $\ldots \ldots \ldots \ldots$

3.2 .2 Catalyst Characterization . . . . . . . . . . . . . . . . . . 59

3.2 .3 Catalytic Reactions . . . . . . . . . . . . . . . . . . . . 60

3.3 Results and Discussion $\ldots \ldots \ldots \ldots$. . . . . . . . . 63

3.3.1 Guerbet Coupling in the Presence of $\mathrm{H}_{2} / \mathrm{D}_{2} \ldots \ldots \ldots$

3.3 .2 Hydrogenation Reaction . . . . . . . . . . . . . . . . . 66

3.3.3 Benzyl Alcohol Dehydrogenation $\ldots \ldots \ldots \ldots . \ldots . \ldots 71$

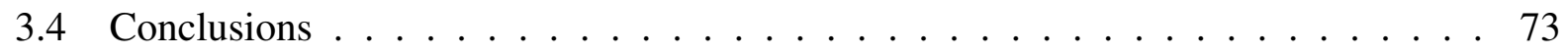

$\begin{array}{llr}4 & \text { Conclusions } & 74\end{array}$

$4.1 \quad$ Summary . . . . . . . . . . . . . . . . . . . . . 74

4.2 Future Work . . . . . . . . . . . . . . . . . . . . . 79

$\begin{array}{lr}\text { References } & 81\end{array}$ 
A Adsorption Microcalorimeter Schematic

B Flow Reactor Schematic

C The Effect of Hydroxyapatite Cation Substitution on the Guerbet Coupling of Ethanol 93

C.1 Introduction . . . . . . . . . . . . . . . . . . . 94

C.2 Materials and Methods . . . . . . . . . . . . . . . . . 97

C.2.1 Catalyst Synthesis . . . . . . . . . . . . . . 97

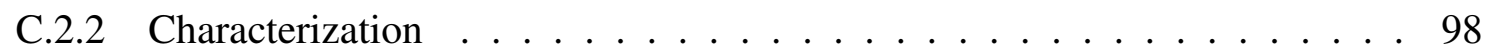

C.2.3 Ethanol Coupling Reaction . . . . . . . . . . . . . . . 98

C.2.4 Adsorption Microcalorimetry _. . . . . . . . . . . . . . 99

C.3 Results and Discussion . . . . . . . . . . . . . . . . . . 99

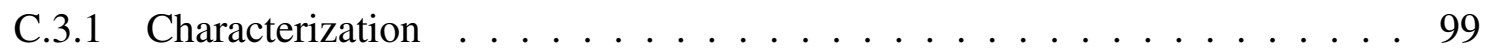

C.3.2 Guerbet Coupling of Ethanol . . . . . . . . . . . . . . . 105

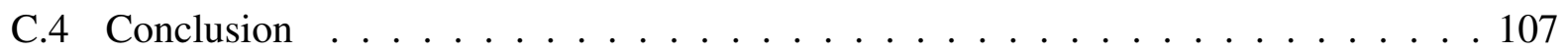

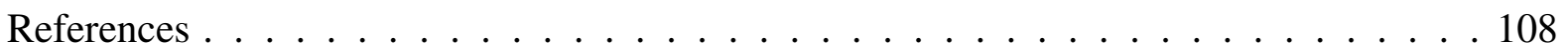

D Multiproduct Steady-State Isotopic Transient Kinetic Analysis of the Ethanol Coupling Reaction over Hydroxyapatite and Magnesia 111

D.1 Introduction . . . . . . . . . . . . . . . . 113

D.2 Materials and Methods . . . . . . . . . . . . . . . . . . . 114

D.2.1 Catalyst Preparation ........................... 114

D.2.2 Catalyst Characterization . . . . . . . . . . . . . . 114

D.2.3 Ethanol Coupling Reactions . . . . . . . . . . . . . . 115

D.2.4 Multi-product SSITKA . . . . . . . . . . . . 116

D.2.5 Adsorption Microcalorimetry . . . . . . . . . . . . . . . 119

D.2.6 Diffuse Reflectance Infrared Fourier Transform Spectroscopy (DRIFTS) . . 120 


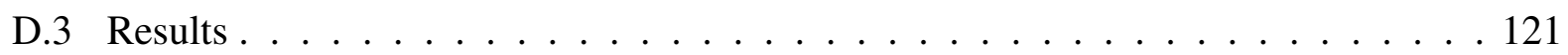

D.3.1 Catalyst Characterization . . . . . . . . . . . . . 121

D.3.2 Steady-State Conversion of Ethanol . . . . . . . . . . . . . 122

D.3.3 Multi-Product SSITKA . . . . . . . . . . . . . . . . 124

D.3.4 STPD of Adsorbed Ethanol Monitored by DRIFTS . . . . . . . . . . . . 127

D.3.5 Adsorption Microcalorimetry of $\mathrm{CO}_{2}$, TEA, and Ethanol . . . . . . . . . 129

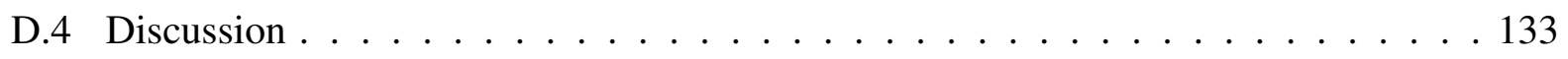

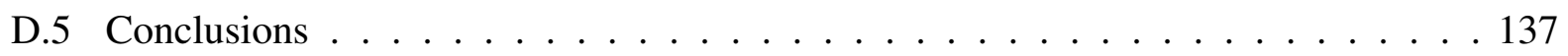

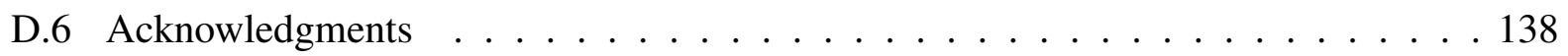

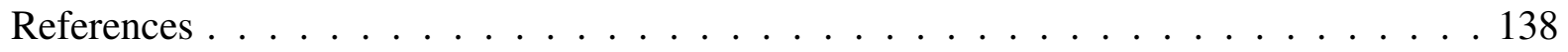

E Rate Equation Derivation $\quad 141$ 


\section{List of Figures}

$1.1 \quad \mathrm{CO}_{2}$ Adsorption Microcalorimetry $\ldots \ldots \ldots \ldots \ldots$

1.2 TEA Adsorption Microcalorimetry . . . . . . . . . . . . . . . . . . 12

2.1 The XRD patterns for anatase $\mathrm{TiO}_{2}, \mathrm{HAP}$, and $\mathrm{MgO} \ldots \ldots \ldots$

2.2 Aldol Condensation versus Time on Stream . . . . . . . . . . . . . . . . . 27

2.3 Low $P_{\text {AcH }}$ Aldol Condensation Rates . . . . . . . . . . . . . . . . . 28

2.4 High $P_{\text {AcH }}$ Aldol Condensation Rates . . . . . . . . . . . . . . . . . . . . . . 32

2.5 Acetaldehyde/Ethanol co-feed time plot over $\mathrm{TiO}_{2} \ldots \ldots \ldots 35$

2.6 Aldol Condensation in the presence of Ethanol over $\mathrm{TiO}_{2}$ and $\mathrm{HAP} \ldots \ldots . \ldots 36$

2.7 Acetaldehyde/Ethanol co-feed timeplot over HAP . . . . . . . . . . . . . . . 37

2.8 Acetaldehyde/Ethanol co-feed timeplot over $\mathrm{MgO} \ldots \ldots \ldots$

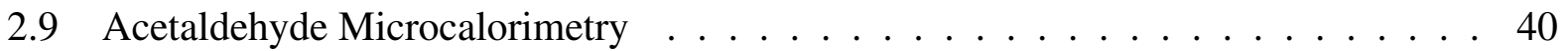

2.10 Ethanol Microcalorimetry . . . . . . . . . . . . . . . . . . 41

$2.11 \mathrm{TiO}_{2}$ DRIFTS of probe molecules $\ldots \ldots \ldots \ldots \ldots$

$2.12 \mathrm{TiO}_{2}$ Ethanol/Acetaldehyde DRIFTS . . . . . . . . . . . . . . . . . . . 46

2.13 HAP DRIFTS of probe molecules $\ldots \ldots \ldots \ldots$. . . . . . . . . 47

2.14 HAP Ethanol/Acetaldehyde DRIFTS . . . . . . . . . . . . . . . . . . . . . . . 49

$2.15 \mathrm{MgO}$ DRIFTS of probe molecules $\ldots \ldots \ldots \ldots$

$2.16 \mathrm{MgO}$ Ethanol/Acetaldehyde DRIFTS . . . . . . . . . . . . . . . . 51 
3.1 Mass Spectra of the Butanol Carbon Backbone in the Presence of $\mathrm{H}_{2}$ and $\mathrm{D}_{2} \ldots \ldots 5$

3.2 The rate of MPV-like Hydrogenation . . . . . . . . . . . . . . . . . 69

3.3 The Rate of Benzyl Alcohol Dehydrogenation . . . . . . . . . . . . . . . 72

C.1 XRD of Substituted HAP . . . . . . . . . . . . . . . . 100

C.2 XRD of BaHAP . . . . . . . . . . . . . . . . 101

C.3 Adsorption Microcalorimetry of Substituted HAPs _ . . . . . . . . . . . . 104

D.1 Diagram of SSITKA Reactor . . . . . . . . . . . . 117

D.2 Normalized Transient Response Curves over HAP . . . . . . . . . . . . . . . . 119

D.3 XRD Patterns of HAP and $\mathrm{MgO} \ldots \ldots \ldots \ldots \ldots$

D.4 Rate of Guerbet Coupling versus Inverse Flow Rate . . . . . . . . . . . . . . . 124

D.5 Normalized Response Curves for Butanol . . . . . . . . . . . . . . . 126

D.6 DRIFTS of Adsorbed Ethanol _ . . . . . . . . . . . . . . . 128

D.7 $\mathrm{CO}_{2}$ Adsorption Microcalorimetry . . . . . . . . . . . . . . 130

D.8 TEA Adsorption Microcalorimetry . . . . . . . . . . . . . . . 131

D.9 Ethanol Adsorption Microcalorimetry . . . . . . . . . . . . . . 132 


\section{List of Tables}

1.1 Ethanol Coverage over $\mathrm{MgO}$ and $\mathrm{HAP} \ldots \ldots \ldots \ldots$

1.2 Acetaldehyde Coverage and $\tau$ over $\mathrm{HAP}$ and $\mathrm{MgO} \ldots \ldots \ldots$

1.3 Butanol Coverage and $\tau$ over $\mathrm{HAP}$ and $\mathrm{MgO} \ldots \ldots \ldots \ldots$

2.1 Kinetic Isotope Effect of Aldol Condensation _ . . . . . . . . . . . . . . . 29

2.2 Aldol Condensation Rate Parameters . . . . . . . . . . . . . . . . . . . . . 34

2.3 Ethanol Conversion . . . . . . . . . . . . . . . . . . . . . 38

2.4 Estimated Aldol Condensation Rate Constants . . . . . . . . . . . . . . . . . . . . 43

3.1 Influence of $\mathrm{H}_{2}$ or $\mathrm{D}_{2}$ on Rate and Selectivity of Ethanol Conversion . . . . . . . 64

C.1 Guerbet Coupling of Ethanol over $\mathrm{MgO} \ldots \ldots$

C.2 Guerbet Coupling of Ethanol over Substituted Hydroxyapatites . . . . . . . . 106

C.3 Ethanol Conversion over Metal Oxides . . . . . . . . . . . . . . . . . 107

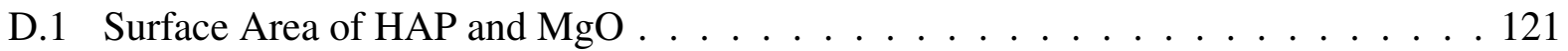

D.2 Guerbet Coupling of Ethanol over $\mathrm{MgO} \ldots \ldots \ldots$

D.3 Guerbet Coupling of Ethanol over HAP _ . . . . . . . . . . . . . . 123

D.4 Time constants and Coverages of Ethanol _ . . . . . . . . . . . . . 125

D.5 Time Constants and Surface Coverages for Acetaldehyde . . . . . . . . . . 127

D.6 Time Constants and Surface Coverages for Butanol . . . . . . . . . . . . . 127 


\section{Nomenclature}

$[*]_{0} \quad$ Total Number of Active Sites

$\beta$-TCP $\beta$-Tricalcium Phosphate

$\Delta H_{\text {ads }}$ Differential Heat of Adsorption

$\tau_{i} \quad$ Mean Surface Residence Time of Reactive Intermediate $i$

$f_{e q} \quad$ Equilibrium Conversion

$K \quad$ Equilibrium Constant

$k \quad$ Rate Constant

$N_{i} \quad$ Number of Reactive Intermediates $i$

$P_{i} \quad$ Partial Pressure of Species $i$

$\mathrm{TiO}_{2}$ Anatase Titanium Oxide

$\mathrm{BuOH}$ Butanol

DRIFTS Diffuse Reflectance Infrared Fourier Transform Spectroscopy

HAP Hydroxyapatite

ICP-OES Inductively Coupled Plasma Optical Emission Spectroscopy

$\mathrm{MgO}$ Magnesium Oxide

MPV Meerwein-Ponndorf-Verley

SSITKA Steady State Isotopic transient Kinetic Analysis

TEA Triethyl Amine

TOF Turnover Frequency

XRD X-ray Diffraction 


\section{Chapter 1}

\section{Introduction}

\subsection{Guerbet Coupling}

This work is a continuation of many years of studying the role acid-base properties have on heterogeneous catalytic reactions, focusing primarily on the use of basic catalysts, by studying reactions that are known to require acid-base functionality. One particularly interesting reaction is the Guerbet coupling reaction of alcohols. First discovered by Marcel Guerbet in $1899,{ }^{1}$ this reaction is commonly used to couple two short-chain alcohols to a longer chain saturated alcohol. Guerbet coupling is often carried out with both a homogeneous base catalyst and a heterogeneous metal catalyst present. ${ }^{2}$ If a sufficiently active heterogeneous base catalyst could be found, it is possible that the reaction could be carried out using only a heterogeneous catalyst. This would make catalyst separation much easier potentially resulting in lower production costs. While Guerbet coupling has been used for many years to couple long chain alcohols into high molecular weight branched alcohols, it could potentially be used to upgrade biorenewable ethanol to higher value products, such as butanol. 
Ethanol is a relativly cheap, easily produced, biorenewable fuel. However, the use of ethanol as an effective fuel additive has been called into question due to its low energy density when compared to gasoline, miscibility with water, and the fact that it is corrosive to current infrastructure at high concentrations. ${ }^{3}$ Additionally, there is little demand for bioethanol outside of its use as a fuel additive. The catalytic upgrading of bioethanol to a more valuable chemical could provide a new use for the large quantity of bioethanol being produced today. One possible method to valorize ethanol is its catalytic conversion to butanol. Butanol has the potential to be a better fuel additive when compared to ethanol because butanol has a comparable energy density to gasoline, is much more hydrophobic than ethanol, and is non-corrosive. However, butanol is currently produced from fossil fuel sources by the hydroformylation of propene (also known as the oxo process). The ability to economically produce biobutanol from bioethanol would allow manufacturers to harness the existing ethanol production infrastructure to synthesize a more versatile, superior fuel additive.

\subsubsection{Catalysts used for Guerbet Coupling}

Many catalytic systems have been used for the Guerbet coupling reaction over the years. Basic metal oxides are the most commonly used heterogeneous catalyst for Guerbet coupling, and $\mathrm{MgO}$ is one of the most commonly studied base catalysts. Other catalytic systems include magnesiumzirconium ${ }^{4}$ or magnesium-aluminum mixed metal oxides, ${ }^{5}$ alkali metal substituted zeolites, ${ }^{6}$ or hydroxyapatite $(\mathrm{HAP})^{7-12}$. Of these catalysts, HAP is the most active and has the highest selectivity to butanol. Hydroxyapatite is a calcium phosphate that has an amphoteric surface with molecular formula $\mathrm{Ca}_{10}\left(\mathrm{PO}_{4}\right)_{6}(\mathrm{OH})_{2}$ and is the main mineral component of bone and teeth. One property of HAP is its ability to take on a variety of non-stoichiometric forms. Stoichiometric HAP has a 
calcium to phosphorous ratio of 1.67 , but both calcium deficient $\mathrm{HAP}(\mathrm{Ca} / \mathrm{P} \leq 1.67)$ and calcium rich $\mathrm{HAP}(\mathrm{Ca} / \mathrm{P} \geq 1.67)$ have been observed. The use of HAP as a catalyst for Guerbet coupling was first reported in 2006 by Tsuchida et al. ${ }^{7}$ In this study, the authors reported a selectivity to butanol of $76 \%$ at a reaction temperature of $573 \mathrm{~K}$. This was a much higher selectivity towards butanol than the $20 \%$ selectivity observed over $\mathrm{MgO}$ at similar conversion. ${ }^{13}$ Additionally, HAP was found to be much more active with comparable rates to $\mathrm{MgO}$ at a temperature $100 \mathrm{~K}$ lower.

In a separate study, Tsuchida et al. ${ }^{8}$ investigated the effect the calcium to phosphorous ratio has on activity. Calcium deficient HAP has the molecular formula $\mathrm{Ca}_{10-x}\left(\mathrm{HPO}_{4}\right)_{x}\left(\mathrm{PO}_{4}\right)_{6-x}(\mathrm{OH})_{2-x}$ for $0 \leq x \leq 1$. Calcium rich HAP has also been reported, but its structure is less understood. It is possible that the high calcium content is caused by well dispersed $\mathrm{CaO}$ such that no $\mathrm{CaO}$ features are observed by X-ray diffraction (XRD). Tsuchida et al. ${ }^{8}$ tested a variety of non-stoichiometric HAP materials and found that on calcium deficient HAP, ethene was the main product formed from ethanol. Ethene is an undesirable side product that can be produced by the dehydration of ethanol. Ethene formation is typically associated with an acidic catalyst surface indicating calcium deficient HAP is an acid catalyst. This acidity is likely caused by the protonated surface phosphates which could act as a Brønstead acid site. A similar calcium phosphate, $\beta$-tricalcium phosphate $(\beta$-TCP, $\left.\mathrm{Ca}_{3}\left(\mathrm{PO}_{4}\right)_{2}\right)$, was also investigated. This material is very similar to HAP but cannot take on nonstoichiometric forms and has no hydroxyl groups. It was found that $\beta$-TCP was able to catalyze butanol formation with $30 \%$ selectivity but also formed ethene with $16 \%$ selectivity at $678 \mathrm{~K}$.

In addition to having a variable $\mathrm{Ca} / \mathrm{P}$, many different ions can incorporate into the HAP structure. The hydroxyl, fluoride, and chloride anions, $\mathrm{Mg}^{2+}, \mathrm{Sr}^{2+}, \mathrm{Ba}^{2+}, \mathrm{Pb}^{2+}, \mathrm{Cd}^{2+}$, and other metal cations, as well as vanadate, arsenate, carbonate, and sulfate have all been observed in the apatite 
structure. ${ }^{10,14-20}$ Cation substitutions have been shown to play a role in the activity and selectivity of the HAP catalyst during the Guerbet coupling of ethanol. In fact, Ogo et al. ${ }^{9}$ showed that fully substituted strontium HAP was more active and had a higher selectivity towards butanol than calcium HAP. To investigate the effect of cation substitution on the Guerbet coupling reaction a partially substituted magnesium HAP and fully substituted strontium HAP and barium HAP were synthesized. The unsubstituted calcium HAP catalyst was found to be the most active and selective catalyst for ethanol coupling at low conversion. A brief summary of this study can be found in Appendix C. Because the calcium HAP had the best performance during ethanol coupling, it was the only catalyst that was further studied.

\subsubsection{Guerbet Coupling Mechanism}

The mechanism of Guerbet coupling is still debated in the literature, but is thought to consist of a sequence of reactions shown in Scheme 1.1. Ethanol is initially dehydrogenated to acetaldehyde, two acetaldehyde molecules then go through an aldol condensation step resulting in the unsaturated product crotonaldehyde (2-butenal). The unsaturated intermediate crotonaldehyde is subsequently hydrogenated to the final saturated product 1-butanol. The constituent reactions that make up the overall Guerbet coupling reaction have all been shown to be catalyzed by catalysts with acidbase functionality. The dehydrogenation/dehydration of an alcohol is a commonly used probe reaction to determine acid-base strength, with basic catalysts favoring dehydrogenation and acid catalysts favoring dehydration. ${ }^{21}$ Aldol condensation and hydrogenation have both been shown to be catalyzed by both acid and base heterogeneous catalysts. ${ }^{22-25}$ The fact that acid-base properties affect each constituent reaction of the Guerbet coupling network make this reaction a useful test 
reaction for studying how small changes to acid-base properties can affect a reaction.

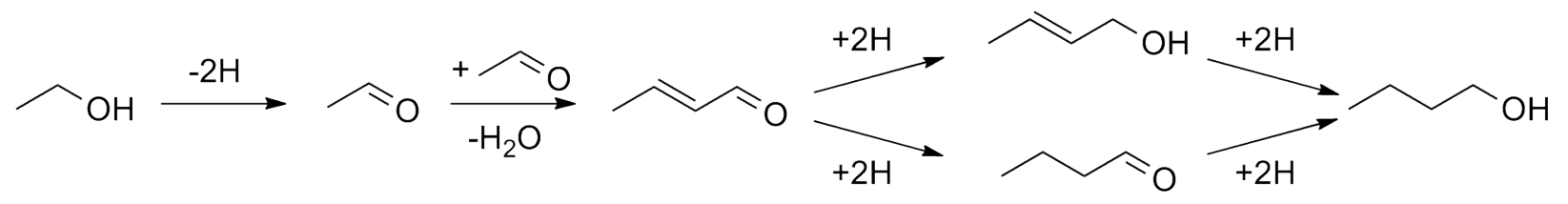

Scheme 1.1: Commonly proposed mechanism for Guerbet coupling

While this sequence of steps is the most widely accepted mechanism, other mechanisms have been proposed. One of the most commonly proposed alternative mechanisms is the direct coupling of two ethanol molecules to butanol first theorized by Yang and Ming. ${ }^{6}$ These authors observed that the rate of butanol production was non-zero at low contact times over alkali metal cation exchanged zeolites, suggesting that butanol is a primary product of ethanol conversion. Additionally, a study by Gines and Iglesia ${ }^{26}$ used a mixture of ${ }^{13} \mathrm{C}$ labeled acetaldehyde with ${ }^{12} \mathrm{C}$ labeled ethanol and found that a small number of $\mathrm{C}_{4}$ products contained no isotopically labeled carbon when the reaction was carried out over $\mathrm{K}-\mathrm{Cu} / \mathrm{MgCeO}_{x}$ suggesting that direct condensation of ethanol can occur. However, Gines and Iglesia ${ }^{26}$ stated that only a minority of the condensation products are formed through the direct path. A third study by Ndou et al. ${ }^{27}$ also concluded that direct coupling was possible over $\mathrm{MgO}$ and alkaline earth promoted $\mathrm{MgO}$. They showed that co-feeding acetaldehyde and ethanol does not increase the amount of butanol formed indicating gas-phase acetaldehyde may not be an intermediate in the reaction.

The fact that the rate of butanol formation is non-zero at low contact times does not necessarily imply that butanol is a primary product. If surface acetaldehyde is able to undergo aldol condensation and subsequent hydrogenation very quickly (i.e. the reaction occurs faster than desorption of acetaldehyde) then the same behavior would be observed. This could be the case if desorption of the aldehyde is slow compared to the desorption of the alcohol. Along the same lines, the small 
amount of unlabeled product observed in the Gines and Iglesia ${ }^{26}$ work could indicate two surface aldehydes formed from the unlabeled ethanol can react very quickly to result in a $\mathrm{C}_{4}$ product.

More recently, Chieregato et al. ${ }^{28}$ published a study on the direct coupling of ethanol over $\mathrm{MgO}$. These authors concluded that crotonaldehyde was not a key intermediate to the reaction based on reactions of crotyl alcohol (2-buten-1-ol) and acetaldol (3-hydroxybutanal) over MgO. The reaction of acetaldol over $\mathrm{MgO}$ resulted predominantly in the reverse aldolization to acetaldehyde as opposed to dehydration to crotonaldehyde implying that aldol condensation is thermodynamically unfavorable at these conditions, and therefore the mechanism cannot contain an aldol condensation step. The authors went on to show that the reaction of crotyl alcohol over $\mathrm{MgO}$ resulted in a similar product distribution as the reaction of ethanol. This result seems to imply that crotyl alcohol is the key reactive intermediate as opposed to acetaldehyde. Unlike the previously mentioned studies, Chieregato et al. ${ }^{28}$ used infrared spectroscopy as well as density functional theory to propose a mechanism for the direct condensation of ethanol. The mechanism involved the formation of a carbanion when a $\beta-\mathrm{H}$ is abstracted from an ethanol molecule. The carbanion then reacts directly with another adsorbed ethanol molecule to form butanol and water.

The carbanion mechanism calls for the abstraction of the $\beta-\mathrm{H}$ of an ethanol molecule leading to a primary carbanion that will react with the $\alpha$-carbon of another ethanol molecule in an $S_{N} 2$-like attack. For ethanol, the abstraction of the $\beta$-H results in a primary carbanion, however the abstraction of a $\beta-\mathrm{H}$ in a longer chain alcohol like 1-propanol would result in a less stable secondary carbanion. In this case, it is likely that intramolecular hydride transfer would rapidly occur to form a more stable primary carbanion. The reaction of a primary carbanion of propanol with another propanol molecule would result in 1-hexanol while the reaction of the secondary 
carbanion of propanol with another propanol molecule would result in the branched product 2methylpropanol. On the other hand, if the reaction involved an aldol condensation step, only the branched 2-methylpropanol product would be observed. A study of the Guerbet coupling of propanol over $\mathrm{MgO}$ by Ndou and Coville ${ }^{29}$ found that the main products of the reaction were 2methylpentanol and propionaldehyde while no 1-hexanol was reported. This result suggests that the reaction does not proceed through a carbanion intermediate. In that study, Ndou and Coville ${ }^{29}$ concluded propanol condensation proceeded through an aldol condensation step.

A theoretical study by Scalbert et al..$^{30}$ used calculated reaction quotients to find that the global reaction shown in Scheme 1.2 is thermodynamically unfavorable at high temperatures over HAP.

$$
2 \text { Acetaldehyde }+2 \mathrm{H}_{2} \rightleftarrows \text { Butanol }+\mathrm{H}_{2} \mathrm{O}
$$

\section{Scheme 1.2}

The use of thermodynamics to analyze reactions can be useful, but is not always applicable. In the study by Scalbert et al. ${ }^{30}$ the use of dihydrogen as a hydrogen source may not be valid. Ogo et al. ${ }^{10}$ have stated that dihydrogen is unable to hydrogenate crotonaldehyde over a strontium substituted hydroxyapatite and others have shown that $\mathrm{H}_{2}$ has no effect on product selectivity or reaction rate during Guerbet coupling. ${ }^{12,31}$ It is possible that if the reaction did not use $\mathrm{H}_{2}$ as the hydrogen source that the reaction could be thermodynamically favorable.

While some studies agree with the direct coupling mechanism, others support the important role of aldol condensation in Guerbet coupling as shown in Scheme 1.1. The work of Gines and Iglesia ${ }^{26}$ stated that the dominant mechanism for $\mathrm{C}_{4}$ product formation was through aldol condensation. Additionally, recent work by Ho et al. ${ }^{11}$ and Moteki and Flaherty ${ }^{12}$ stated that aldol condensation is kinetically relevant to the Guerbet coupling reaction. Ho et al. ${ }^{11}$ showed that the 
reaction appears to be autocatalytic, where small amounts of acetaldehyde that are co-fed with ethanol will result in much greater than stoichiomeric amounts of butanol being produced. Moteki and Flaherty ${ }^{12}$ also showed a similar result. It seems likely that this autocatalytic reaction is due to the fact that ethanol must be used as a hydrogen source for crotonaldehyde hydrogenation resulting in the formation of two molecules of acetaldehyde for every molecule of butanol that is produced. Those two acetaldehyde molecules can then undergo an aldol condensation reaction resulting in the formation of another molecule of crotonaldehyde. In this way butanol can be rapidly produced from a very small initial amount of acetaldehyde.

\subsection{Surface Characterization}

One difficulty in studying acid-base catalysts is defining the acidity of a surface. In the aqueous phase, the definition of aciditiy using $\mathrm{pH}$ is trivial. However, it is difficult to define what makes a surface acidic or basic. Despite the difficulty in determining the acid-base characteristics of a surface, some methods have been developed to characterize acid-base surface properties. For example, adsorption and desorption studies ${ }^{32,33}$ can be carried out with characteristic acidic or basic probe molecules such as $\mathrm{CO}_{2}$ or $\mathrm{NH}_{3}$, test reactions that have been shown to have different selectivities when carried out over acid or base catalysts such as 2-propanol dehydration/dehydrogenation, ${ }^{21}$ and theoretical calculations of deprotonation energy have all been used to determine acid-base characteristics. ${ }^{34}$

The difference between Lewis and Brønstead character of the acid-base sites also plays an important role in selectivity. This is another difficult aspect to measure, but spectroscopic mea- 
surements of adsorbed pyridine can distinguish between Lewis-acid and Brønstead-acid sites. ${ }^{35}$ Reactions of alcohols over Brønstead or Lewis-acid catalysts can result in very different products. Brønstead acid catalysts have been found to favor dehydration reaction because the Brønstead site is able to protonate the alcohol group resulting in a subsequent $E_{1}$ reaction. Both dehydration and dehydrogenation reactions have been observed over a Lewis acid-base site pair. The Lewis acid site will stabilize an alkoxide intermediate allowing either an $\alpha-\mathrm{H}$ or $\beta-\mathrm{H}$ to be abstracted resulting in an aldehyde or olefin respectively.

\subsubsection{Adsorption Microcalorimetry}

A common method that is used to determine the acid-base properties of a surface is adsorption microcalorimetry. This technique involves adsorbing a a small amount of a probe molecule onto a surface and measuring the heat that is generated by the formation of a bond between the adsorbent and the surface. Adsorption is usually a spontaneous process $(\Delta G<0)$ and is associated with the loss of of translational and rotational degrees of freedom of the adsorbent $(\Delta S>0)$. Therefore, the enthalpy of the process must be less than zero, resulting in the generation of heat during adsorption. This heat generation can be measured and used to calculate the heat of adsorption of the probe molecule. Adsorption microcalorimetry is typically carried out by adding a well known volume of adsorbent to a reference cell as well as a cell containing the material of interest. The difference in the heat generated in the sample cell versus the reference cell can be used to calculate the differential heat of adsorption $\left(\Delta H_{\mathrm{ads}}\right)$. At the same time, the pressure after the adsorption takes place can be measured to determine the amount of species adsorbed to the surface. In this way both an adsorption isotherm as well as a plot of the differential heat of adsorption as a function of 
coverage can be produced. A schematic of the adsorption microcalorimeter used in this study is shown in Appendix A.

This technique has been used to determin the adid-base properties of catalytic materials. Typically, probe molecules are used to determine both the number and the strength of acid or base sites. Some commonly used probe molecules include carbon dioxide, an acidic adsorbent used to probe base properties, and ammonia, a basic adsorbent used to probe acid properties. ${ }^{4,36-38}$ Previous work from our group over $\mathrm{HAP}$ and $\mathrm{MgO}$ used $\mathrm{CO}_{2}$ and a derivative of ammonia, triethylamine (TEA), to characterize the strength and number of acid-base sites present ${ }^{39}$.

Figure 1.1 shows typical results from an adsorption microcalorimetry experiment. At low adsorption pressures there is a high increase in the uptake of the probe molecule. This region is associated with strongly interacting sites and corresponds to the high differential heat of adsorption observed at low coverage. At high adsorption pressures, the slope of the isotherm decreases, but does not reach zero. This section of the isotherm is associated with either weak physisorption of the adsorbent or multilayer adsorption. This section of the the isotherm corresponds to the low differential heat of adsorption measured at high surface coverage. From Figure 1.1 we can see that the $\mathrm{MgO}$ catalyst has a few very strong base sites with a $-\Delta H_{\text {ads }}>100 \mathrm{~kJ} \mathrm{~mol}^{-1}$. Additionally there are a few moderate strength basic sites with $-\Delta H_{\mathrm{ads}}<100 \mathrm{~kJ} \mathrm{~mol}^{-1}$. Compared to $\mathrm{MgO}$, HAP has a large number of moderate strength basic sites indicated by the high uptake and the constant heat of adsorption over a wide range of coverages.

Figure 1.2 shows the isotherms and heats of adsorption of TEA on HAP and MgO. There is very little TEA adsorption on $\mathrm{MgO}$ indicated by the very low coverage and the lack of a steep 

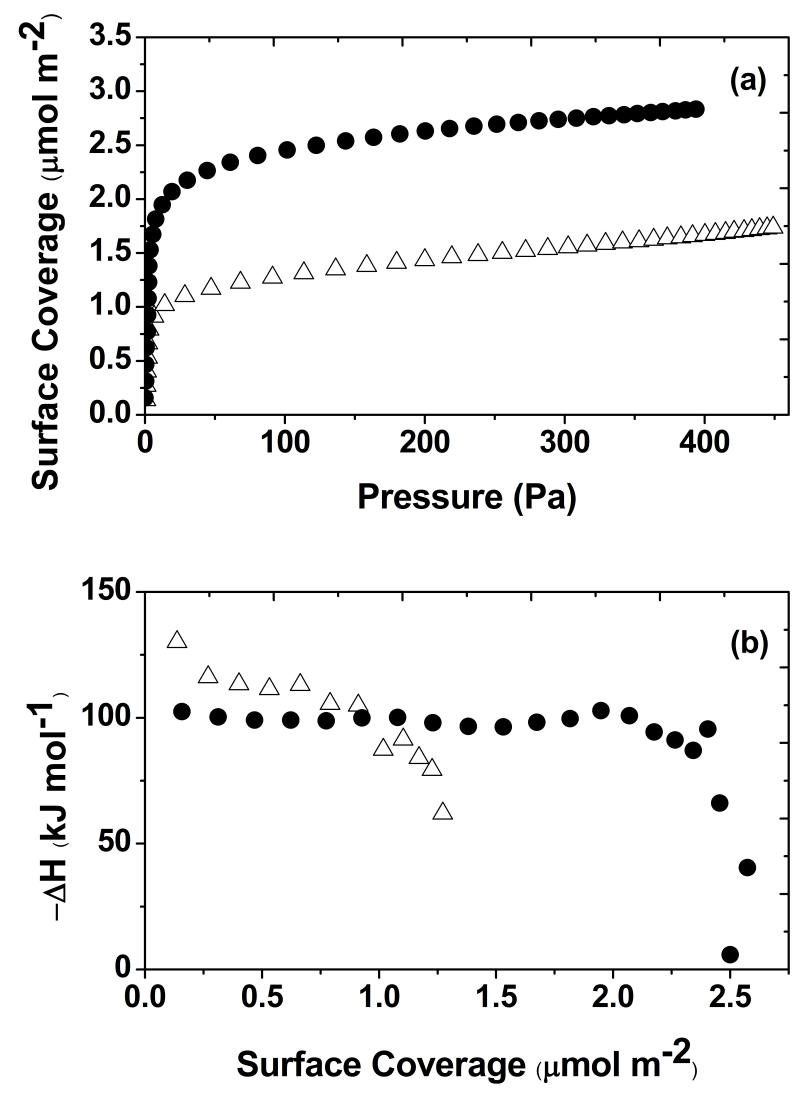

Figure 1.1: Adsorption microcalorimetry of carbon dioxide on $(\triangle) \mathrm{MgO}$ and $(\bullet)$ stoichiometric hydroxyapatite (HAP) catalysts at $303 \mathrm{~K}$; (a) adsorption isotherms of carbon dioxide (b) differential heats of adsorption as a function of coverage.

increase in coverage with pressure. On the other hand, HAP interacts relatively strongly with TEA indicating that there are acidic sites present on the HAP surface. Taken together, the adsorption microcalorimetry of both $\mathrm{CO}_{2}$ and TEA shows that $\mathrm{MgO}$ is a predominantly basic surface with strong base sites and very few acid sites while HAP has a large number of both acid and base sites. The presence of a high number of moderate strength acid-base site pairs is likely the cause of the high activity of ethanol coupling observed over HAP.

In addition to measuring the acid-base characteristics of a surface, adsorption microcalorimetry 

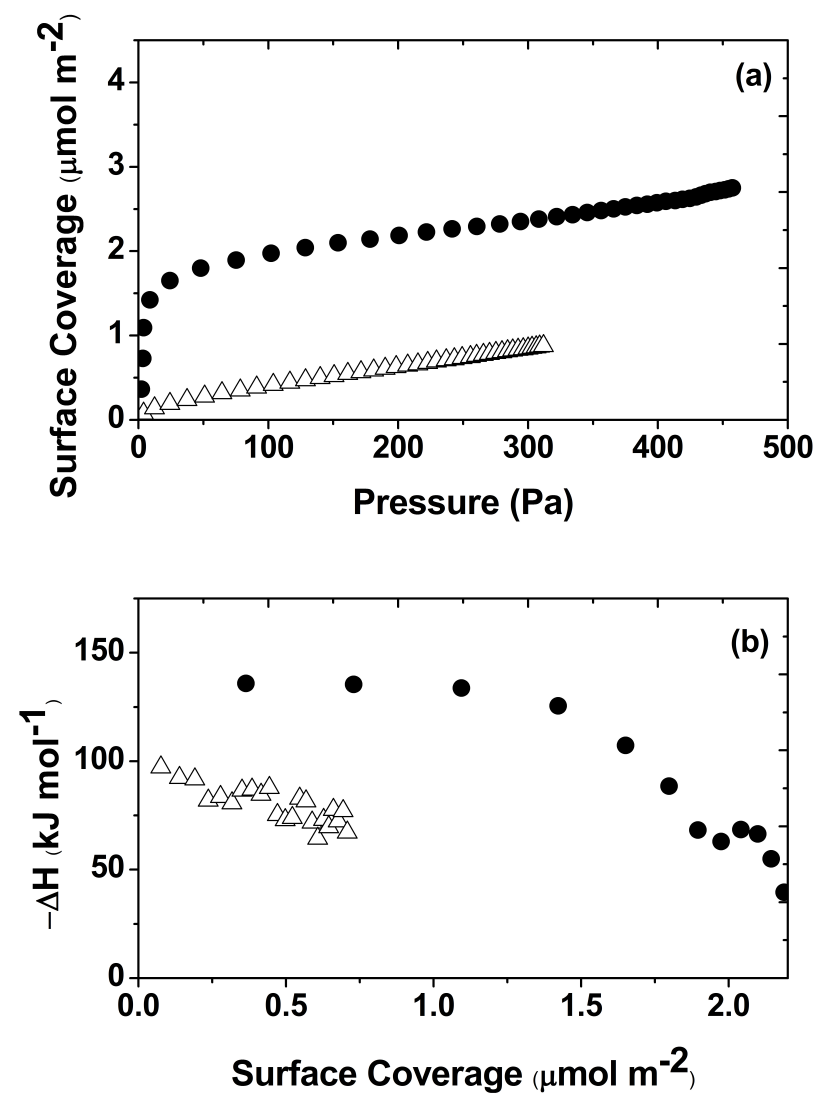

Figure 1.2: Adsorption microcalorimetry of triethylamine (TEA) on $(\triangle) \mathrm{MgO}$ and $(\bullet)$ stoichiometric hydroxyapatite (HAP) catalysts at $303 \mathrm{~K}$; (a) adsorption isotherms of triethylamine (b) differential heats of adsorption as a function of coverage.

can also be used to measure the interaction of a surface with a reactant or product to determine the affinity for reaction intermediates. Knowing the relative $\Delta H_{\text {ads }}$ of reaction intermediates can indicate relative surface coverages under reaction conditions. Additionally, the number of adsorbed reactants can be used as an estimate of the number of active sites. 


\subsubsection{Diffuse Reflectance Infrared Fourier Transform Spectroscopy (DRIFTS)}

Another common technique that can be used to characterize adsorbed species is diffuse reflectance infrared Fourier transform spectroscopy (DRIFTS). In a DRIFTS experiment, IR radiation is scattered off a powdered sample, with wavelenghts corresponding to IR active modes being absorbed. The scattered radiation is focused and sent to a detector resulting in an IR spectrum that has the absorption peaks that correspond to the catalyst as well as any adsorbed molecule. A typical DRIFTS experiment will consist of collecting a background scan of the catalyst alone. Following this, a probe molecule will be passed over the catalyst. An inert gas will be passed over the catalyst for a short amount of time to remove any weakly or physically adsorbed species before another scan is collected, subtracting out the catalyst background. In this way the absorption maxima corresponding to the probe molecule adsorbed on the surface are isolated.

The location of the absorption maxima associated with an adsorbed species are typically very similar to the absorption maxima of a gas phase molecule, however there can be some differences. If a vibrational mode is perturbed by a surface bond the location of the band can be either red or blue shifted. A typical example of this is $\mathrm{CO}$ adsorption. When $\mathrm{CO}$ interacts with a metal surface or a metal ion, the metal can backdonate electrons to antibonding orbitals, reducing the strength of the $\mathrm{C} \equiv \mathrm{O}$ bond and causing the IR peak to shift to a lower wavenumber. If the surface does not strongly interact with the vibrational mode being measured, very little shift will be observed. Another common phenomena that can be observed in DRIFTS is the appearance of vibrational modes that are typically associated with a forbidden transition. For example, the vibrational mode associated with the $\mathrm{N} \equiv \mathrm{N}$ bond is not observed in a gas phase IR experiment because there is no 
change in the dipole moment of the bond during vibration. However, if the $\mathrm{N}_{2}$ molecule interacts with the surface, the symmetry of the molecule is broken, resulting in the absorption of IR radiation corresponding to the $\mathrm{N} \equiv \mathrm{N}$ bond. Another common observation is the appearance of new vibrational modes associated with the surface bound species. This is commonly observed during DRIFTS involving $\mathrm{CO}_{2}$ which has many adsorption modes including unidentate carbonate, bidentate carbonate, and bicarbonate. ${ }^{5}$

Many studies have been carried out using various probe molecules to determine the acid-base properties of various probe molecules. A recent work from our group used $\mathrm{C} \equiv \mathrm{O}$, pyridine, $\mathrm{CO}_{2}$, ethyne, and glycine to characterize acid-base sites on $\mathrm{MgO}$ (a strong basic catalyst), HAP (an amphoteric material), and $\mathrm{ZrO}_{2}$ (an acid catalyst). ${ }^{40}$ As expected, $\mathrm{ZrO}_{2}$ had the strongest acid sites determined by strong interactions with pyridine and $\mathrm{C} \equiv \mathrm{O}$ and $\mathrm{MgO}$ had strong base sites indicated by the strong interaction with $\mathrm{CO}_{2}$. The HAP surface did not interact strongly with any molecule. Additionally, near stoichiometric HAP had no Brønstead-acid sites as determined by the pyridine spectrum.

\subsection{Steady State Isotopic Transient Kinetic Analysis}

From the previous work in this field, it is clear that better mechanistic understanding of Guerbet coupling is needed. In particular, the role of aldol condensation in Guerbet coupling needs to be explored. Steady state isotopic transient kinetic analysis (SSITKA) of Guerbet coupling was performed over both $\mathrm{HAP}$ and $\mathrm{MgO}$ in order to investigate the kinetics of the reaction. This is a powerful transient method that can be used to determine information such as the number of 
surface intermediates leading to products and the residence time of these intermediates. Once these parameters are known, this information can be used to estimate the intrinsic turnover frequency of the catalyst. Briefly, SSITKA involves allowing a catalytic system to come to steady state and subsequently perturbing the system with a step change in the isotopic composition of the reactants, typically a change from fully unlabeled ${ }^{12} \mathrm{C}$ reactant to fully isotopically labeled ${ }^{13} \mathrm{C}$ reactant. Mass spectrometry of the products can track the transient change of the isotopic content of the products. Simultaneously, an inert tracer is used to determine the gas holdup of the reactor. The gas holdup along with the normalized transient response curves are used to determine the residence time $(\tau)$ of the reactive intermediates leading to the products. For more information on the SSITKA technique see Appendix D Section D.2.4. Once the surface residence time $\tau$ has been determined, a turnover frequency (TOF) can be calculated (TOF $=\tau^{-1}$ ). A more commonly used method to determine the TOF of a heterogeneous catalyst normalizes the rate of reaction to the coverage of a chemisorbed species. The amount of the chemisorbed molecule is used as an estimate for the number of active sites. This method provides a lower bound for the TOF because it assumes that all adsorption sites are capable of completing a catalytic cycle, which may not be the case and is likely an overestimate. For metal oxides and metal phosphates, normalizing to the coverage of a chemisorbed probe molecule is tenuous because there is no way to verify that the probe molecule is only adsorbed to catalytically active sites. In the case of SSITKA, every adsorbed intermediate that leads to a product is assumed to be associated with a site. This is likely a more accurate method to find the true number of sites, and therefore an accurate TOF.

Guerbet coupling of ethanol over HAP and $\mathrm{MgO}$ was studied using SSITKA in an attempt to elucidate the mechanism of this reaction. The calculated number of surface intermediates as well 
Table 1.1: Time constants and surface coverages of ethanol $\left(N_{\mathrm{EtOH}}\right)$ during the steady-state Guerbet coupling of ethanol over $\mathrm{MgO}$ and $\mathrm{HAP}$ at $653 \mathrm{~K}$ and $613 \mathrm{~K}$, respectively.

\begin{tabular}{|c|c|c|c|c|}
\hline \multirow{2}{*}{$\begin{array}{l}\text { Total Flow } \\
\text { Rate } \\
\left(\mathrm{cm}^{3} \mathrm{~min}^{-1}\right)\end{array}$} & \multicolumn{2}{|c|}{$\tau_{\mathrm{EtOH}}(\mathrm{s})$} & \multicolumn{2}{|c|}{$\begin{array}{l}\text { Coverage of Ethanol } N_{\mathrm{EtOH}} \\
\left(\mathrm{mol} \mathrm{m}^{-2}\right)\end{array}$} \\
\hline & $\mathrm{MgO}(653 \mathrm{~K})$ & HAP $(613 \mathrm{~K})$ & $\operatorname{MgO}(653 \mathrm{~K})$ & HAP $(613 \mathrm{~K})$ \\
\hline 30 & 25 & 43 & $4.8 \times 10^{-6}$ & $2.7 \times 10^{-5}$ \\
\hline 50 & 18 & 8.8 & $5.7 \times 10^{-6}$ & $9.1 \times 10^{-6}$ \\
\hline 75 & 10 & 7.1 & $4.5 \times 10^{-6}$ & $1.1 \times 10^{-5}$ \\
\hline
\end{tabular}

Table 1.2: Time constants and surface coverages of reactive intermediates leading to acetaldehyde $\left(N_{\mathrm{AcH}}\right)$ during the steady-state Guerbet coupling of ethanol over $\mathrm{MgO}$ and $\mathrm{HAP}$ at $653 \mathrm{~K}$ and $613 \mathrm{~K}$, respectively.

\begin{tabular}{|c|c|c|c|c|}
\hline \multirow{2}{*}{$\begin{array}{l}\text { Total Flow } \\
\text { Rate } \\
\left(\mathrm{cm}^{3} \min ^{-1}\right)\end{array}$} & \multicolumn{2}{|c|}{$\tau_{\mathrm{AcH}}(\mathrm{s})$} & \multicolumn{2}{|c|}{$\begin{array}{l}\text { Coverage of intermediates to } \\
\text { acetaldehyde } N_{\mathrm{AcH}}\left(\mathrm{mol} \mathrm{m}^{-2}\right)\end{array}$} \\
\hline & $\mathrm{MgO}(653 \mathrm{~K})$ & HAP (613 K) & $\mathrm{MgO}(653 \mathrm{~K})$ & HAP $(613 \mathrm{~K})$ \\
\hline 30 & 15 & 4.4 & $1.1 \times 10^{-7}$ & $4.3 \times 10^{-8}$ \\
\hline 50 & 13 & 4.6 & $1.2 \times 10^{-7}$ & $6.5 \times 10^{-8}$ \\
\hline 75 & 11 & 4.6 & $1.2 \times 10^{-7}$ & $8.2 \times 10^{-8}$ \\
\hline
\end{tabular}

as the surface residence times of ethanol, acetaldehyde, and butanol are shown in Table 1.1, 1.2, and 1.3 , respectively.

Over $\mathrm{MgO}$, the calculated $\tau_{\mathrm{EtOH}}$ in Table 1.1 and $\tau_{\mathrm{AcH}}$ in Table 1.2 are similar at constant flowrate. Comparing Table 1.2 and 1.3 shows that $\tau_{\mathrm{BuOH}}>\tau_{\mathrm{AcH}}$ over $\mathrm{MgO}$ at constant flowrate. Under reaction conditions, the coverage of ethanol over $\mathrm{MgO}$ is at least an order of magnitude higher than the coverage of intermediates leading to acetaldehyde and butanol. In fact, it is estimated that half of the surface $\mathrm{Mg}-\mathrm{O}$ pairs are bound to adsorbed ethanol or ethoxide. ${ }^{13}$ Additionally, $N_{\mathrm{AcH}}>N_{\mathrm{BuOH}}$ which shows that the coverage of intermediates leading to acetaldehyde is higher than the coverage of intermediates leading to butanol. Over HAP, $\tau_{\text {AcH }}<\tau_{\text {EtOH }}$ at a flowrate of $30 \mathrm{~cm}^{3} \mathrm{~min}^{-1}$ and $50 \mathrm{~cm}^{3} \mathrm{~min}^{-1}$ while $\tau_{\mathrm{EtOH}} \approx \tau_{\mathrm{AcH}}$ at $75 \mathrm{~cm}^{3} \mathrm{~min}^{-1}$ implying that dehydrogenation of ethanol is very fast under reaction conditions. It can also be seen that $\tau_{\mathrm{BuOH}}>\tau_{\mathrm{AcH}}$ like 
Table 1.3: Time constants and surface coverages of reactive intermediates leading to butanol $\left(N_{\mathrm{BuOH}}\right)$ during the steady-state Guerbet coupling of ethanol over $\mathrm{MgO}$ and HAP at $653 \mathrm{~K}$ and $613 \mathrm{~K}$, respectively.

\begin{tabular}{|c|c|c|c|c|}
\hline \multirow{2}{*}{$\begin{array}{l}\text { Total Flow } \\
\text { Rate } \\
\left(\mathrm{cm}^{3} \min ^{-1}\right)\end{array}$} & \multicolumn{2}{|c|}{$\tau_{\mathrm{BuOH}}(\mathrm{s})$} & \multicolumn{2}{|c|}{$\begin{array}{l}\text { Coverage of intermediates to } \\
\text { acetaldehyde } N_{\mathrm{BuOH}} \\
\left(\mathrm{mol} \mathrm{m}^{-2}\right)\end{array}$} \\
\hline & $\mathrm{MgO}(653 \mathrm{~K})$ & HAP $(613 \mathrm{~K})$ & $\mathrm{MgO}(653 \mathrm{~K})$ & HAP $(613 \mathrm{~K})$ \\
\hline 30 & 93 & 310 & $2.8 \times 10^{-7}$ & $4.8 \times 10^{-6}$ \\
\hline 50 & 53 & 117 & $8.1 \times 10^{-8}$ & $1.7 \times 10^{-6}$ \\
\hline 75 & 27 & 69 & $4.6 \times 10^{-8}$ & $1.1 \times 10^{-6}$ \\
\hline
\end{tabular}

$\mathrm{MgO}$. Unlike $\mathrm{MgO}$, on $\mathrm{HAP} N_{\mathrm{BuOH}} \gg N_{\mathrm{AcH}}$. The coverage of intermediates leading to butanol is much higher over HAP than $\mathrm{MgO}$ while the coverage of intermediates leading to acetaldehyde is higher over $\mathrm{MgO}$ than over HAP.

The similar residence time of acetaldehyde and ethanol over both catalysts implies that acetaldehyde is being formed very rapidly, indicating dehydrogenation of ethanol is very fast under these conditions. The relatively high $\tau_{\mathrm{BuOH}}$ (when compared to $\tau_{\mathrm{AcH}}$ ) over both catalysts indicates that coupling to $\mathrm{C}_{4}$ product is slow and could be rate determining which is consistent with the proposed idea that aldol condensation is rate determining for Guerbet coupling of ethanol over HAP. ${ }^{10-12}$ Another clear difference between HAP and $\mathrm{MgO}$ is the difference in the coverage of intermediates leading to acetaldehyde versus the coverage of intermediates leading to butanol. Over $\mathrm{MgO} N_{\mathrm{BuOH}}<N_{\mathrm{AcH}}$ while over HAP $N_{\mathrm{BuOH}} \gg N_{\mathrm{AcH}}$. This difference suggests that most of the acetaldehyde formed over $\mathrm{MgO}$ desorbs into the gas phase while most of the acetaldehyde over HAP goes on to couple to butanol. This difference helps explain the much larger selectivity HAP has to butanol compared to $\mathrm{MgO}$. The high $N_{\mathrm{BuOH}}$ over HAP indicates that the high rate over HAP is due to a greater number of active sites as opposed to a higher TOF when compared to $\mathrm{MgO}$. 


\subsection{Outline of Completed Work}

Based on the SSITKA results and other works ${ }^{10-12,39}$, it appears as though the aldol condensation step is kinetically relevant to the overall Guerbet coupling reaction. However, this conclusion is not consistent with other studies. Specifically, it has been shown that the addition of a metal capable of alcohol dehydrogenation, such as copper, would increase the rate of Guerbet coupling. ${ }^{26}$ To provide further mechanistic insight into the Guerbet coupling reaction, the constituent reactions (dehydrogenation, aldol condensation, hydrogenation) were all studied independently of the overall Guerbet coupling network. First, the aldol condensation of acetaldehyde was studied over HAP, MgO and anatase $\mathrm{TiO}_{2}$ to explore the mechanism of aldol condensation over acid-base catalysts. The results of this study can be found in Chapter 2. Subsequently, hydrogenation and dehydrogenation reactions were studied. The rates of $\mathrm{C}=\mathrm{C}$ and $\mathrm{C}=\mathrm{O}$ bond hydrogenation were also studied using both $\mathrm{H}_{2}$ and ethanol as a hydrogen source. The alcohol dehydrogenation reaction was also studied by measuring the rate of benzyl alcohol dehydrogenation over HAP and $\mathrm{MgO}$. The results from these reactions can be found in Chapter 3. By breaking down the Guerbet coupling reaction network into individual reactions, we were able to gain a good understanding of how Guerbet coupling proceeds and what reactions are important to the rate and selectivity. 


\title{
Chapter 2
}

\section{Aldol Condensation of Acetaldehyde over}

\section{Titania, Hydroxyapatite, and Magnesia}

This chapter was adapted from: Z.D. Young, S. Hanspal, and R.J. Davis, "Aldol Condensation of Acetaldehyde over Titania, Hydroxyapatite, and Magnesia." Published in ACS Catalysis. DOI:10.1021/acscatal.6b00264

\begin{abstract}
The kinetics of aldol condensation of acetaldehyde were studied over anatase titania $\left(\mathrm{TiO}_{2}\right)$, hydroxyapatite $(\mathrm{HAP})$ and magnesia $(\mathrm{MgO})$. Reactions were carried out in a fixed bed reactor with a total system pressure of $220 \mathrm{kPa}$ at temperatures between $533 \mathrm{~K}$ to $633 \mathrm{~K}$ and acetaldehyde partial pressures between $0.05 \mathrm{kPa}$ to $50 \mathrm{kPa}$. Cro-
\end{abstract}


tonaldehyde was the only product observed over all three catalysts and severe catalyst deactivation occurred at acetaldehyde partial pressures of $5 \mathrm{kPa}$ or greater. The aldol condensation reaction over all three catalysts was first order at low acetaldehyde partial pressure and approached zero order at high acetaldehyde partial pressure. No kinetic isotope effect (KIE) was observed with fully deuterated acetaldehyde reacting over $\mathrm{TiO}_{2}$ or HAP implying $\mathrm{C}-\mathrm{H}$ bond activation is not kinetically relevant. These measurements are consistent with a mechanism in which adsorption and desorption steps are kinetically significant during the reaction. Characterization of the catalysts by adsorption microcalorimetry of acetaldehyde and ethanol and diffuse reflectance Fourier transform infrared spectroscopy of adsorbed acetaldehyde, crotonaldehyde and acetic acid revealed a very high reactivity of these catalysts, even at low temperatures.

\subsection{Introduction}

As described in Chapter 1, Guerbet coupling is a sequence of reactions that results in the formation of a long chain saturated alcohol from two shorter chain saturated alcohols. Guerbet coupling is thought to consist of many elementary steps including dehydrogenation, aldol condensation, and hydrogenation. Many heterogeneous catalytic systems have been studied for this reaction including, for example, magnesia $(\mathrm{MgO}),{ }^{5,8,13,27,39} \mathrm{Mg}$ - $\mathrm{Al}$ mixed metal oxides, ${ }^{5,41}$ and hydroxyapatite (HAP). ${ }^{7-10,39,42}$

Although the mechanism of Guerbet coupling of ethanol is still debated, it is generally thought to proceed through the following sequence of steps. First, ethanol is dehydrogenated to acetalde- 
hyde, two molecules of acetaldehyde form crotonaldehyde through aldol condensation and finally crotonaldehyde is hydrogenated to form saturated 1-butanol. The final hydrogenation step likely involves hydrogen transfer from ethanol to regenerate acetaldehyde through a Meerwein-PonndorfVerley-like step which has been shown to be very active over hydroxyapatite. ${ }^{43}$ The aldol condensation of acetaldehyde has been proposed to be the rate determining step of this reaction over strontium-substituted hydroxyapatite. ${ }^{10}$ Additionally a recent publication by Ho et al. ${ }^{11}$ has stated that enolate formation is the rate determining step in Guerbet coupling of ethanol over hydroxyapatite. In contrast, Scalbert et al. ${ }^{30}$ use a thermodynamic argument to claim aldol condensation plays only a minor role in butanol formation from ethanol over HAP at temperatures between $633 \mathrm{~K}$ to $673 \mathrm{~K}$. Chieregato et al. ${ }^{28}$ have also questioned the relevance of aldol condensation over $\mathrm{MgO}$ stating that Guerbet coupling proceeds through a direct condensation mechanism. In an attempt to elucidate the role of aldol condensation in the Guerbet coupling reaction, the aldol condensation of acetaldehyde was studied over a series of catalysts. For more information on these works see Chapter 1 Section 1.1.

Aldol condensation is a well-studied reaction that forms a carbon-carbon bond between two aldehyde or ketone molecules. Aldol condensation is a critical step in the production of 2ethylhexanal, isophorone and crotonaldehyde. This reaction can be catalyzed by a wide variety of solid acid or base catalyst such as zeolites, ${ }^{44}$ hydrotalcites and hydrotalcite-derived materials, ${ }^{5,45-49}$ metal oxides and supported metal oxides ${ }^{22,23,50-55}$ and hydroxyapatite..$^{56}$

In the current study, rate measurements were carried out over multiple catalysts to explore the kinetic mechanism of aldol condensation and provide insight to the Guerbet coupling of ethanol. The condensation reaction was studied over three catalysts, anatase $\mathrm{TiO}_{2}, \mathrm{HAP}$, and $\mathrm{MgO}$. Both 
HAP and $\mathrm{MgO}$ are common Guerbet coupling catalysts whereas $\mathrm{TiO}_{2}$ is a commonly-studied catalyst for aldol condensation. Diffuse reflectance infrared Fourier transform spectroscopy (DRIFTS) and adsorption microcalorimetry of various probe molecules were used to probe the affinity of catalyst surfaces for species relevant to the condensation reaction.

\subsection{Materials and Methods}

\subsubsection{Catalyst Synthesis}

A near stoichiometric hydroxyapatite was synthesized using the co-precipitation method described by Tsuchida et al. ${ }^{7}$ Briefly, $200 \mathrm{~cm}^{3}$ of $0.5 \mathrm{M}$ calcium nitrate tetrahydrate $\left(\mathrm{Ca}\left(\mathrm{NO}_{3}\right)_{2} \cdot 4\left(\mathrm{H}_{2} \mathrm{O}\right)\right.$, Acros Organics) and $200 \mathrm{~cm}^{3}$ of $0.3 \mathrm{M}$ diammonium phosphate $\left(\left(\mathrm{NH}_{4}\right)_{2} \mathrm{HPO}_{4}\right.$, Aldrich, $\left.>99.99 \%\right)$ adjusted to $\mathrm{pH} 10$ using ammonium hydroxide were added dropwise to $100 \mathrm{~cm}^{3}$ of distilled and deionized water at $353 \mathrm{~K}$. The slurry was left for $24 \mathrm{~h}$ at $353 \mathrm{~K}$ while stirring. The resulting powder was filtered and washed with distilled and deionized water three times and dried overnight in air at $373 \mathrm{~K}$.

Commercially-available magnesia (Ube Material Industries, Ltd., Lot Number 109071725) and anatase titania (Aldrich, 99.8\%) were purchased. All three catalysts were thermally-treated at $873 \mathrm{~K}$ under $100 \mathrm{~cm}^{3} \mathrm{~min}^{-1}$ flowing air for $2 \mathrm{~h}$ prior to characterization and use in reaction. The powders were subsequently pelletized, crushed and sieved to $106 \mu \mathrm{m}$ to $180 \mu \mathrm{m}$. 


\subsubsection{Catalyst Characterization}

X-ray diffraction (XRD) was performed with a PANalytical X'Pert Pro diffractometer using Cu$\mathrm{K} \alpha$ radiation to verify crystal structure and phase purity.

Elemental analysis of HAP was performed by Galbraith Laboratories (Knoxville, TN) using inductively coupled plasma optical emission spectroscopy (ICP-OES) for calcium and phosphorous content.

Catalyst surface area was obtained from $\mathrm{N}_{2}$ adsorption at $77 \mathrm{~K}$ on a Micromeritics ASAP 2020 automated analyzer using the BET method.

\subsubsection{Aldol Condensation of Acetaldehyde}

Kinetic studies were carried out in a stainless steel, downward flow, fixed bed reactor. A schematic of the reactor is shown in Appendix B. Prior to reaction, $\mathrm{HAP}$ and $\mathrm{MgO}$ were heated in situ at $773 \mathrm{~K}$ for $1 \mathrm{~h}$ in $100 \mathrm{~cm}^{3} \mathrm{~min}^{-1}$ dry air (GTS-Welco) while $\mathrm{TiO}_{2}$ was heated for $2 \mathrm{~h}$ at $773 \mathrm{~K}$ in $100 \mathrm{~cm}^{3} \mathrm{~min}^{-1}$ dry air. A dinitrogen (GTS-Welco, 99.999\%) stream containing acetaldehyde was passed over the catalyst for 10 min prior to product analysis with an on-line gas chromatograph equipped with a PoraPLOT Q-HT column and flame ionization detector. The concentration of acetaldehyde was controlled by diluting the saturated dinitrogen stream with flowing dinitrogen as well as cooling the saturator with either a water-ice bath or a dry ice-acetone bath. The total system pressure was maintained at $220 \mathrm{kPa}$ using a back pressure regulator.

Aldol condensation in the presence of ethanol was conducted in the same way while flowing 
ethanol to a vaporizer using a syringe pump. In some cases, ethanol was fed to the catalyst without acetaldehyde to explore Guerbet coupling. The only product alcohol observed during Guerbet coupling was butanol and there were no peaks associated with unknown compounds in the gas chromatograms.

Aldol condensation of fully-deuterated acetaldehyde was carried out using the same reactor described above. The HAP catalyst was pretreated at $773 \mathrm{~K}$ for $1 \mathrm{~h}$ in $100 \mathrm{~cm}^{3} \mathrm{~min}^{-1}$ dinitrogen while $\mathrm{TiO}_{2}$ was pretreated at $773 \mathrm{~K}$ for $2 \mathrm{~h}$ in $100 \mathrm{~cm}^{3} \mathrm{~min}^{-1}$ dry air for $2 \mathrm{~h}$. There was no observed difference in reactivity over HAP pretreated in dinitrogen versus HAP pretreated in dry air. Unlabeled acetaldehyde reacted over the catalyst until steady state was achieved, and then the feed was quickly switched to fully-deuterated acetaldehyde (Cambridge Isotopes, $99 \%$ ). After $4 \mathrm{~h}$, the reactant was switched back to unlabeled acetaldehyde.

All nonlinear fits were done using the least squares curve fitting algorithm lsqcurvefit in Matlab.

\subsubsection{Adsorption Microcalorimetry}

Adsorption microcalorimetry experiments were performed using a home built heat-flow microcalorimeter described previously. ${ }^{36,37,57,58}$ A schematic of the adsorption microcalorimeter is shown in Appendix A. A sample was first outgassed at $773 \mathrm{~K}$ for $16 \mathrm{~h}$ at $10^{-2} \mathrm{~Pa}$. The treated sample was then cooled and placed in an isothermal block maintained at $303 \mathrm{~K}$ for $2 \mathrm{~h}$ to reach thermal equilibrium. The sample was exposed to doses of acetaldehyde or ethanol via a volumetric dosing system and each dose was allowed to reach equilibrium with the sample over 15 min. The acetaldehyde (Aldrich, 99.5\%) and ethanol (Aldrich, anhydrous, $>99.5 \%$ ) used in 
these experiments were further degassed by three freeze-pump-thaw cycles prior to adsorption experiments.

\subsubsection{Diffuse Reflectance Infrared Fourier Transform Spectroscopy (DRIFTS)}

Stepwise temperature-programmed desorption of acetaldehyde, crotonaldehyde, and acetic acid was measured using a Bio-Rad (FTS-60A) FTIR spectrometer equipped with a liquid $\mathrm{N}_{2}$ cooled MCT detector. A 5 wt. $\%$ catalyst sample $\left(\mathrm{TiO}_{2}, \mathrm{HAP}\right.$, or $\left.\mathrm{MgO}\right)$ diluted with $\mathrm{KBr}$ powder was pretreated at $773 \mathrm{~K}$ for $1 \mathrm{~h}$ under $30 \mathrm{~cm}^{3} \mathrm{~min}^{-1}$ flowing He. Background scans were collected at multiple temperatures after waiting for $15 \mathrm{~min}$ to allow the catalyst bed to reach thermal equilibrium. After background scans were collected, a $30 \mathrm{~cm}^{3} \mathrm{~min}^{-1} \mathrm{He}$ stream passed through a saturator at either room temperature (for crotonaldehyde and acetic acid) or dry ice-acetone temperature (for acetaldehyde). The saturated He stream was passed over the catalyst for $15 \mathrm{~min}$ at $303 \mathrm{~K}$. The catalyst was purged with pure $\mathrm{He}$ for $15 \mathrm{~min}$ at $303 \mathrm{~K}$ to remove the gas phase and weakly-adsorbed probe molecules. The temperature was then increased in a stepwise manner while continuously flowing He. Scans were collected at each temperature after the system was allowed to purge for $15 \mathrm{~min}$ at that temperature. 


\subsection{Results and Discussion}

\subsubsection{Catalyst Characterization}

The BET surface areas of $\mathrm{TiO}_{2}, \mathrm{HAP}$, and $\mathrm{MgO}$ were found to be $9 \mathrm{~m}^{2} \mathrm{~g}^{-1}, 29 \mathrm{~m}^{2} \mathrm{~g}^{-1}$ and $35 \mathrm{~m}^{2} \mathrm{~g}^{-1}$, respectively. The ICP-OES results for HAP showed a $\mathrm{Ca} / \mathrm{P}$ ratio of 1.70 which is very close to the stoichiometric value of 1.67. All catalysts were found to be phase pure and had XRD patterns that matched well with reference patterns as shown in Figure 2.1.

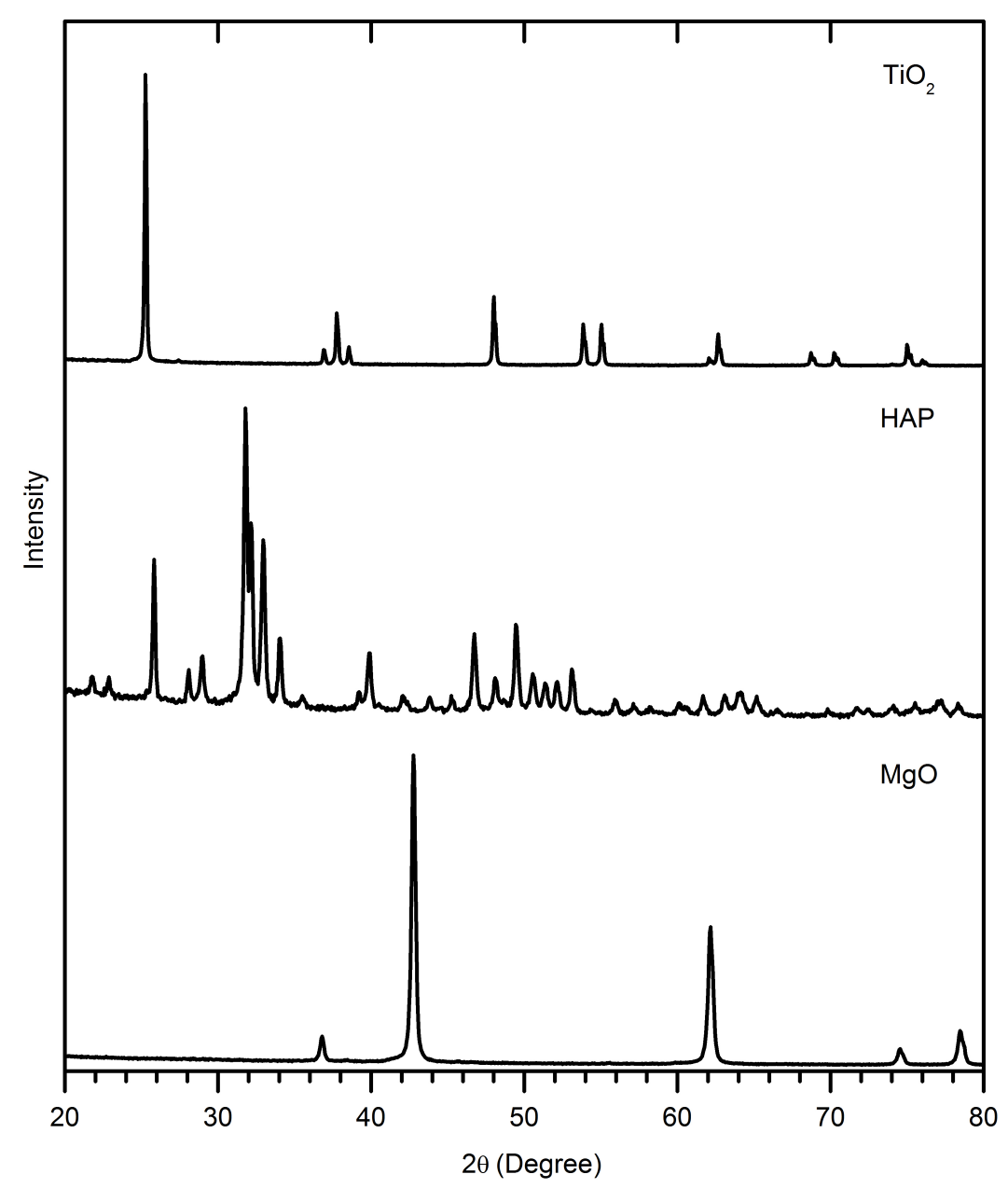

Figure 2.1: The XRD patterns for anatase $\mathrm{TiO}_{2}, \mathrm{HAP}$, and $\mathrm{MgO}$. Patterns offset for clarity. 

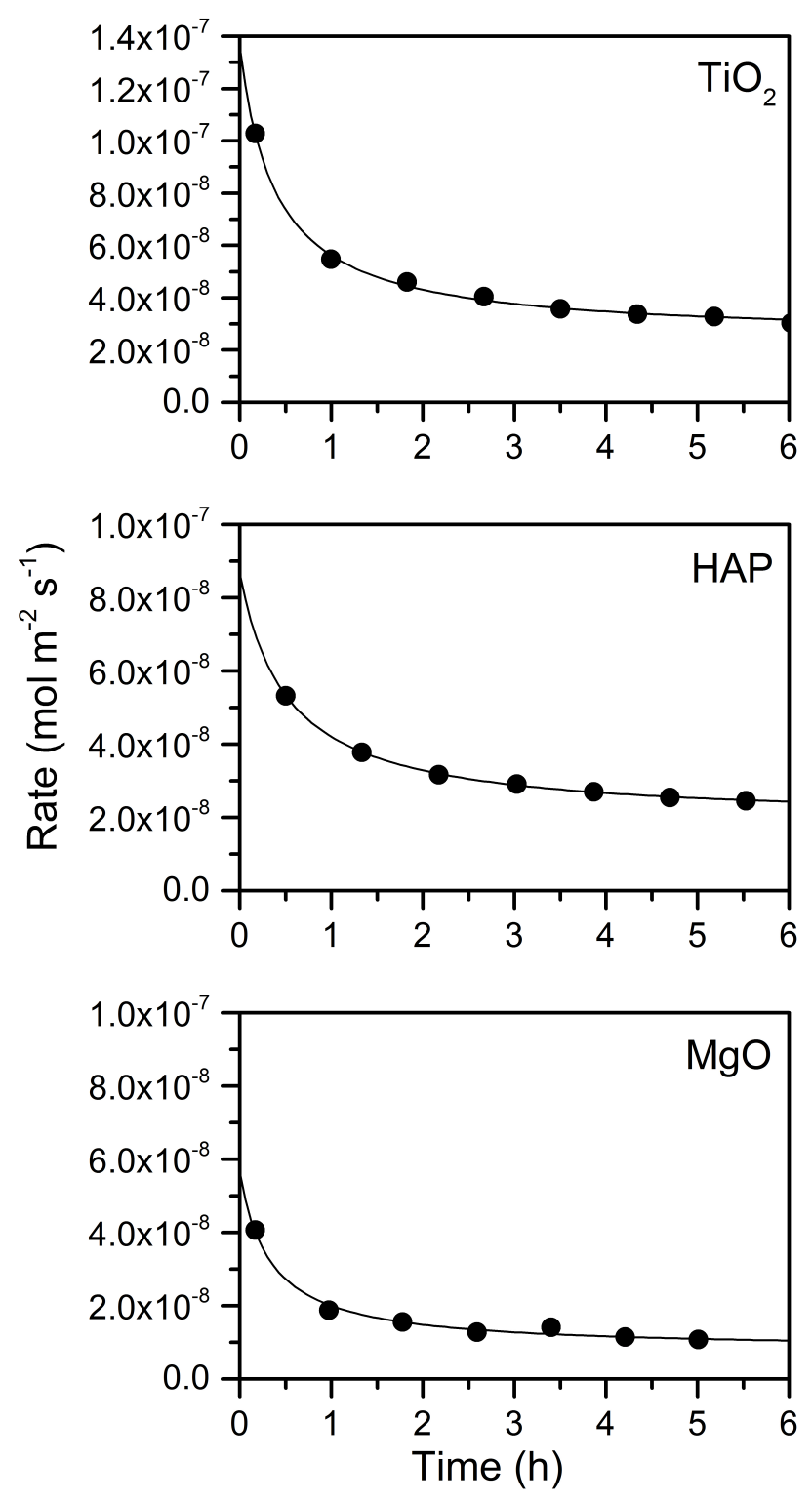

Figure 2.2: Rates collected over $6 \mathrm{~h}$ at $5 \mathrm{kPa}$ acetaldehyde partial pressure. $\mathrm{TiO}_{2}$ and $\mathrm{HAP}$ were run at $553 \mathrm{~K}, \mathrm{MgO}$ was run at $673 \mathrm{~K}$. Results were fitted to a three parameter empirical hyperbolic function.

\subsubsection{Aldol Condensation Kinetics}

Aldol condensation of acetaldehyde at low conversion was performed over anatase $\mathrm{TiO}_{2}, \mathrm{HAP}$, and $\mathrm{MgO}$, and the only product observed over all catalysts was crotonaldehyde. Titania and HAP 

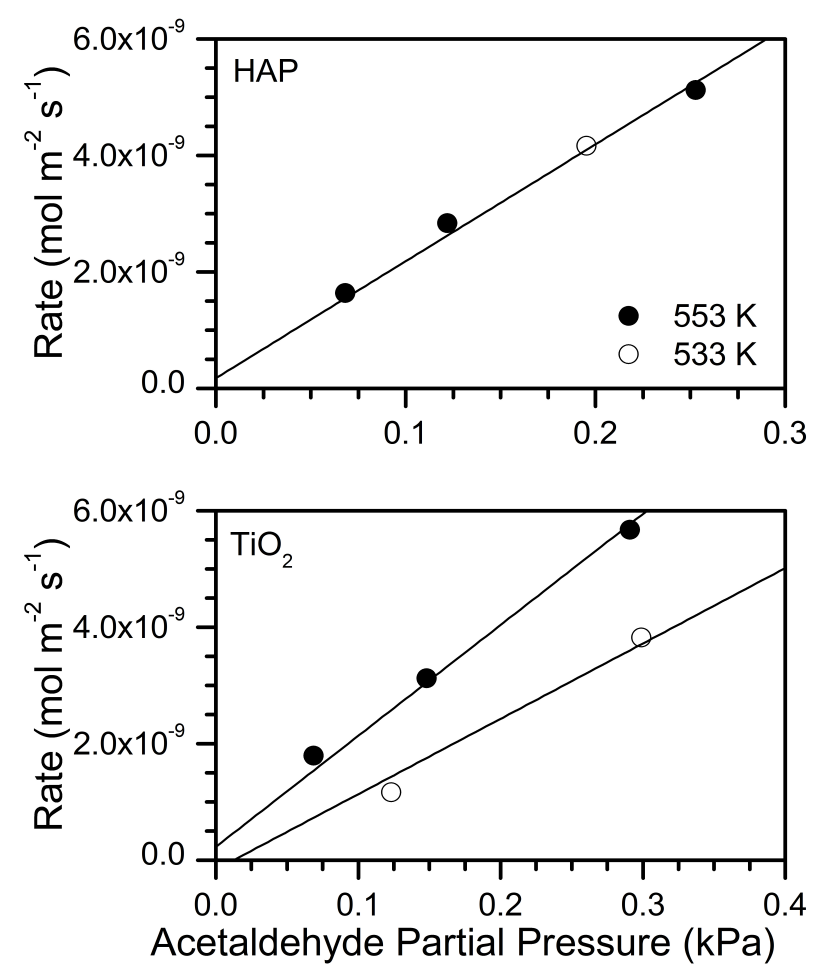

Figure 2.3: Rate of aldol condensation of acetaldehyde at low partial pressure over HAP (top) and $\mathrm{TiO}_{2}$ (bottom).

were active at $553 \mathrm{~K}$ while $\mathrm{MgO}$ had comparable areal rates at $633 \mathrm{~K}$. In all three cases, significant deactivation was observed over the first $6 \mathrm{~h}$ on stream with acetaldehyde partial pressures of $5 \mathrm{kPa}$ or greater. Typical deactivation curves over the three catalysts in $5 \mathrm{kPa}$ of acetaldehyde are shown in Figure 2.2. Deactivation is commonly observed during aldol condensation of acetaldehyde over heterogeneous catalysts and is most likely the result of high molecular weight compounds formed by sequential reactions of the product aldehyde. $22,50,52,56$

We observed very little deactivation over $\mathrm{HAP}$ and $\mathrm{TiO}_{2}$ at acetaldehyde pressures below $0.4 \mathrm{kPa}$. In fact, at these low acetaldehyde partial pressures steady state rates were measured over both $\mathrm{TiO}_{2}$ and $\mathrm{HAP}$. Interestingly, even at very low partial pressures of acetaldehyde, deactivation still occurred over $\mathrm{MgO}$. Figure 2.3 shows the rate of reaction versus acetaldehyde partial pressure 
at $553 \mathrm{~K}$ and $533 \mathrm{~K}$ over $\mathrm{TiO}_{2}$ and $\mathrm{HAP}$ under steady state conditions at low acetaldehyde pressure. The order of reaction over HAP at these conditions is 0.9 . Interestingly, changing the reaction temperature by $20 \mathrm{~K}$ had no measurable effect on the rate of reaction over HAP implying a very low activation energy. The reaction is also first order over $\mathrm{TiO}_{2}$, but the temperature dependence of the rate indicated an apparent activation energy of $47 \mathrm{~kJ} \mathrm{~mol}^{-1}$, which is also low. An apparent activation energy for $\mathrm{MgO}$ was not measured because of deactivation even at low partial pressures of acetaldehyde.

In an attempt to explore the mechanism of aldol condensation over $\mathrm{TiO}_{2}$ and $\mathrm{HAP}$, fully deuterated acetaldehyde was used to check for a kinetic isotope effect (KIE). The kinetic isotope studies were carried out at low acetaldehyde partial pressures to avoid the effects of deactivation. Table 2.1 shows the KIE evaluated over both $\mathrm{TiO}_{2}$ and $\mathrm{HAP}$. The apparent first order rate constants $k_{H}$ and $k_{D}$ were calculated by normalizing the rate of reaction by the acetaldehyde partial pressure. The ratio of $k_{H}$ to $k_{D}$ is very close to unity for the reactions on $\mathrm{TiO}_{2}$ and $\mathrm{HAP}$. The lack of a kinetic isotope effect shows that $\mathrm{C}-\mathrm{H}$ activation is not kinetically relevant over either catalyst.

Table 2.1: Kinetic isotope effect for aldol condensation of acetaldehyde over $\mathrm{HAP}$ and $\mathrm{TiO}_{2}$ at $553 \mathrm{~K}$.

\begin{tabular}{|c|c|c|c|c|}
\hline Catalyst & $\begin{array}{l}\text { Acetaldehyde } \\
\text { Partial Pressure } \\
\qquad(\mathrm{kPa})\end{array}$ & $\begin{array}{c}k_{H} \\
\left(\mathrm{~mol} \mathrm{kPa}^{-1} \mathrm{~m}^{-2} \mathrm{~s}^{-1}\right)\end{array}$ & $\begin{array}{c}k_{D} \\
\left(\mathrm{~mol} \mathrm{kPa}^{-1} \mathrm{~m}^{-2} \mathrm{~s}^{-1}\right)\end{array}$ & $k_{H} / k_{D}$ \\
\hline HAP & 0.097 & $2.5 \times 10^{-8}$ & $2.2 \times 10^{-8}$ & 1.1 \\
\hline $\mathrm{TiO}_{2}$ & 0.26 & $8.6 \times 10^{-9}$ & $8.8 \times 10^{-9}$ & 0.98 \\
\hline
\end{tabular}

Elementary steps for aldol condensation include acetaldehyde adsorption, enolate formation, 
$\mathrm{C}-\mathrm{C}$ coupling, dehydration and product desorption. The fact that $\mathrm{C}-\mathrm{H}$ bond activation is not kinetically relevant implies that enolate formation is not the rate determining step because it is the result of $\alpha$-H abstraction from a surface-bound aldehyde. Results from adsorption microcalorimetry and infrared spectroscopy, discussed later, indicate that surface reactions of adsorbed aldehydes occur readily under very mild conditions. If a bimolecular surface reaction between surface enolate and acetaldehyde were rate limiting, the condensation reaction would be second order in acetaldehyde instead of the observed first order. Construction of a Langmuir-Hinshelwood rate equation assuming that desorption of products is rate determining also reveals that the rate would be second order in acetaldehyde at low partial pressures. As described in Appendix E, a potential kinetic model that might explain the experimental results involves the irreversible adsorption of acetaldehyde and kinetically relevant desorption of either crotonaldehyde or water as shown in Scheme 2.1.

$$
\begin{gathered}
\mathrm{AcH}+* \stackrel{\mathrm{k}_{1}}{\longrightarrow} \mathrm{AcH} * \\
\ldots \\
\text { Product } * \stackrel{\mathrm{k}_{2}}{\longrightarrow} \text { Product }+*
\end{gathered}
$$

\section{Scheme 2.1}

In an attempt to further explore the kinetic mechanism, the influence of acetaldehyde on the condensation rate was evaluated at higher partial pressures. Unfortunately, all three catalysts deactivate rapidly at high acetaldehyde partial pressures and steady state rates cannot be measured. Indeed, Rekoske and Barteau ${ }^{22}$ discovered severe deactivation of titania during the first $10 \mathrm{~min}$ of aldol condensation of acetaldehyde under conditions similar to the high pressure acetaldehyde experiments reported here. In an attempt to minimize the influence of deactivation on the reac- 
tion kinetics, initial rates were estimated by extrapolating the rate curves over $6 \mathrm{~h}$ of reaction to zero time on stream. A three parameter hyperbolic function shown in Equation 2.1 was used to determine initial rates.

$$
r=\frac{c_{1}}{1+c_{2} t}+c_{3}
$$

The functional form was found to fit the deactivation curves well as shown in Figure 2.2. An empirical function such as this is commonly used to model a deactivating catalyst. ${ }^{59}$

The aldol condensation reaction over the three catalysts was performed at multiple acetaldehyde partial pressures and the results are shown in Figure 2.4. Titania was the most active catalyst (per square meter) for aldol condensation of acetaldehyde followed by HAP and MgO. The activity of $\mathrm{MgO}$ was so low that the reaction temperature was increased by $80 \mathrm{~K}$ to obtain comparable rates to HAP. All of the catalysts exhibit significant deviation from first order behavior at higher acetaldehyde pressures and some appear to approach zero order. Over $\mathrm{TiO}_{2}$ the approach to zero order at high acetaldehyde partial pressures is less apparent. Rekoske and Barteau ${ }^{22}$ showed that the rate of deactivation is zero order with respect to acetaldehyde partial pressure so the decrease in observed reaction order over titania at higher aldehyde pressure is not the result of a higher rate of deactivation.

Equation 2.2 shows the functional form of the rate equation from Scheme 1 as derived in 


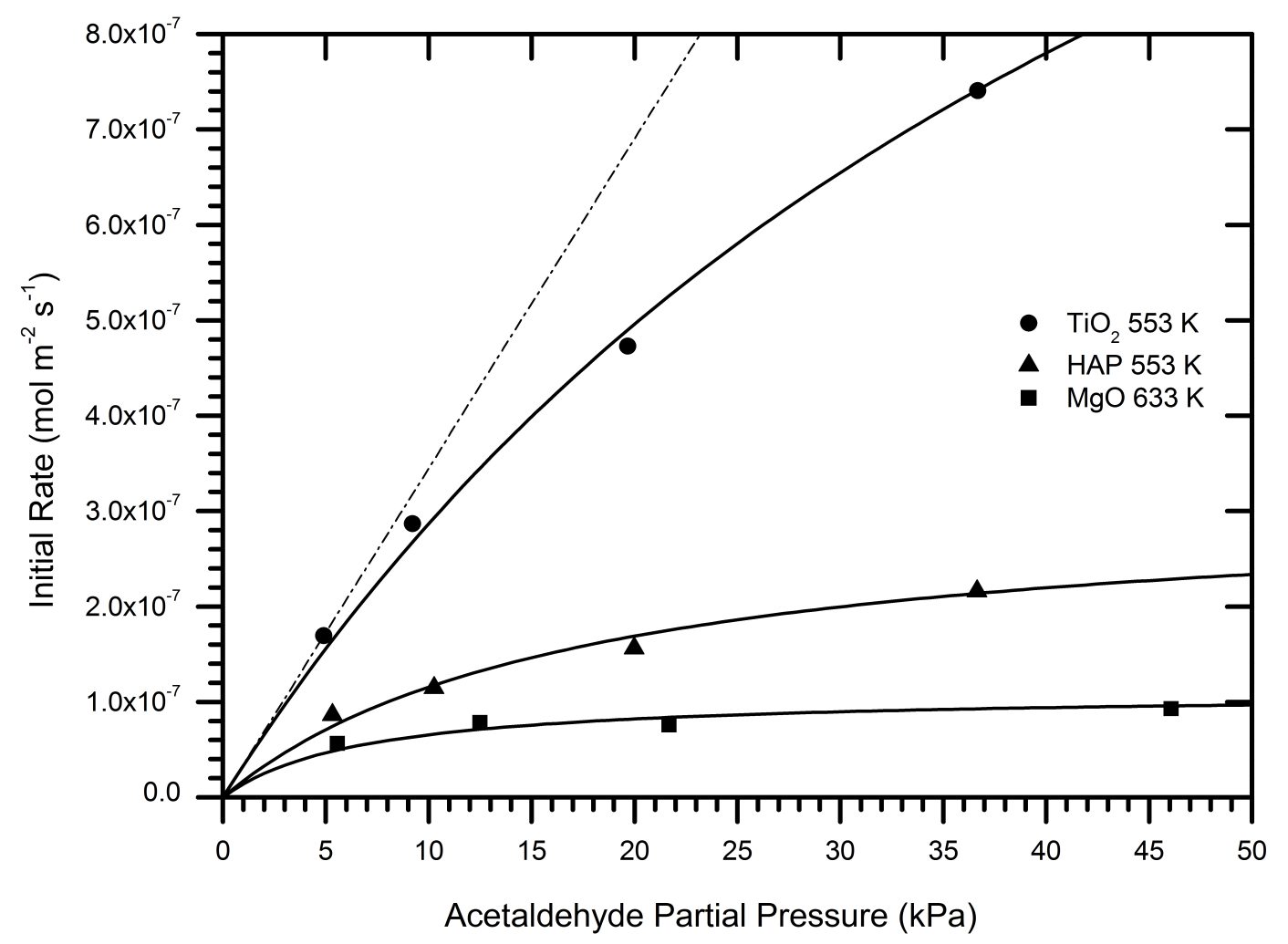

Figure 2.4: Initial rates of aldol condensation of acetaldehyde over $\mathrm{TiO}_{2}, \mathrm{HAP}$ and $\mathrm{MgO}$. The dashed line indicates the expected trend for a first order reaction over $\mathrm{TiO}_{2}$.

Appendix E and assuming that either crotonaldehyde or water is the most abundant surface species

$$
r=\frac{1 / 2[*]_{0} k_{1} P_{A c H}}{1+\frac{k_{1}}{2 k_{2}} P_{A c H}}
$$

where $[*]_{0}$ is the number density of surface sites, $k_{1}$ is the rate constant for acetaldehyde adsorption and $k_{2}$ is the rate constant for product desorption.

Equation 2.2 was used to fit the rates reported in Figure 2.4. The model parameters were used to extrapolate the high pressure rates to the steady state rates measured at low acetaldehyde partial pressure. The kinetic model was able to predict the observed steady state rates measured at 
low pressure to within a factor of 2 over $\mathrm{TiO}_{2}$ and within $30 \%$ over HAP. The model agreement involving rates measured at steady state (low pressure) and initial rates measured on a deactivating system (higher pressure) suggests that the initial rates are a reasonable approximation of the steady state rates at higher acetaldehyde partial pressures, although the uncertainty in $k_{2}$ could be quite high as it is determined solely by the high pressure initial rates.

The calculated groupings of rate parameters are shown in Table 2.2. It was not possible to statistically evaluate individual rate constants based on the current data set because the value of $[*]_{0}$ was highly correlated to $k_{1}$. Therefore we need to seek an independent estimate of $[*]_{0}$, which will be discussed later. The acetaldehyde adsorption rate constant $k_{1}$ appears to be relatively similar among the three catalysts, assuming the active site density $[*]_{0}$ among the catalysts is not too different. The order of magnitude difference in $k_{1} / 2 k_{2}$ suggests the main difference among the catalysts is the rate at which product desorbs from the catalyst surface. Indeed, the fitted values indicate the lowest value of $k_{2}$, the product desorption rate constant, is associated with $\mathrm{MgO}$, which is a strong base catalyst, and the greatest value of $k_{2}$ is associated with $\mathrm{TiO}_{2}$. Because the product desorption rate constant has significant uncertainty as it was estimated from rapidly deactivating catalysts, additional information about the interactions of aldehydes with the catalysts is needed to validate the reactivity trends. Hence, we used adsorption microcalorimetry and DRIFTS of adsorbed aldehydes to complement the results derived from reaction kinetics, as will be discussed later.

At first glance, our results may seem inconsistent with those of Ho et al. ${ }^{11}$ who propose enolate formation from acetaldehyde as the rate determining step during Guerbet coupling of ethanol over HAP. Under the conditions of Guerbet coupling, however, ethanol acts as a hydrogen source, 
Table 2.2: Calculated rate parameters from kinetic model in Equation 2.2.

\begin{tabular}{cccc}
\hline Catalyst & $\mathrm{T}(\mathrm{K})$ & $\begin{array}{c}\frac{[*]_{0} k_{1}}{2} \\
\left(\mathrm{~mol} \mathrm{kPa}^{-1} \mathrm{~m}^{-2} \mathrm{~s}^{-1}\right)\end{array}$ & $\frac{k_{1}}{2 k_{2}}\left(\mathrm{kPa}^{-1}\right)$ \\
\hline $\mathrm{TiO}_{2}$ & 553 & $3.6 \times 10^{-8}$ & 0.021 \\
$\mathrm{HAP}$ & 553 & $1.9 \times 10^{-8}$ & 0.063 \\
$\mathrm{MgO}$ & 633 & $2.6 \times 10^{-8}$ & 0.26 \\
\hline
\end{tabular}

resulting in the rapid hydrogenation of crotonaldehyde to butanol. This rapid hydrogen transfer could shift the kinetically-relevant step from product desorption to enolate formation under Guerbet coupling conditions whereas enolate formation appears to be relatively fast under the aldol condensation conditions studied here.

\subsubsection{Aldol Condensation in the Presence of Ethanol}

The effect of ethanol partial pressure on acetaldehyde condensation over $\mathrm{TiO}_{2}$ is shown in Figure 2.5. Unlike $\mathrm{HAP}$ and $\mathrm{MgO}, \mathrm{TiO}_{2}$ did not deactivate in the presence of ethanol. Additionally, the rate of aldol condensation over $\mathrm{TiO}_{2}$ was inhibited by adding ethanol to the feed. Using the kinetic parameters in Table 2.2, a competitive adsorption model, shown in Equation 2.3, was fit to the results. The ethanol co-feeding experiments were performed with $5 \mathrm{kPa}$ acetaldehyde because we did not have the ability to measure accurate product compositions at very low acetaldehyde pressures if ethanol inhibited the aldol condensation rate.

$$
r=\frac{1 / 2[*]_{0} k_{1} P_{A c H}}{1+\frac{k_{1}}{2 k_{2}} P_{A c H}+K_{E t O H} P_{E t O H}}
$$

As seen in Figure 2.6 this model fits the results well and yields an adsorption equilibrium 


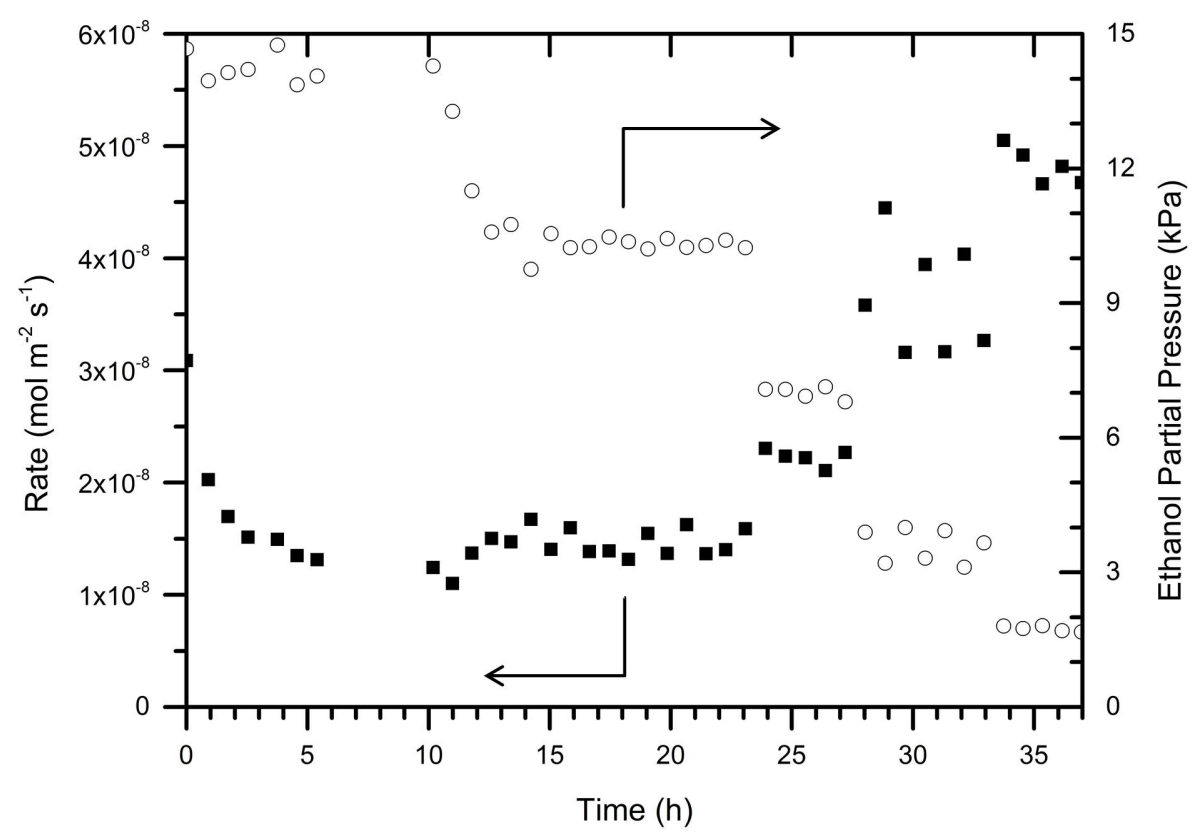

Figure 2.5: Rate of aldol condensation of acetaldehyde over $\mathrm{TiO}_{2}$ at $5 \mathrm{kPa}$ acetaldehyde partial pressure and $553 \mathrm{~K}$ in the presence of ethanol.

constant of ethanol $K_{\mathrm{EtOH}}$ of $1.3 \mathrm{kPa}^{-1}$ at $553 \mathrm{~K}$ under reaction conditions.

Ethanol and acetaldehyde were also reacted over HAP at $553 \mathrm{~K}$ to compare with results on $\mathrm{TiO}_{2}$. At this temperature ethanol does not react catalytically on the HAP surface. The effect of added ethanol on the rate of aldol condensation is shown in Figure 2.6. Over HAP, the added ethanol had little effect of the rate of aldol condensation and the small changes that were observed were the result of slight changes in the deactivation of the catalyst. The time plot of the rate of reaction is shown in Figure 2.7, which clearly shows that step changes in ethanol partial pressure had no influence on the rate of aldol condensation over HAP.

Co-feeding ethanol and acetaldehyde was also studied over $\mathrm{MgO}$ at $633 \mathrm{~K}$. At this temperature, the only product observed during ethanol conversion (no acetaldehyde co-fed) on $\mathrm{MgO}$ was a small 

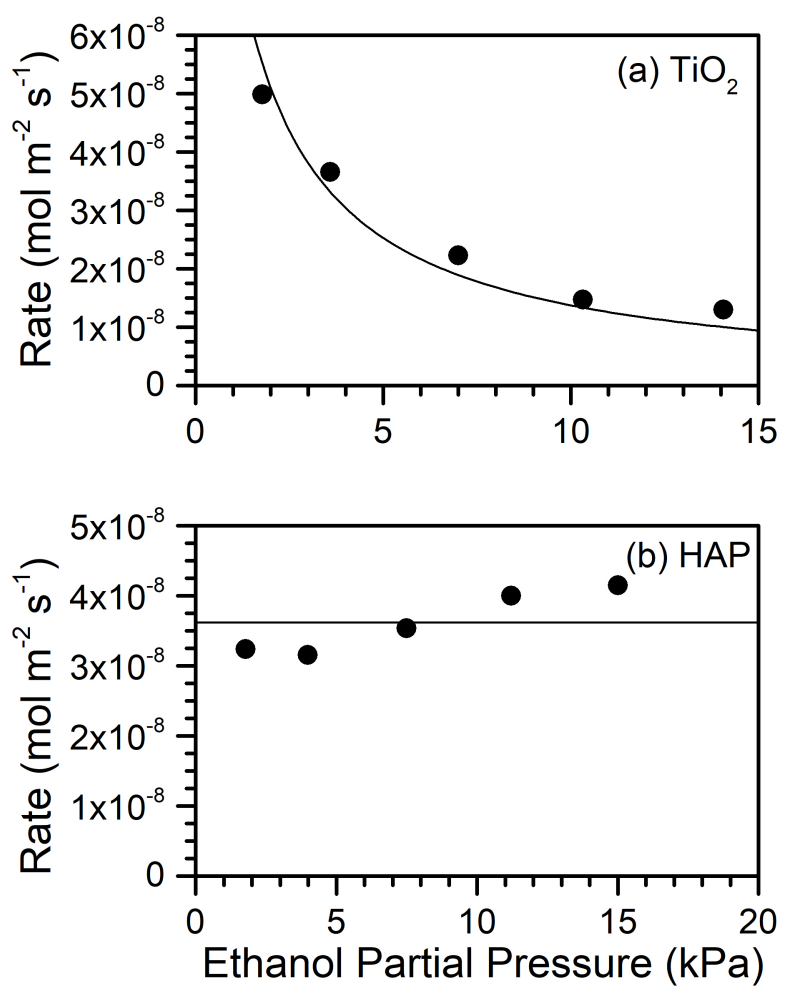

Figure 2.6: Rate of aldol condensation of acetaldehyde in the presence of ethanol over (a) $\mathrm{TiO}_{2}$ and (b) HAP. The curve in (a) is a fit to a competitive adsorption model while the line in (b) is the average rate. Reaction conditions: $5 \mathrm{kPa}$ acetaldehyde partial pressure, $553 \mathrm{~K}$.

amount of ethene. The effect of co-feeding ethanol on the acetaldehyde condensation rate over $\mathrm{MgO}$ is shown in Figure 2.8. Step changes in ethanol partial pressure did not result in step changes in the rate of aldol condensation. Although the catalyst continued to deactivate throughout the experiment, there was no evidence that adding ethanol perturbed the aldol condensation rate.

Although the ethanol co-feeding experiments were performed under conditions at which some deactivation was observed, the overall trends in the results are consistent with those derived by aldol condensation reaction kinetics. Specifically, the $\mathrm{TiO}_{2}$ catalyst appeared to be most affected by the presence of ethanol in the feed indicating a role of competitive adsorption of the alcohol during aldol condensation. Since there did not appear to be any influence of ethanol on the aldol condensation reaction over $\mathrm{HAP}$ or $\mathrm{MgO}$, the number density of strongly-bound reaction interme- 


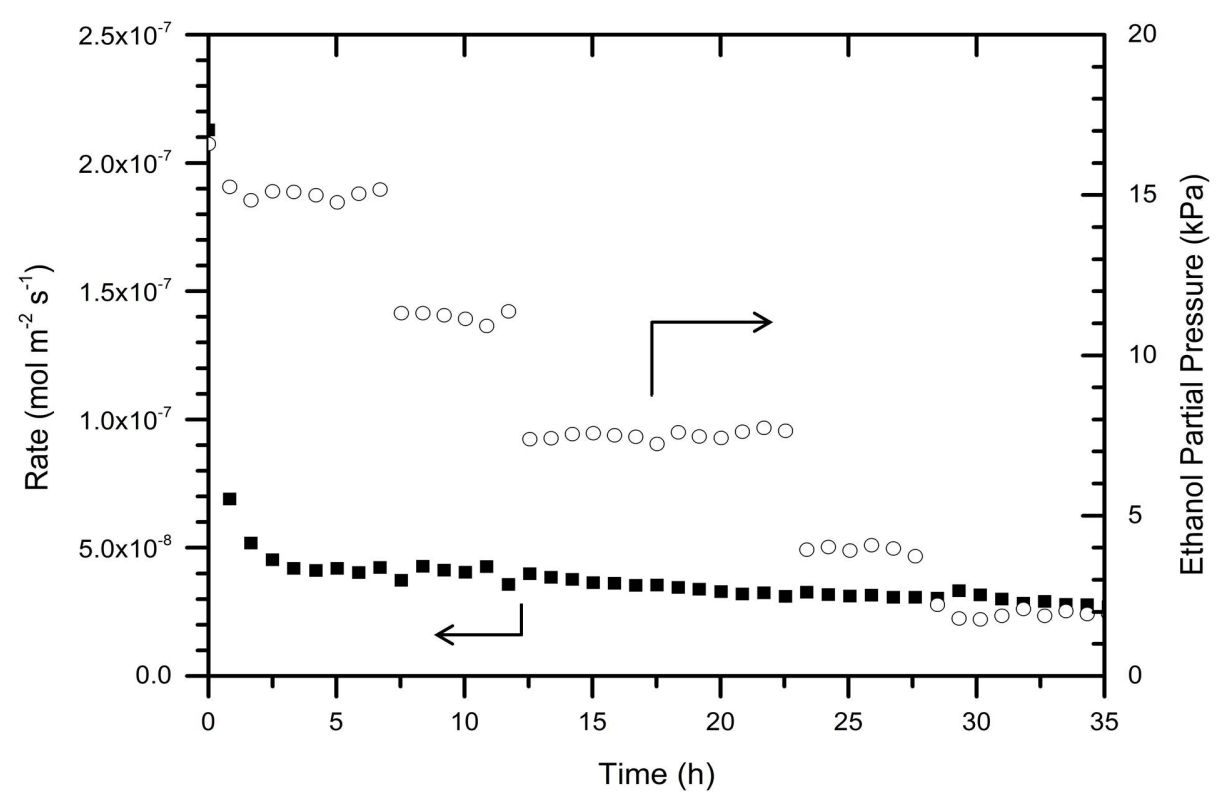

Figure 2.7: Rate of aldol condensation of acetaldehyde over HAP at $5 \mathrm{kPa}$ acetaldehyde partial pressure and $553 \mathrm{~K}$ in the presence of ethanol.

diates and products on those catalysts does not appear to be perturbed by the ethanol. Thus, the combination of reaction kinetics and ethanol co-feeding experiments both point to the conclusion that aldehydes interact strongly with $\mathrm{MgO}$ followed by $\mathrm{HAP}$ and $\mathrm{TiO}_{2}$.

\subsubsection{Ethanol Conversion}

Ethanol conversion was performed over all three catalysts to further investigate the role of aldol condensation on Guerbet coupling. The temperatures of the ethanol reactions were higher than those used to co-feed ethanol so that some catalytic activity could be observed. Table 2.3 shows the rate of ethanol consumption and the product selectivity over $\mathrm{TiO}_{2}, \mathrm{HAP}$ and $\mathrm{MgO}$. At the low levels of conversion during Guerbet coupling of ethanol, the concentration of acetaldehyde was 


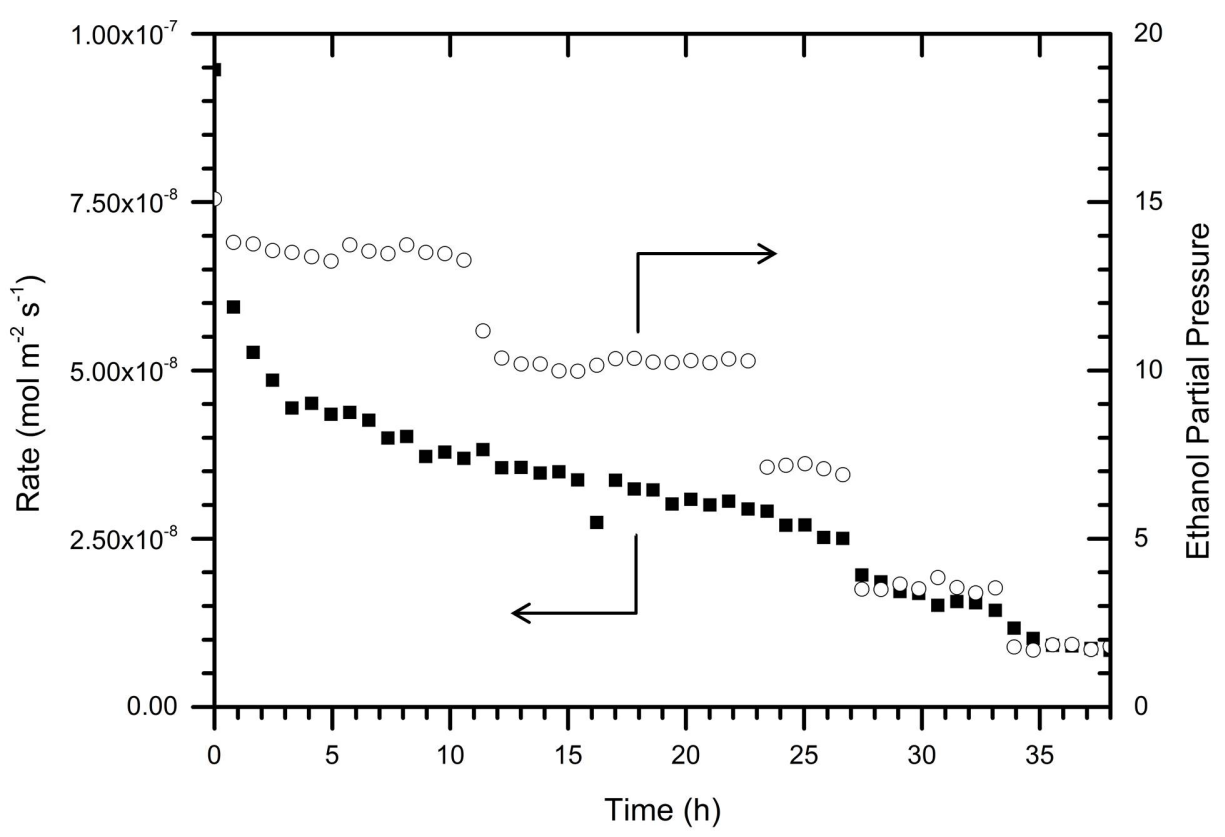

Figure 2.8: Rate of aldol condensation of acetaldehyde over $\mathrm{MgO}$ at $5 \mathrm{kPa}$ acetaldehyde partial pressure and $633 \mathrm{~K}$ in the presence of ethanol.

always below $1 \mathrm{kPa}$, which is in the low pressure region of the aldol condensation reaction (see Figure 2.4).

Table 2.3: Ethanol Reaction ( $8 \mathrm{kPa}$ ) over $\mathrm{HAP}, \mathrm{MgO}$ and $\mathrm{TiO}_{2}$. Results for $\mathrm{HAP}$ and $\mathrm{MgO}$ were previously reported by Hanspal et al. ${ }^{39}$ Acetaldehyde is abbreviated AcH and diethyl ether is abbreviated DEE.

\begin{tabular}{ccccccccc}
\hline & & Conversion & Rate & \multicolumn{5}{c}{ Selectivity $(\mathrm{C} \%)$} \\
\cline { 5 - 8 } Catalyst & $\mathrm{T}(\mathrm{K})$ & (Carbon $\%)$ & $\left(\mathrm{mol} / \mathrm{m}^{2} / \mathrm{s}\right)$ & Ethene & Ethane & AcH & Butanol & DEE \\
\hline $\mathrm{TiO}_{2}$ & 613 & 1.9 & $1.3 \times 10^{-8}$ & 0 & 7 & 51 & 0 & 42 \\
$\mathrm{HAP}$ & 613 & 4.3 & $4.4 \times 10^{-8}$ & 1 & 0 & 32 & 67 & 0 \\
$\mathrm{MgO}$ & 653 & 4.5 & $1.4 \times 10^{-8}$ & 12 & 0 & 67 & 21 & 0 \\
\hline
\end{tabular}

Although $\mathrm{TiO}_{2}$ is the most active catalyst for aldol condensation at lower temperature, it is 
unable to convert ethanol to butanol at $613 \mathrm{~K}$, instead favoring diethyl ether formation. Since the production of diethyl ether is typically associated with an acidic catalyst, the $\mathrm{TiO}_{2}$ surface is apparently too acidic to convert ethanol to butanol at elevated temperatures.

The HAP sample is the most active of the three catalysts for Guerbet coupling with a selectivity to butanol of $67 \%$ at a temperature $40 \mathrm{~K}$ lower than used for $\mathrm{MgO}$.

Magnesia is the least active catalyst, requiring a temperature $40 \mathrm{~K}$ higher than $\mathrm{HAP}$ and $\mathrm{TiO}_{2}$ to achieve a similar rate of conversion. Hydroxyapatite has a higher selectivity to butanol while $\mathrm{MgO}$ has a higher selectivity to acetaldehyde. The high selectivity towards butanol over HAP is likely due to a large number of appropriate strength acid-base pairs on the surface, which will be discussed in the next section.

\subsubsection{Adsorption Microcalorimetry}

Adsorption microcalorimetry was used to investigate the affinity of the catalysts for acetaldehyde and ethanol at $303 \mathrm{~K}$ and to estimate an upper bound on the total number of active sites on each catalyst. The acetaldehyde adsorption isotherms and differential heats of adsorption are shown in Figure 2.9. A high heat of adsorption as well as a high acetaldehyde uptake were observed on both $\mathrm{HAP}$ and $\mathrm{MgO}$. We suspect that a surface reaction occurred during the adsorption microcalorimetry experiment, resulting in higher heats of adsorption and perhaps higher surface coverages than would be expected from simple chemisorption. On $\mathrm{TiO}_{2}$, the $-\Delta H_{\text {ads }}$ of acetaldehyde was much lower compared to that on HAP and $\mathrm{MgO}$. Extrapolating the high pressure linear section of the adsorption isotherm on $\mathrm{TiO}_{2}$ to zero pressure gives an amount of chemisorbed acetaldehyde of 
$3.2 \mu \mathrm{mol} \mathrm{m}{ }^{-2}$, which is in good agreement with the value of $3.7 \mu \mathrm{mol} \mathrm{m}{ }^{-2}$ reported by Rekoske and Barteau. $^{22}$ In an analogous fashion, the uptake of acetaldehyde on $\mathrm{HAP}$ and $\mathrm{MgO}$ was calculated to be $10 \mu \mathrm{mol} \mathrm{m}{ }^{-2}$ and $8.7 \mu \mathrm{mol} \mathrm{m}^{-2}$ respectively, as summarized in Table 2.4. The lowest values of $-\Delta H_{\text {ads }}$ of acetaldehyde were associated with $\mathrm{TiO}_{2}$, which is completely consistent with the predicted trend in the strength of aldehyde interactions with the catalysts from the reaction kinetics $\left(\mathrm{TiO}_{2}<\mathrm{HAP}<\mathrm{MgO}\right)$ as discussed earlier.
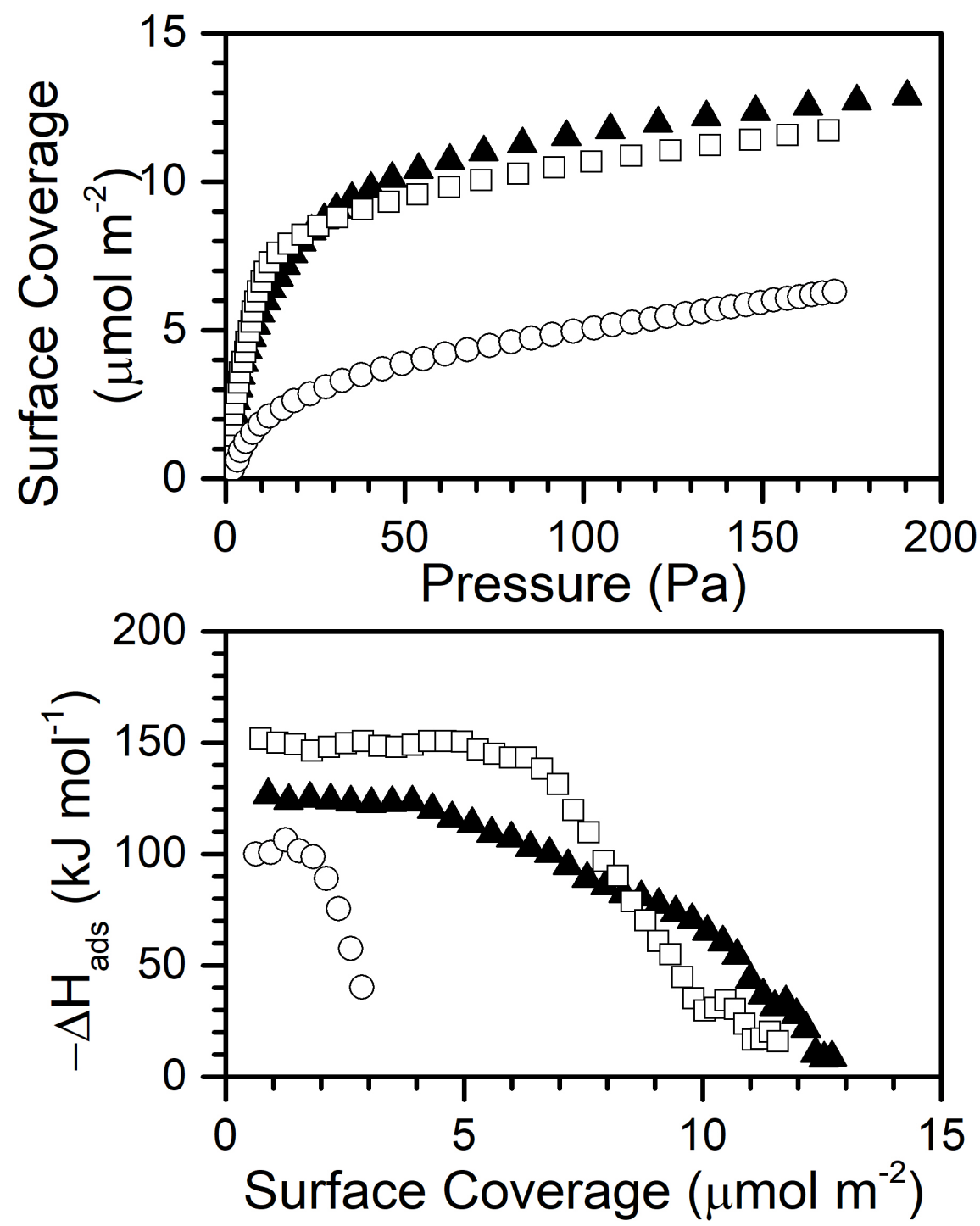

Figure 2.9: Acetaldehyde uptake (top) and differential heat of adsorption (bottom) over $\mathrm{TiO}_{2}(\bigcirc)$, $\mathrm{HAP}$ $(\boldsymbol{\Lambda})$ and $\mathrm{MgO}(\square)$ at $303 \mathrm{~K}$. 
Ethanol adsorption microcalorimetry was also performed over all three catalysts at $303 \mathrm{~K}$. Figure 2.10 shows the coverage of ethanol and heat of adsorption on $\mathrm{TiO}_{2}, \mathrm{HAP}$ and $\mathrm{MgO}$. Extrapolating the high pressure linear portion of the adsorption isotherm to zero pressure gives a coverage of $4.5 \mu \mathrm{mol} \mathrm{m}{ }^{-2}, 5.2 \mu \mathrm{mol} \mathrm{m}^{-2}$ and $5.2 \mu \mathrm{mol} \mathrm{m}^{-2}$ over $\mathrm{TiO}_{2}$, HAP, and $\mathrm{MgO}$, respectively. The average $-\Delta H_{\text {ads }}$ of ethanol on $\mathrm{MgO}$ is approximately $118 \mathrm{~kJ} \mathrm{~mol}^{-1}$ while that on both $\mathrm{HAP}$ and $\mathrm{TiO}_{2}$ is approximately $90 \mathrm{~kJ} \mathrm{~mol}^{-1}$.
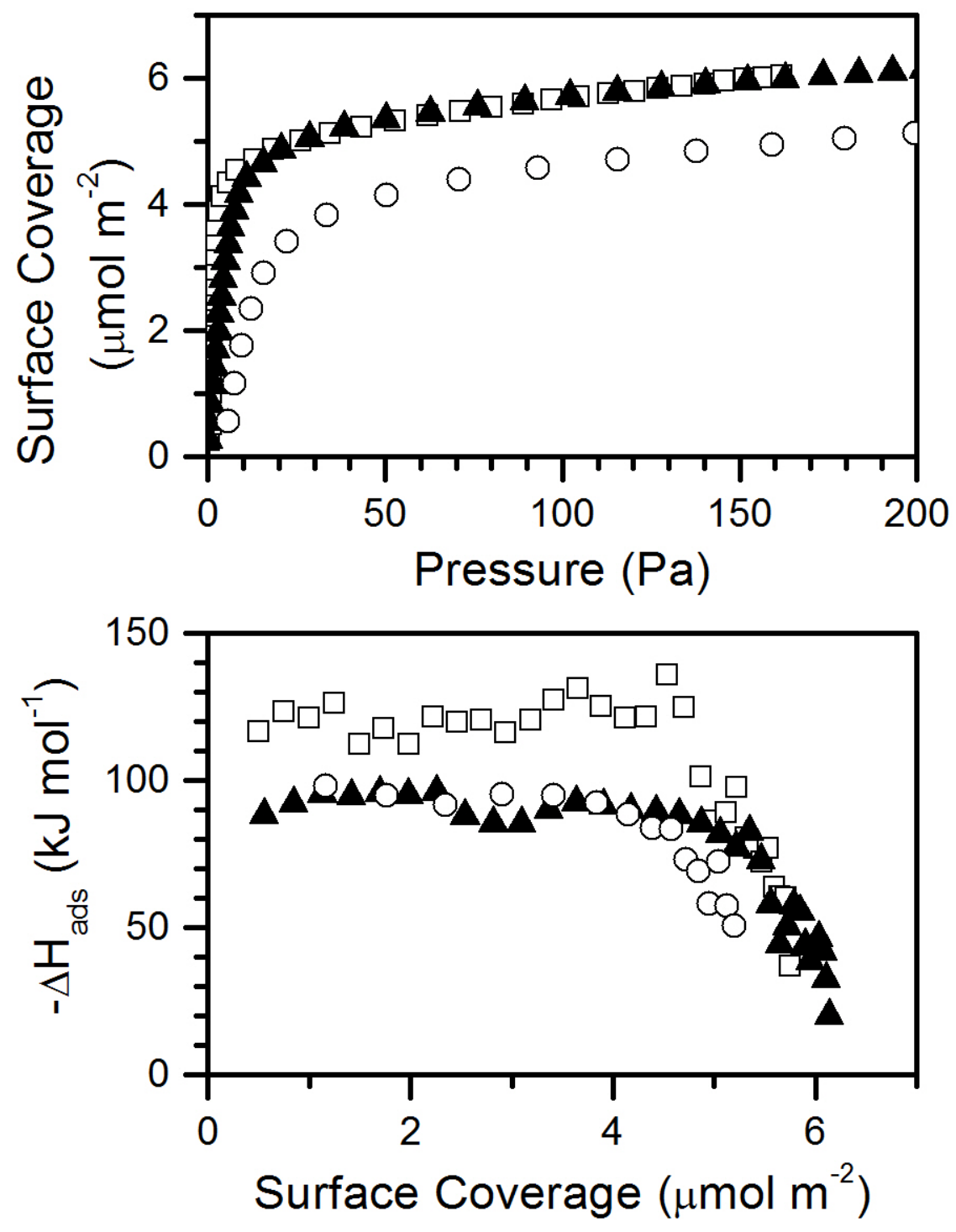

Figure 2.10: Ethanol uptake (top) and differential heat of adsorption (bottom) over $\mathrm{TiO}_{2}(\bigcirc), \mathrm{HAP}(\boldsymbol{\Lambda})$ and $\mathrm{MgO}(\square)$ at $303 \mathrm{~K}$. Data for $\mathrm{MgO}$ previously reported by Hanspal et al. ${ }^{39}$ 
The adsorption microcalorimetry results help explain the effect of added ethanol on the rate of acetaldehyde condensation. Hydroxyapatite clearly has a higher affinity for acetaldehyde than $\mathrm{TiO}_{2}$ whereas both catalysts have a similar affinity for ethanol. The adsorption properties of acetaldehyde are likely similar to those of crotonaldehyde because both molecules have an aldehyde functional group that will interact with the acid-base sites on the surface. The higher affinity of HAP for the aldehyde suggests that under steady state reaction of acetaldehyde, the surface coverage of crotonaldehyde prevents the competitive adsorption of ethanol. The weak affinity of $\mathrm{TiO}_{2}$ for aldehyde allows the surface to turn over more rapidly, but also allows ethanol to compete for active sites.

We can use the acetaldehyde uptakes reported in Table 2.4 as an upper bound on the active site density $\left([*]_{0}\right)$ for acetaldehyde condensation on the catalysts. From the results reported in Table 2.2 and the acetaldehyde uptakes from adsorption microcalorimetry, the individual rate constants for acetaldehyde adsorption $\left(k_{1}\right)$ and product desorption $\left(k_{2}\right)$ were determined and they are summarized in Table 2.4. Although the rate constant of acetaldehyde adsorption varied by less than a factor of 6 (which may be a function of the assumption of active site density estimate), the rate constant for desorption varied by a factor of almost 50. The rate constant for product desorption is greatest for $\mathrm{TiO}_{2}$ followed by that for $\mathrm{HAP}$ and $\mathrm{MgO}$, which correlates well to the rate of aldol condensation and supports the hypothesis that product desorption is kinetically relevant. We again state here that the numerical value of $k_{2}$ was determined from a rapidly deactivating system, so we are drawing conclusions only from the trend in $k_{2}$ among the catalysts as opposed to the absolute value of $k_{2}$ as a true desorption rate constant. 
Table 2.4: Calculated rate constants for adsorption of acetaldehyde $\left(k_{1}\right)$ and desorption of product $\left(k_{2}\right)$ assuming an active site density based on the uptake of acetaldehyde from adsorption microcalorimetry.

\begin{tabular}{ccccc}
\hline Catalyst & $\begin{array}{c}\text { Acetaldehyde } \\
\text { Uptake } \\
\left.(\mu \mathrm{mol} \mathrm{m})^{-2}\right)\end{array}$ & Reaction T $(\mathrm{K})$ & $k_{1}\left(\mathrm{kPa}^{-1} \mathrm{~s}^{-1}\right)$ & $k_{2}\left(\mathrm{~s}^{-1}\right)$ \\
\hline $\mathrm{TiO}_{2}$ & 3.2 & 553 & $2.2 \times 10^{-2}$ & $5.3 \times 10^{-1}$ \\
$\mathrm{HAP}$ & 10 & 553 & $3.7 \times 10^{-3}$ & $2.9 \times 10^{-2}$ \\
$\mathrm{MgO}$ & 8.7 & 633 & $5.9 \times 10^{-3}$ & $1.1 \times 10^{-2}$ \\
\hline
\end{tabular}

\subsubsection{DRIFTS}

In addition to adsorption microcalorimetry, the catalysts were interrogated by DRIFTS of the adsorbed probe molecules acetaldehyde, crotonaldehyde and acetic acid. Figure 2.11 shows the carbonyl stretching region of the three probe molecules adsorbed and purged at various temperatures on $\mathrm{TiO}_{2}$. Adsorbed acetaldehyde had five major features on $\mathrm{TiO}_{2}$. Peaks at $1708 \mathrm{~cm}^{-1}, 1373 \mathrm{~cm}^{-1}$ and $1288 \mathrm{~cm}^{-1}$ were present up to $373 \mathrm{~K}$ while peaks at $1575 \mathrm{~cm}^{-1}$ and $1416 \mathrm{~cm}^{-1}$ were observed up to a temperature of $473 \mathrm{~K}$. Adsorbed crotonaldehyde had features at $1722 \mathrm{~cm}^{-1}, 1684 \mathrm{~cm}^{-1}$ and $1622 \mathrm{~cm}^{-1}$, which decreased in intensity as the temperature increased to $573 \mathrm{~K}$. Acetic acid had features at $1724 \mathrm{~cm}^{-1}, 1595 \mathrm{~cm}^{-1}, 1423 \mathrm{~cm}^{-1}$ and $1294 \mathrm{~cm}^{-1}$. The peaks at $1724 \mathrm{~cm}^{-1}$ and $1294 \mathrm{~cm}^{-1}$ were not observed at temperatures above $373 \mathrm{~K}$ while the peaks at $1595 \mathrm{~cm}^{-1}$ and $1423 \mathrm{~cm}^{-1}$ were observed up to $573 \mathrm{~K}$.

For acetaldehyde adsorption on $\mathrm{TiO}_{2}$, the peak at $1708 \mathrm{~cm}^{-1}$ can be assigned to the $\mathrm{C}=\mathrm{O}$ stretching mode of acetaldehyde while the peak at $1373 \mathrm{~cm}^{-1}$ can be assigned to the $\delta\left(\mathrm{CH}_{3}\right)$ mode of acetaldehyde, which are in good agreement with features observed by Rekoske and Barteau. ${ }^{60}$ Neither of those features were observed above $373 \mathrm{~K}$ indicating acetaldehyde is weakly held on $\mathrm{TiO}_{2}$. The features at $1575 \mathrm{~cm}^{-1}, 1416 \mathrm{~cm}^{-1}$ and $1288 \mathrm{~cm}^{-1}$ are very similar in shape and thermal 

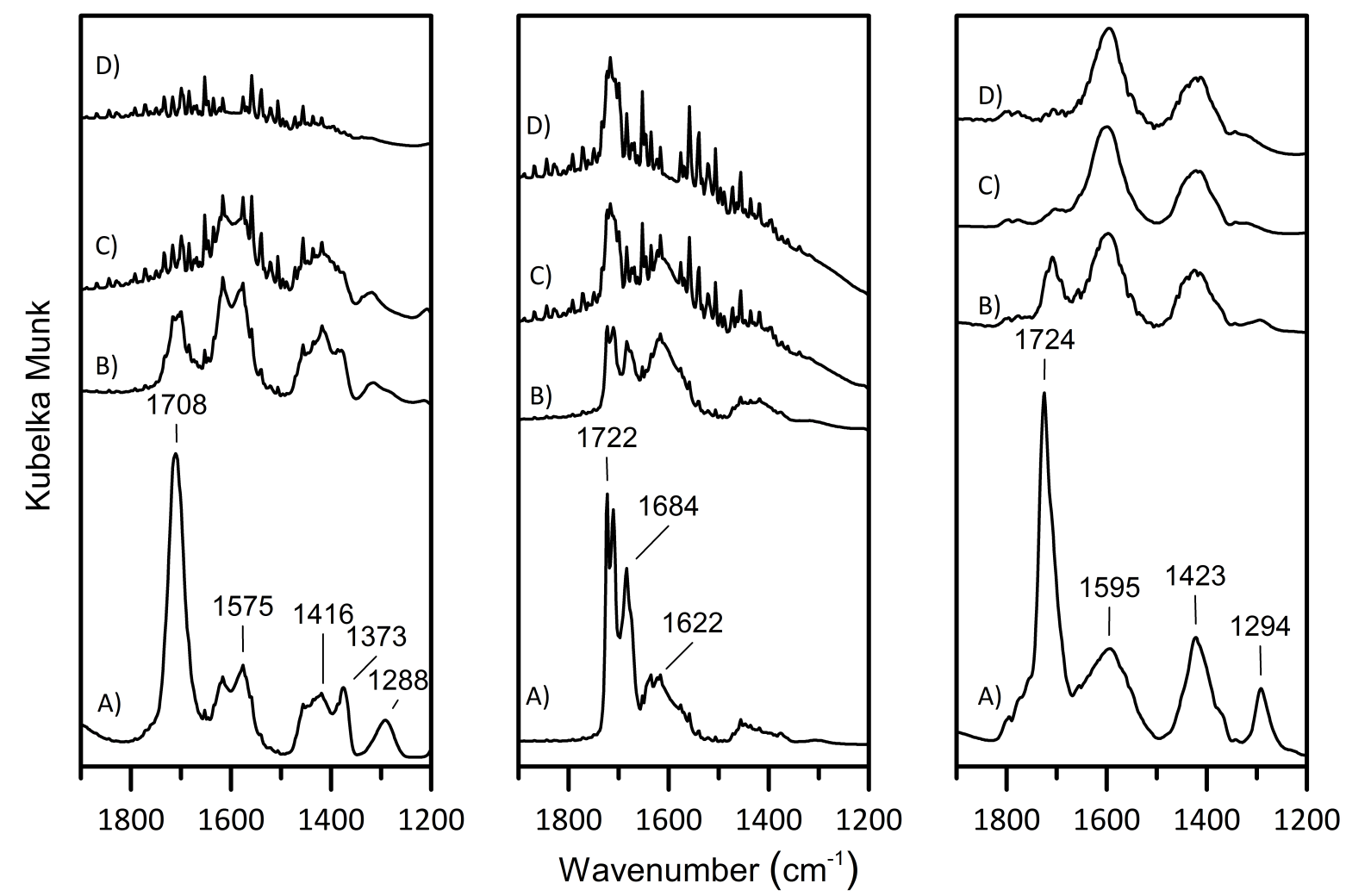

Figure 2.11: DRIFTS spectra of the $\mathrm{C}=\mathrm{O}$ stretching region for adsorbed acetaldehyde (left), crotonaldehyde (center), acetic acid (right) on $\mathrm{TiO}_{2}$ after purging at (A) $303 \mathrm{~K}$, (B) $373 \mathrm{~K}$, (C) $473 \mathrm{~K}$ and D) $573 \mathrm{~K}$.

response as the features observed during acetic acid adsorption and therefore are likely attributed to a surface acetate species. The acetate species is probably formed from a Cannizzaro reaction that has been shown to take place on basic surfaces such as $\mathrm{MgO}^{61}$ The fact that the peak at $1708 \mathrm{~cm}^{-1}$ is gone by $473 \mathrm{~K}$ implies that intact acetaldehyde is not strongly held to the $\mathrm{TiO}_{2}$ surface. Acetate, on the other hand, appears to be a more strongly bound species which remains on the surface to at least $573 \mathrm{~K}$. Adsorbed crotonaldehyde has a feature at $1684 \mathrm{~cm}^{-1}$ which can be assigned to the $\mathrm{C}=\mathrm{O}$ stretching mode and is in good agreement with the work of Rekoske and Barteau. ${ }^{60}$ The features at $1722 \mathrm{~cm}^{-1}$ and $1622 \mathrm{~cm}^{-1}$ are currently unassigned but may be due to poly-condensation products. The feature observed at $1724 \mathrm{~cm}^{-1}$ in the spectrum of adsorbed acetic acid is likely due 
to the $\mathrm{C}=\mathrm{O}$ stretching of the acid group. Since this peak disappears by $373 \mathrm{~K}$, the adsorbed acid is very weakly held on $\mathrm{TiO}_{2}$. The broad peaks at $1595 \mathrm{~cm}^{-1}$ and $1423 \mathrm{~cm}^{-1}$ are present up to $573 \mathrm{~K}$ and are likely due to a strongly adsorbed acetate species.

The effect of pre-adsorbed ethanol on the adsorption of acetaldehyde on $\mathrm{TiO}_{2}$ is shown in Figure 2.12. The presence of adsorbed ethanol is clear due to the features in the $\mathrm{C}-\mathrm{H}$ stretching region of the IR spectrum. Adsorbed ethanol does not appear to affect the features of adsorbed acetaldehyde. Thus, based on the large observed inhibition of acetaldehyde condensation by ethanol during catalysis, we suspect that ethanol simply competes for active sites on the surface.

Figure 2.13 shows the $\mathrm{C}=\mathrm{O}$ stretching region of the probe molecules adsorbed on HAP. Adsorbed acetaldehyde shows two features at $1707 \mathrm{~cm}^{-1}$ and $1572 \mathrm{~cm}^{-1}$. The peak at $1707 \mathrm{~cm}^{-1} \mathrm{can}$ be assigned to the $\mathrm{C}=\mathrm{O}$ stretching mode of acetaldehyde. The $1707 \mathrm{~cm}^{-1}$ feature completely disappeared by $473 \mathrm{~K}$ while the $1572 \mathrm{~cm}^{-1}$ feature was still observed at $673 \mathrm{~K}$. Adsorbed crotonaldehyde has two major features at $1674 \mathrm{~cm}^{-1}$ and $1601 \mathrm{~cm}^{-1}$. As with adsorbed acetaldehyde, the $1674 \mathrm{~cm}^{-1}$ peak disappeared by $473 \mathrm{~K}$ while the feature at $1601 \mathrm{~cm}^{-1}$ was present up to $573 \mathrm{~K}$. Adsorption of acetic acid resulted in four major peaks: $1707 \mathrm{~cm}^{-1}, 1661 \mathrm{~cm}^{-1}, 1562 \mathrm{~cm}^{-1}$ and $1298 \mathrm{~cm}^{-1}$. The features at $1707 \mathrm{~cm}^{-1}$ and $1298 \mathrm{~cm}^{-1}$ were no longer observed at $473 \mathrm{~K}$ and the intensity of the $1661 \mathrm{~cm}^{-1}$ and $1562 \mathrm{~cm}^{-1}$ peaks decreased as the temperature was increased.

The $1707 \mathrm{~cm}^{-1}$ feature in the spectrum of adsorbed acetaldehyde on HAP that is assigned to the $\mathrm{C}=\mathrm{O}$ stretching mode is in good agreement with work by Rekoske and Barteau ${ }^{60}$ with acetaldehyde adsorbed on rutile titania $\left(1703 \mathrm{~cm}^{-1}\right)$. This peak is approximately $30 \mathrm{~cm}^{-1}$ red shifted from gas phase acetaldehyde because of interactions with the surface. The feature at $1572 \mathrm{~cm}^{-1}$ is likely 


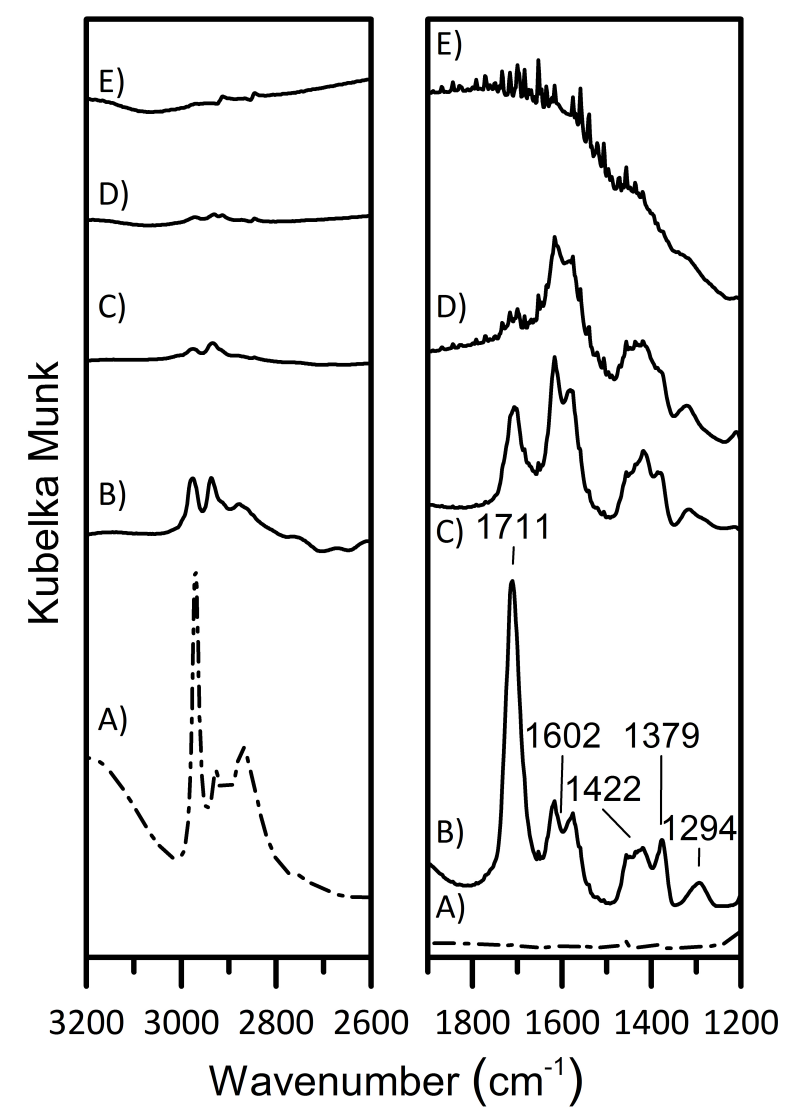

Figure 2.12: DRIFT spectra of adsorbed acetaldehyde with preadsorbed ethanol on $\mathrm{TiO}_{2}$. (A) adsorbed ethanol after purging at $303 \mathrm{~K}$, adsorbed acetaldehyde and ethanol after purging at (B) $303 \mathrm{~K}$, (C) $373 \mathrm{~K}$, (D) $473 \mathrm{~K}$, (E) $573 \mathrm{~K}$.

an indication of adsorbed acetate. Strongly bound acetate species on HAP have been reported previously by Tanaka et al. ${ }^{62}$ in which they show acetate features at $1574 \mathrm{~cm}^{-1}$ and $1545 \mathrm{~cm}^{-1}$ remain on HAP up to temperatures of $723 \mathrm{~K}$. The spectra in Figure 2.13 reveal the presence of acetate after acetaldehyde adsorption at room temperature, indicating a high reactivity of acetaldehyde on HAP even at low temperature. The high reactivity of acetaldehyde on HAP may explain the measured high heat of adsorption during acetaldehyde adsorption microcalorimetry (Figure 2.9).

The spectrum of adsorbed crotonaldehyde on HAP revealed similar features as that for ad- 

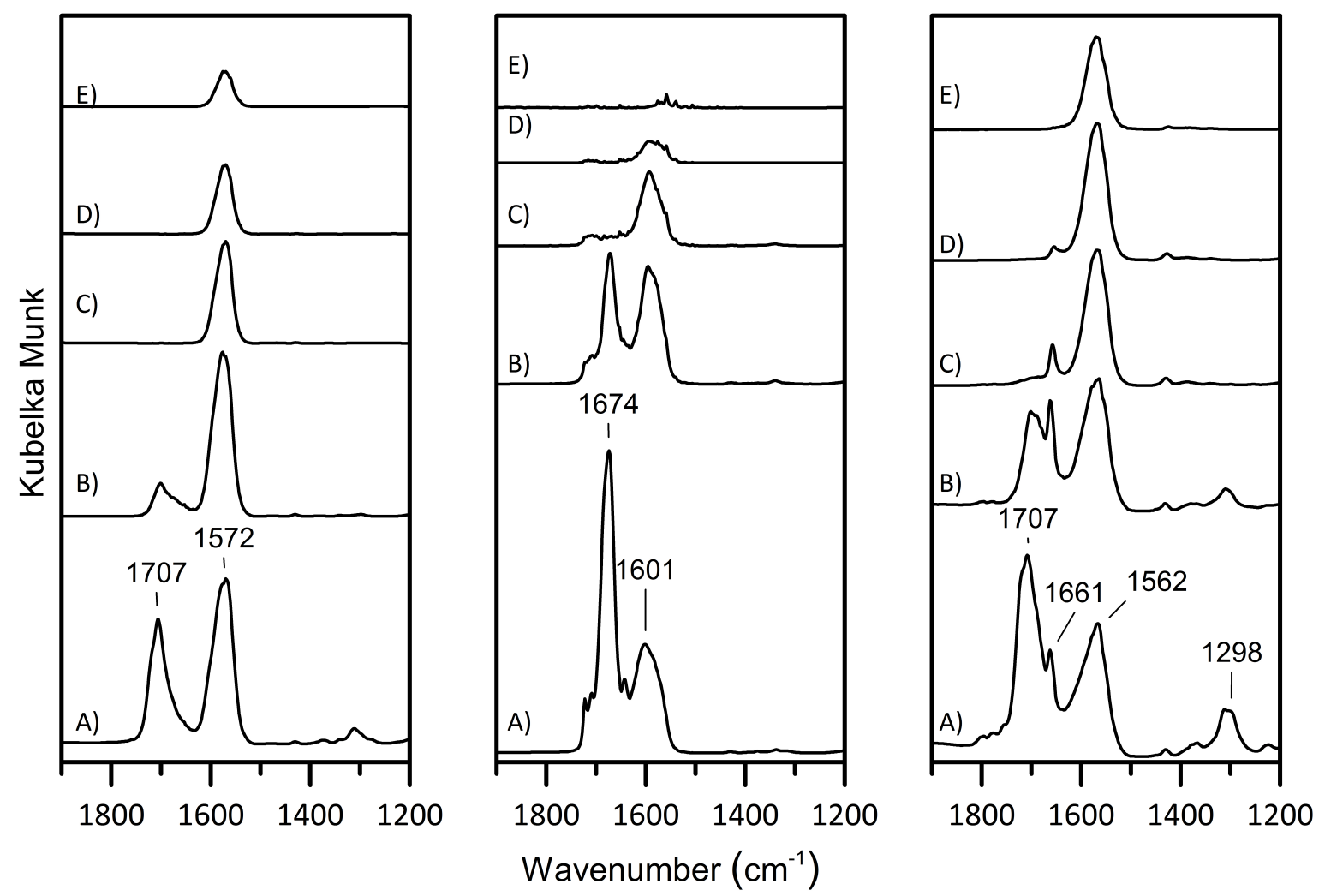

Figure 2.13: DRIFT spectra of the $\mathrm{C}=\mathrm{O}$ stretching region for adsorbed acetaldehyde (left), crotonaldehyde (center), acetic acid (right) on HAP after purging at (A) $303 \mathrm{~K}$, (B) $373 \mathrm{~K}$, (C) $473 \mathrm{~K}$, (D) $573 \mathrm{~K}$, (E) $673 \mathrm{~K}$.

sorbed acetaldehyde (Figure 2.13). A peak at $1674 \mathrm{~cm}^{-1}$ is observed at $373 \mathrm{~K}$ while the feature at $1601 \mathrm{~cm}^{-1}$ is present up to $573 \mathrm{~K}$. The peak at $1674 \mathrm{~cm}^{-1}$ is attributed to the $\mathrm{C}=\mathrm{O}$ stretching mode of crotonaldehyde, which is $40 \mathrm{~cm}^{-1}$ red shifted from gas phase crotonaldehyde. It is not clear what the feature at $1601 \mathrm{~cm}^{-1}$ results from and may be either a $\mathrm{C}_{4}$ carboxylate or the $\mathrm{C}=\mathrm{C}$ stretching mode of crotonaldehyde.

Acetic acid adsorption on HAP initially resulted in four major features at $1707 \mathrm{~cm}^{-1}$, $1661 \mathrm{~cm}^{-1}, 1562 \mathrm{~cm}^{-1}$ and $1298 \mathrm{~cm}^{-1}$. The band at $1707 \mathrm{~cm}^{-1}$ can be assigned to the $\mathrm{C}=\mathrm{O}$ stretching mode of the acid while the band at $1562 \mathrm{~cm}^{-1}$ is due to the $\mathrm{C}=\mathrm{O}$ stretch of an acetate species. At low temperature, both the acid and the acetate species are present, but at high temper- 
ature only the peak associated with acetate is observed. Our results are in good agreement with Tanaka et al. ${ }^{62}$ who claimed that acetic acid adsorbs as a weakly-bound acid species as well as a strongly-bound acetate species.

Figure 2.14 shows the effect of pre-adsorbed ethanol on acetaldehyde adsorption on HAP. Pre-adsorbed ethanol was confirmed on the surface of HAP by the presence of features in the $\mathrm{C}-\mathrm{H}$ stretching region. After adsorbing acetaldehyde, the intensity of the $\mathrm{C}-\mathrm{H}$ stretching peaks decreased while multiple peaks appeared in the $\mathrm{C}=\mathrm{O}$ stretching region. There are features at $1703 \mathrm{~cm}^{-1}, 1666 \mathrm{~cm}^{-1}, 1641 \mathrm{~cm}^{-1}$ and $1568 \mathrm{~cm}^{-1}$. The peaks at $1703 \mathrm{~cm}^{-1}, 1666 \mathrm{~cm}^{-1}$ and $1641 \mathrm{~cm}^{-1}$ decrease as the temperature is increased while the peak at $1568 \mathrm{~cm}^{-1}$ increased in intensity after heating to $473 \mathrm{~K}$ before slightly decreasing at higher temperature.

Pre-adsorbed ethanol clearly had an influence on acetaldehyde adsorption on HAP. The main difference between adsorption of acetaldehyde with and without preadsorbed ethanol is that ethanol prevents the formation of acetate at low temperature. As the temperature is increased, weakly bound ethanol desorbs from HAP and allows adsorbed acetaldehyde to form strongly bound acetate species.

Figure 2.15 shows the carbonyl stretching region of acetaldehyde, crotonaldehyde, and acetic acid adsorbed on $\mathrm{MgO}$. There are four major features for acetaldehyde adsorbed on $\mathrm{MgO}$, a peak at $1719 \mathrm{~cm}^{-1}$ observed up to $373 \mathrm{~K}$, two broad peaks at $1584 \mathrm{~cm}^{-1}$ and $1442 \mathrm{~cm}^{-1}$ that are present even at $673 \mathrm{~K}$, and a feature at $1326 \mathrm{~cm}^{-1}$ observed up to $573 \mathrm{~K}$. The spectra of adsorbed crotonaldehyde reveal similar features to those of adsorbed acetaldehyde, a peak at $1719 \mathrm{~cm}^{-1}$ present up to $373 \mathrm{~K}$, and two broad peaks at $1574 \mathrm{~cm}^{-1}$ and $1444 \mathrm{~cm}^{-1}$ that are present up to $673 \mathrm{~K}$. The spectra of 


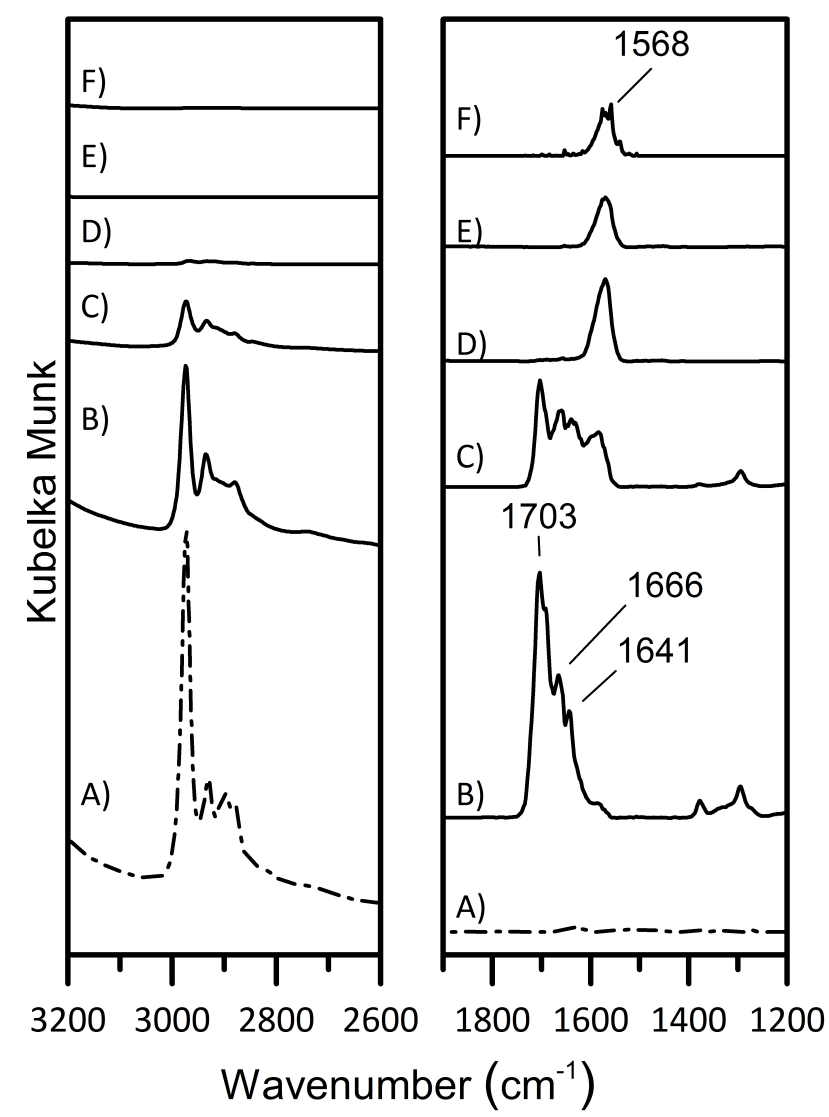

Figure 2.14: DRIFT spectra of adsorbed acetaldehyde with preadsorbed ethanol on HAP. (A) adsorbed ethanol after purging at $303 \mathrm{~K}$, adsorbed acetaldehyde and ethanol after purging at (B) $303 \mathrm{~K}$, (C) $373 \mathrm{~K}$, (D) $473 \mathrm{~K}$, (E) $573 \mathrm{~K}$, (F) $673 \mathrm{~K}$.

adsorbed acetic acid have four features, a peak at $1709 \mathrm{~cm}^{-1}$ that is present at $303 \mathrm{~K}$, but not at higher temperatures, a peak at $1341 \mathrm{~cm}^{-1}$ present up to $573 \mathrm{~K}$ and two broad peaks at $1599 \mathrm{~cm}^{-1}$ and $1425 \mathrm{~cm}^{-1}$ that are present up to $673 \mathrm{~K}$ with maximum intensity at $573 \mathrm{~K}$.

The peak at $1719 \mathrm{~cm}^{-1}$ can be assigned to the $\mathrm{C}=\mathrm{O}$ stretching of adsorbed acetaldehyde on $\mathrm{MgO}$, which disappears by $473 \mathrm{~K}$, indicating it is weakly adsorbed. The peaks at $1584 \mathrm{~cm}^{-1}$, $1442 \mathrm{~cm}^{-1}$ and $1326 \mathrm{~cm}^{-1}$ are quite similar to the main features observed with acetic acid adsorption on $\mathrm{MgO}$ and are attributed to surface acetate. The fact that these peaks are present up to $673 \mathrm{~K}$ 

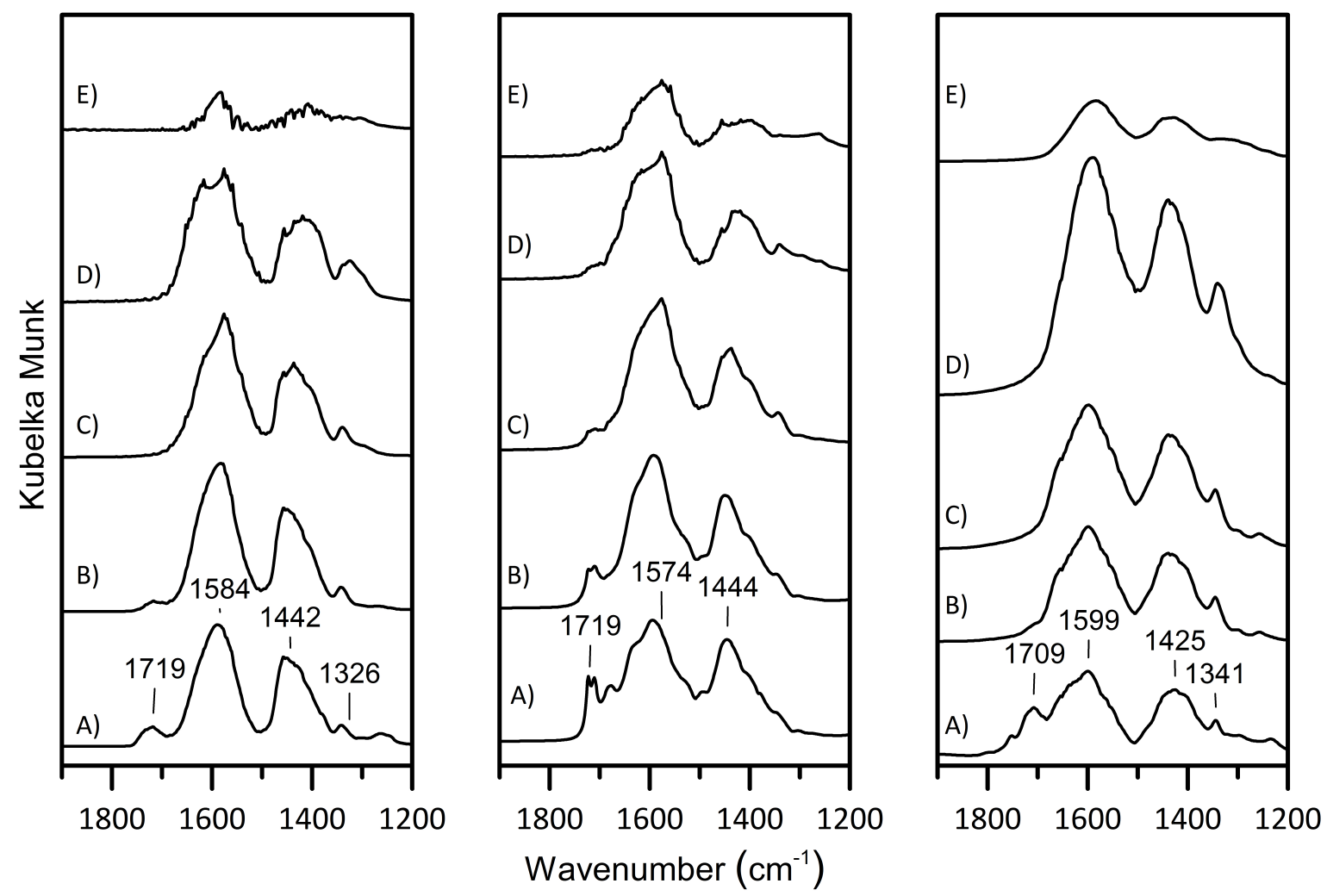

Figure 2.15: DRIFT spectra of the $\mathrm{C}=\mathrm{O}$ stretching region for adsorbed acetaldehyde (left), crotonaldehyde (center), acetic acid (right) on $\mathrm{MgO}$ after purging at (A) $303 \mathrm{~K}$, (B) $373 \mathrm{~K}$, (C) $473 \mathrm{~K}$, (D) $573 \mathrm{~K}$, (E) $673 \mathrm{~K}$.

shows that acetate was very strongly bound to the surface. The peak at $1719 \mathrm{~cm}^{-1}$ in the spectra of adsorbed crotonaldehyde is likely due to the $\mathrm{C}=\mathrm{O}$ stretching of crotonaldehyde and since it disappears by $473 \mathrm{~K}$, indicating crotonaldehyde is relatively weakly adsorbed compared to acetaldehyde. The peaks at $1574 \mathrm{~cm}^{-1}$ and $1444 \mathrm{~cm}^{-1}$ are attributed to either a surface carboxylate or to poly condensation products of crotonaldehyde. The minor peak at $1709 \mathrm{~cm}^{-1}$ in the spectra of acetic acid is likely caused by the $\mathrm{C}=\mathrm{O}$ stretching of the acid, whereas the majority of the peaks are associated with acetate species.

The effect of preadsorbed ethanol on $\mathrm{MgO}$ prior to acetaldehyde adsorption is presented in Figure 2.16. The similarity between Figure 2.15 and 2.16 indicates pre-adsorption of ethanol on 


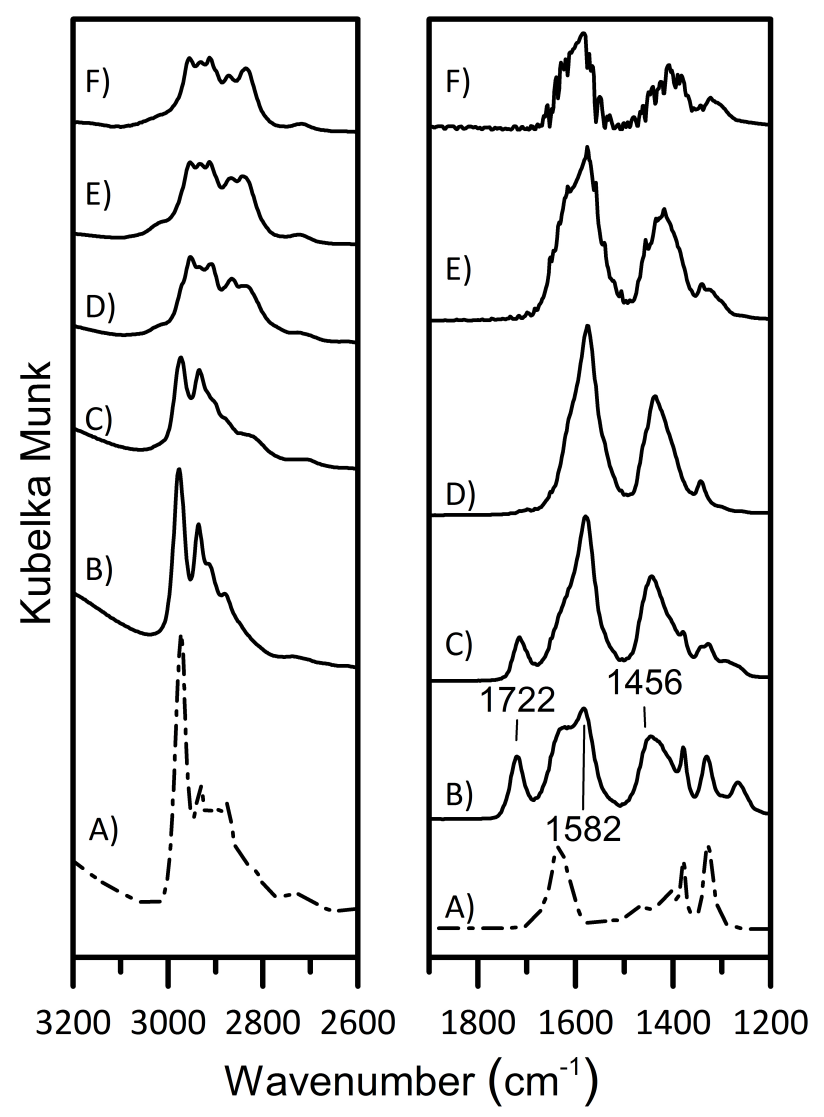

Figure 2.16: DRIFT spectra of adsorbed acetaldehyde with preadsorbed ethanol on $\mathrm{MgO}$. (A) adsorbed ethanol at $303 \mathrm{~K}$, adsorbed acetaldehyde and ethanol after purging at (B) $303 \mathrm{~K}$, (C) $373 \mathrm{~K}$, (D) $473 \mathrm{~K}$, (E) $573 \mathrm{~K}$, (F) $673 \mathrm{~K}$.

$\mathrm{MgO}$ had very little effect on IR features present after acetaldehyde adsorption.

\subsection{Conclusions}

Aldol condensation occurs readily over $\mathrm{TiO}_{2}, \mathrm{HAP}$ and $\mathrm{MgO}$, producing only crotonaldehyde at low conversion. However, severe deactivation was observed at high acetaldehyde partial pressures. Initial rate measurements were therefore used to examine the influence of acetaldehyde pressure 
and reaction temperature on the kinetics and to rank the activity of the catalysts. Results revealed an activity ranking per surface area of $\mathrm{TiO}_{2}>\mathrm{HAP} \gg \mathrm{MgO}$. Aldol condensation using fully deuterated acetaldehyde showed no kinetic isotope effect indicating that $\mathrm{C}-\mathrm{H}$ bond activation is not kinetically relevant. A plausible mechanism of aldol condensation over these materials consists of kinetically relevant reactant adsorption and product desorption steps. At the conditions used here, the presence of ethanol had no effect on the rate of aldol condensation over HAP or $\mathrm{MgO}$, but inhibited the rate of aldol condensation over $\mathrm{TiO}_{2}$. The performance of the materials in aldol condensation can be related to the relative affinity of the surface for aldehydes, and other intermediate species with $\mathrm{TiO}_{2}$ having the lowest affinity (greatest reaction rate) and $\mathrm{MgO}$ having the greatest affinity (lowest reaction rate). The weak affinity of $\mathrm{TiO}_{2}$ for the reacting species accounts for the inhibiting effect of ethanol on the aldol condensation rate because of the competitive adsorption. 


\title{
Chapter 3
}

\section{Hydrogen Transfer Reactions Relevant to}

\author{
Guerbet Coupling of Alcohols over
}

\section{Hydroxyapatite and Magnesium Oxide}

\section{Catalysts}

\begin{abstract}
Hydrogenation and dehydrogenation reactions were performed over hydroxyapatite $\left(\mathrm{Ca}_{10}\left(\mathrm{PO}_{4}\right)_{6}(\mathrm{OH})_{2}, \mathrm{HAP}\right)$ and magnesia $(\mathrm{MgO})$ to explore their role in the reaction network for the Guerbet coupling of ethanol to butanol. In particular, the dehydrogenation of benzyl alcohol at $633 \mathrm{~K}$ and the hydrogenation of ethene and acetone at $473 \mathrm{~K}$ using both $\mathrm{H}_{2}$ and ethanol as a hydrogen source were studied. The $\mathrm{H}_{2}-\mathrm{D}_{2}$ ex-
\end{abstract}


change reaction at room temperature and the Guerbet coupling of ethanol at $613 \mathrm{~K}$ to $673 \mathrm{~K}$ in the presence of $\mathrm{D}_{2}$ were also performed. Although there was no consequence of adding $\mathrm{D}_{2}$ to the Guerbet coupling of ethanol in terms of rate or selectivity, incorporation of deuterium into product butanol was only observed over $\mathrm{MgO}$. This was attributed to the rapid exchange of $\mathrm{H}_{2}-\mathrm{D}_{2}$ that can occur over $\mathrm{MgO}$ but not over HAP. Hydrogenation of acetone occurred with ethanol as a sacrificial hydrogen donor via an MPV-like reaction whereas hydrogenation with $\mathrm{H}_{2}$ was not observed. Hydrogenation of ethene with $\mathrm{H}_{2}$ or ethanol was not observed above background. Comparing the rate of benzyl alcohol dehydrogenation to the rate of ethanol coupling over HAP and MgO suggests that the MPV-like hydrogen transfer reaction over HAP is mostly responsible for generating intermediate acetaldehyde during the Guerbet reaction instead of direct dehydrogenation.

\subsection{Introduction}

Catalytic reactions involving hydrogen have been well studied for many years. Olefin hydrogenation, ${ }^{24,25,63-65}$ butene isomerization ${ }^{37,66}$, and $\mathrm{H}_{2}-\mathrm{D}_{2}$ exchange ${ }^{67}$ are all examples of commonly studied reactions involving hydrogen. The mechanism for $\mathrm{H}_{2}$ activation is known to be different over metal catalysts compared to basic metal oxides. While $\mathrm{H}_{2}$ is generally accepted to dissociate into two hydrogen atoms on metal catalysts, ${ }^{68} \mathrm{H}_{2}$ activation either does not occur on basic metal oxides such as $\mathrm{MgO}$, or is heterolytically dissociated to a hydride and a proton ${ }^{66}$ over surface acid and base sites respectively. 
Many catalytic reactions involving hydrogen transfer can be important to the rate and desired product selectivity in more complex reaction networks. One example is the Guerbet coupling of alcohols. The Guerbet reaction consists of coupling two short chain alcohols to form a longer chain alcohol and water. The Guerbet coupling reaction has experienced a surge in recent interest because it is a potential method to upgrade biorenewable ethanol to butanol and longer chain alcohols. For more information on the Guerbet coupling reaction see Chapter 1.

Although many studies have been performed on the overall Guerbet coupling reaction, 6,7,9,11-13,29,39 the key elementary steps that comprise the reaction path need to be understood to facilitate catalyst design and optimization. In particular, aldol condensation has been studied over catalysts that have demonstrated activity for Guerbet coupling. ${ }^{22,48,49,51,52,54,69,70}$ Our previous work on the aldol condensation of acetaldehyde over $\mathrm{HAP}$ and $\mathrm{MgO}$ showed that surface reactions such as enolate formation are very rapid while the adsorption of acetaldehyde as well as product desorption are kinetically relevant. ${ }^{69}$ However, the role of hydrogenation and dehydrogenation reactions during Guerbet coupling over HAP and $\mathrm{MgO}$ are much less understood, despite being critical steps in the initial dehydrogenation of ethanol to acetaldehyde as well as the final hydrogenation reactions of crotonaldehyde to butanol. Indeed, the importance of hydrogen transfer reactions during Guerbet coupling has been demonstrated by the promotion of activity by adding metal components to the catalyst. $^{26}$ The presence of the added metal is thought to increase the rate of Guerbet coupling by facilitating the initial dehydrogenation of ethanol.

In the absence of metal promoters, ethanol dehydrogenation on basic metal oxides typically takes place at relatively high temperatures and is thought to proceed through an $E_{1 c B}$ mechanism as shown in Scheme 3.1. ${ }^{71}$ Moteki and Flaherty ${ }^{12}$ as well as Hanspal et al. ${ }^{31}$ have shown that co- 
feeding $\mathrm{H}_{2}$ during the Guerbet coupling reaction over HAP has no effect on the rate or selectivity at $548 \mathrm{~K}$ and $613 \mathrm{~K}$, respectively. Additionally, Ogo et al. ${ }^{10}$ have shown that $\mathrm{H}_{2}$ is unable to hydrogenate crotonaldehyde to butanol at $573 \mathrm{~K}$. However, when 2-butanol was used as a hydrogen source the formation of 1-butanol from crotonaldehyde via hydrogen transfer was observed.

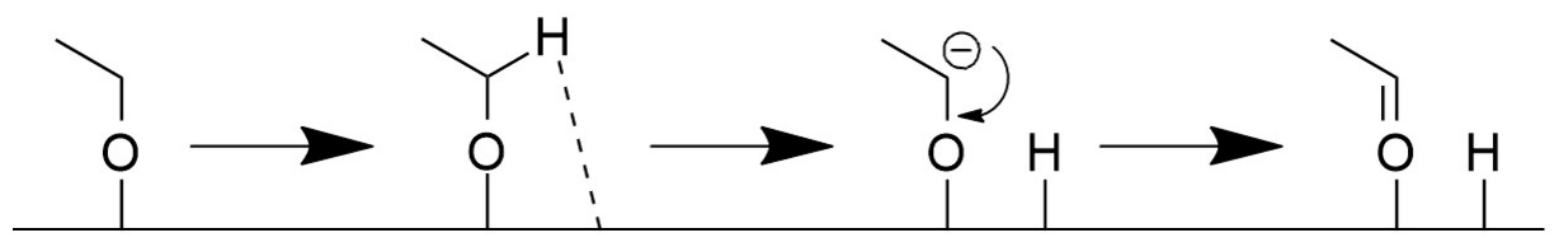

Scheme 3.1: Mechanism of the $E_{1} c B$ dehydrogenation reaction.

The observation that $\mathrm{H}_{2}$ does not change the rate or selectivity of Guerbet coupling over HAP and the ability of an alcohol to hydrogenate crotonaldehyde over HAP suggests that hydrogen transfer occurs through a Meerwein-Ponndorf-Verley-like (MPV-like) mechanism. The MPV reaction consists of the hydrogenation of an aldehyde or ketone through direct hydrogen transfer from a sacrificial alcohol. In the case of Guerbet coupling, an MPV-like hydrogenation of adsorbed intermediate crotonaldehyde by ethanol would produce crotyl alcohol and acetaldehyde. This type of hydrogen transfer reaction was shown to occur rapidly over HAP by Kibby and Hall ${ }^{43}$ many years ago. In that work, 2-butanol-2 $\mathrm{d}_{1}$ was reacted with 3-pentanone to form 3-pentanol- 
$3 \mathrm{~d}_{1}$ at $423 \mathrm{~K}$. Moteki and Flaherty ${ }^{12}$ used isotope experiments to show that MPV-like hydrogen transfer saturates the $\mathrm{C}=\mathrm{O}$ bond of butanal over HAP. Those authors claimed that the $\mathrm{C}=\mathrm{C}$ bond of crotyl alcohol was hydrogenated by surface hydrogen. Although there are excellent studies of hydrogen transfer reactions, it is still unclear if the sacrificial alcohol transfers hydrogen directly to the carbonyl group, or if this hydrogen transfer is mediated by the catalyst surface.

Prior work on the Guerbet coupling of ethanol suggest that the reaction is autocatalytic, during which butanol is produced in great excess beyond the small amount of acetaldehyde produced by dehydrogenation of ethanol to produce $\mathrm{H}_{2} \cdot{ }^{11,12}$ However, if ethanol provides $\mathrm{H}$ atoms to hydrogenate adsorbed intermediates produced from aldol condensation, then intermediate acetaldehyde is produced in the appropriate stoichiometric amount. The direct MPV-like hydrogen transfer from ethanol to adsorbed crotonaldehyde starts a reaction cascade that will result in the eventual production of one molecule of 1-butanol together with the formation of two molecules of acetaldehyde that were consumed in the aldol condensation reaction.

The role of surface hydrogen in hydrogenation reactions of alkenes has also been studied. ${ }^{12,24,25}$ For example, ethene hydrogenation can occur on $\mathrm{MgO}$ that has been thermally treated at very high temperatures $(>1000 \mathrm{~K}){ }^{24,25,65,72}$ The reaction occurs on sites capable of heterolytically dissociating $\mathrm{H}_{2}$ that are exposed during the high temperature treatment. A surface hydride attacks the adsorbed olefin resulting in a carbanion that is subsequently protonated by a surface proton. ${ }^{66}$ While this reaction can take place under temperatures relevant to Guerbet coupling, it was also shown that the introduction of water to the thermally-treated $\mathrm{MgO}$ destroys the sites that are active for heterolytic hydrogen dissociation. ${ }^{72}$ 
Other reactions that involve surface hydrogen have also been studied on basic metal oxides, namely 1-butene isomerization and $\mathrm{H}_{2}-\mathrm{D}_{2}$ exchange. The isomerization reaction is thought to occur through the abstraction of an allylic hydrogen resulting in an allyl anion. This anion is then protonated by a surface proton resulting in a mixture of 1-butene, cis-2-butene, and trans-2butene. ${ }^{66}$ Since crotyl alcohol has a similar electronic structure to butene, it is feasible that on basic metal oxides double bond isomerization could produce an enol, which would rapidly tautomerize to adsorbed butanal. The $\mathrm{H}_{2}-\mathrm{D}_{2}$ exchange reaction was studied by Boudart et al. ${ }^{67}$ who demonstrated exchange occurs at $78 \mathrm{~K}$ on $\mathrm{MgO}$ that was thermally-activated between $773 \mathrm{~K}$ to $1173 \mathrm{~K}$ in vacuum. The proposed mechanism for $\mathrm{H}_{2}-\mathrm{D}_{2}$ exchange on $\mathrm{MgO}$ involves reaction of molecularly-adsorbed $\mathrm{D}_{2}$ with a surface hydroxyl group through a triangular transition state. Unlike the case of olefin hydrogenation on $\mathrm{MgO}$, hydride is not present during the exchange reaction.

In an attempt to better understand the role of hydrogen transfer reaction on the Guerbet coupling reaction, this paper investigates relevant hydrogenation and dehydrogenation reactions over HAP and MgO. In particular, benzyl alcohol dehydrogenation was chosen as a probe reaction because it has an $\alpha$-hydrogen, which allows the dehydrogenation reaction to occur, but it does not have a $\beta$-hydrogen which prevents aldol condensation of the aldehyde product. Preventing aldol condensation is important because higher levels of aldehyde formation would be measured if the alcohol is being oxidized during an MPV-like reaction with the aldol condensation product. Hydrogenation of acetone with either $\mathrm{H}_{2}$ or ethanol was evaluated over $\mathrm{HAP}$ and $\mathrm{MgO}$ to explore the relative importance of MPV-like hydrogen transfer on the catalysts. In addition, the rate of the $\mathrm{H}_{2}-\mathrm{D}_{2}$ exchange reaction as well as the effect of $\mathrm{H}_{2}$ or $\mathrm{D}_{2}$ on the Guerbet coupling of ethanol over HAP and $\mathrm{MgO}$ were evaluated. 


\subsection{Materials and Methods}

\subsubsection{Catalyst Synthesis}

Hydroxyapatite was synthesized using a co-precipitation method originally developed by Tsuchida et al. ${ }^{42}$ and described in previous works. ${ }^{39,69} \mathrm{~A} 200 \mathrm{~cm}^{3}$ solution of $0.5 \mathrm{M}$ calcium nitrate tetrahydrate $\left(\mathrm{Ca}\left(\mathrm{NO}_{3}\right)_{2} \cdot 4 \mathrm{H}_{2} \mathrm{O}\right.$, Acros Organics) and a $200 \mathrm{~cm}^{3}$ solution of $0.3 \mathrm{M}$ diammonium phosphate $\left(\left(\mathrm{NH}_{4}\right)_{2} \mathrm{HPO}_{4}\right.$, Aldrich, $\left.>99.99 \%\right)$ were slowly added to $100 \mathrm{~cm}^{3}$ of distilled, deionized (DDI) water at $353 \mathrm{~K}$. The slurry was aged over night before being filtered and washed three times with DDI water. The solid was subsequently dried in air at $373 \mathrm{~K}$ before being thermally treated at $673 \mathrm{~K}$ for $2 \mathrm{~h}$ in flowing air.

Commercially available $\mathrm{MgO}$ was purchased from Ube Material Industries (Lot No. 109071725) and was thermally treated at $673 \mathrm{~K}$ for $2 \mathrm{~h}$ in flowing air. The particles of both $\mathrm{HAP}$ and $\mathrm{MgO}$ were sized between $106 \mu \mathrm{m}$ to $180 \mu \mathrm{m}$ prior to catalysis.

\subsubsection{Catalyst Characterization}

Phase purity was determined using XRD with a PANalytical X'Pert Pro diffractometer using Cu$\mathrm{K} \alpha$ radiation. These materials have been used in previous studies and XRD patterns can be found in Chapter 2 Figure 2.1.

Elemental analysis of HAP was performed by Galbraith Laboratories (Knoxville, TN) using ICP-OES. The catalyst was found to be very nearly stoichiometric with a measured $\mathrm{Ca} / \mathrm{P}=1.67$. 
The catalyst surface area was determined with $\mathrm{N}_{2}$ using the BET adsorption method on a Micromeritics ASAP 2020 at liquid $\mathrm{N}_{2}$ temperature. Both HAP and $\mathrm{MgO}$ had a surface area of $35 \mathrm{~m}^{2} \mathrm{~g}^{-1}$

\subsubsection{Catalytic Reactions}

\section{Guerbet Coupling in the Presence of $\mathrm{H}_{2} / \mathrm{D}_{2}$}

Guerbet coupling was carried out in the presence of both $\mathrm{H}_{2}$ (GTS-Welco, 99.999\%) and $\mathrm{D}_{2}$ (GTSWelco, $99.7 \%$ ) to determine if gas phase or surface hydrogen could be incorporated into the product. These isotopic studies were carried out using a downward-flow, fixed-bed, 1/4" O.D. stainless steel reactor that was connected to an on-line mass spectrometer and an on-line gas chromatograph (GC). The catalyst bed (HAP or $\mathrm{MgO}$ ) was supported in the reactor on quartz wool and was thermally treated in $50 \mathrm{~cm}^{3} \mathrm{~min}^{-1}$ flowing argon (GTS-Welco, $99.999 \%$ ) at $773 \mathrm{~K}$ prior to the reaction. Ethanol (Sigma, 99.5\%) was introduced to the feed by flowing $\mathrm{H}_{2}$ through a saturator at room temperature. The ethanol/ $\mathrm{H}_{2}$ stream was then passed over the catalyst (either $\mathrm{HAP}$ or $\mathrm{MgO})$. After the reaction came to steady-state, fifteen mass spectra of the product stream were collected. The carrier gas flowing through the saturator was then switched to $\mathrm{D}_{2}$ and allowed to pass over the catalyst for $1 \mathrm{~h}$ before reaction rates were measured using an online GC equipped with a flame ionization detector and a Restek MXT-Q-Bond column (0.53 mm i.d., $30 \mathrm{~m}$ length). Subsequently, fifteen mass spectra were collected. Finally, the carrier gas was switched to He and the ethanol conversion rates were measured. A small amount of methane was introduced to the reactant stream to serve as an internal standard. 
Product selectivity and conversion were calculated as

$$
\begin{aligned}
& \text { Selec. }=\frac{N_{i} n_{i}}{\sum N_{i} n_{i}} \\
& \text { Conv. }=\frac{\sum N_{i} n_{i}}{2 n_{\mathrm{EtOH}}}
\end{aligned}
$$

where $N_{i}$ is the number of carbons in the product, $n_{i}$ is the molar flow rate of the product, and $n_{\mathrm{EtOH}}$ is the molar flow rate of the reactant ethanol.

\section{$\mathrm{H}_{2}-\mathrm{D}_{2}$ Exchange}

The $\mathrm{H}_{2}-\mathrm{D}_{2}$ exchange reaction was performed in the same reactor as described above for the Guerbet coupling in the presence of $\mathrm{H}_{2} / \mathrm{D}_{2}$. During these reactions, an equimolar mixture of $\mathrm{H}_{2}$ and $\mathrm{D}_{2}$ was diluted in Ar. The partial pressure of the equimolar $\mathrm{H}_{2} / \mathrm{D}_{2}$ reaction mixture was varied while the total pressure was maintained at $1 \mathrm{~atm}$. The catalyst bed (either $\mathrm{HAP}$ or $\mathrm{MgO}$ ) was supported on quartz wool and was pretreated at $773 \mathrm{~K}$ in $100 \mathrm{~cm}^{3} \mathrm{~min}^{-1} \mathrm{Ar}$ for $1 \mathrm{~h}$ prior to the reaction. The $\mathrm{H}_{2} / \mathrm{D}_{2} / \mathrm{Ar}$ mixture was then passed over the catalyst at room temperature and the product stream was analyzed using a mass spectrometer measuring $\mathrm{m} / \mathrm{z}=2,3,4$ and 40 . 


\section{Benzyl Alcohol Dehydrogenation}

A downward-flow, fixed-bed, 1/4" O.D. stainless steel reactor with an on-line GC was used for the benzyl alcohol dehydrogenation reaction. A schematic of the reactor is shown in Appendix B. The catalyst bed was supported on quartz wool and was pretreated at $773 \mathrm{~K}$ for $1 \mathrm{~h}$ in $100 \mathrm{~cm}^{3} \mathrm{~min}^{-1}$ $\mathrm{N}_{2}$ (GTS-Welco, 99.999\%) prior to reaction. Pure benzyl alcohol (Sigma-Aldrich, 99.8\%) was introduced to the system with a syringe pump and was vaporized in a high temperature mixing chamber together with flowing $\mathrm{N}_{2}$. A small amount of methane $\left(1 \mathrm{~cm}^{3} \mathrm{~min}^{-1}\right)$ was added to the product stream downstream of the reactor as an internal standard. The reaction products were analyzed with an on-line gas chromatograph using a PoraPLOT Q-HT column and a flame ionization detector.

\section{Hydrogenation of Acetone and Ethene}

The same flow reactor and catalyst pretreatment conditions described for the benzyl alcohol dehydrogenation reaction were used for the hydrogenation reactions. When acetone was hydrogenated using ethanol as a hydrogen source, a 95 wt.\% ethanol, 5 wt.\% acetone (Sigma-Aldrich, 99.9\%) solution was fed to the high temperature mixing chamber together with flowing $\mathrm{N}_{2}$.

When ethene was hydrogenated using ethanol as a hydrogen source, a $\mathrm{N}_{2}$ /ethene (ethene from GTS Welco $99.5 \%, 4 \mathrm{kPa}$ ethene, $1 \mathrm{~atm}$ total pressure) gas mixture was passed through the high temperature mixing chamber with a $95 \mathrm{wt} . \%$ ethanol $/ 5 \mathrm{wt} . \%$ octane solution. Octane was used as an internal standard. 
To explore the reaction of acetone with $\mathrm{H}_{2}$, pure $\mathrm{H}_{2}$ carrier gas was passed through an acetone saturator that was submerged in a dry ice/acetone bath, which should produce $0.02 \%$ acetone in $\mathrm{H}_{2}$. Methane was introduced downstream of the reactor as an internal standard. For ethene hydrogenation with $\mathrm{H}_{2}$ a mixture of ethene/ $\mathrm{H}_{2}$ feed ( $4 \mathrm{kPa}$ ethene, 1 atm total pressure) was passed over the catalyst.

\subsection{Results and Discussion}

\subsubsection{Guerbet Coupling in the Presence of $\mathrm{H}_{2} / \mathrm{D}_{2}$}

Dihydrogen is a byproduct that can be produced during the Guerbet coupling reaction by alcohol dehydrogenation. Although $\mathrm{H}_{2}$ is not a product of the coupling of ethanol into butanol, one molecule of $\mathrm{H}_{2}$ is produced for every molecule of acetaldehyde, which is a common side product during the Guerbet coupling reaction. Our group and others have shown that adding gaseous $\mathrm{H}_{2}$ has no effect on the rate of the ethanol coupling reaction or the selectivity towards butanol over HAP. ${ }^{10,12,31}$ These observations do not preclude the possibility that $\mathrm{H}_{2}$ interacts with the catalyst surface and can incorporate into product molecules. To explore this, the Guerbet coupling of ethanol was performed in the presence of dideuterium gas. The rate of ethanol conversion using $\mathrm{He}, \mathrm{H}_{2}$, or $\mathrm{D}_{2}$ as a diluent are shown in Table 3.1. The Guerbet reaction was carried out at low conversion in all cases $(\leq 5 \%)$. Both the rate and selectivity were relatively unaffected by the presence of $\mathrm{H}_{2}$ or $\mathrm{D}_{2}$. This similarity in rate and selectivity among $\mathrm{H}_{2}, \mathrm{D}_{2}$, and $\mathrm{He}$ as a diluent gas over each catalyst is consistent with previous reports showing a negligible influence of $\mathrm{H}_{2}$ on 
coupling kinetics. Moreover, there is no kinetic isotope effect involving $\mathrm{H}_{2}$ and $\mathrm{D}_{2}$.

Table 3.1: Influence of $\mathrm{H}_{2}$ or $\mathrm{D}_{2}$ on Rate and Selectivity of Ethanol Conversion over HAP and $\mathrm{MgO}^{(\mathrm{a})}$

\begin{tabular}{ccccc}
\hline Catalyst & $\mathrm{T}(\mathrm{K})$ & Diluent Gas & $\begin{array}{c}\text { Ethanol Conversion } \\
\text { Rate }\left(\mathrm{mol} \mathrm{m}^{-2} \mathrm{~s}^{-1}\right)\end{array}$ & Butanol Selectivity (C\%) \\
\hline $\mathrm{HAP}$ & 613 & $\mathrm{He}$ & $5.0 \times 10^{-8}$ & 65 \\
$\mathrm{HAP}$ & 613 & $\mathrm{H}_{2}$ & $6.4 \times 10^{-8}$ & 61 \\
$\mathrm{HAP}$ & 613 & $\mathrm{D}_{2}$ & $7.2 \times 10^{-8}$ & 63 \\
$\mathrm{MgO}$ & 673 & $\mathrm{He}$ & $2.5 \times 10^{-8}$ & 17 \\
$\mathrm{MgO}$ & 673 & $\mathrm{H}_{2}$ & $2.5 \times 10^{-8}$ & 23 \\
$\mathrm{MgO}$ & 673 & $\mathrm{D}_{2}$ & $2.7 \times 10^{-8}$ & 14
\end{tabular}

(a) Partial Pressure of ethanol $=6 \mathrm{kPa}$, remainder diluent gas to give $1 \mathrm{~atm}$ total pressure. All ethanol conversion levels were $<5 \%$.

The mass spectra of butanol produced over $\mathrm{HAP}$ and $\mathrm{MgO}$ in $\mathrm{H}_{2}$ and $\mathrm{D}_{2}$ diluent gas are shown in Figure 3.1. For butanol production over HAP, the mass spectrum changes very little after the switch from $\mathrm{H}_{2}$ to $\mathrm{D}_{2}$. In contrast, the intensity of the butanol peaks at $\mathrm{m} / \mathrm{z}=57$ and 58 increases significantly when $\mathrm{MgO}$ was used as the catalyst, indicating a fraction of $\mathrm{D}_{2}$ from the gas phase incorporates into the butanol product, although there is no kinetic influence of $\mathrm{D}_{2}$ on the reaction. Incorporation of deuterium into butanol can result from direct hydrogenation of $\mathrm{C}=\mathrm{C}$ and/or $\mathrm{C}=\mathrm{O}$ by $\mathrm{D}_{2}$ or exchange of deuterium with surface bound hydrogen atoms that eventually incorporate into butanol. From the mass spectrum in Figure 3.1B, we estimate that $31 \%$ of the butanol had no deuterium, whereas $36 \%, 27 \%$ and $6 \%$ had one $\mathrm{D}$, two $\mathrm{D}$, and three $\mathrm{D}$ atoms substituted into 
butanol, respectively. The lack of deuterium incorporation into the product butanol produced over HAP suggests that direct hydrogenation of $\mathrm{C}=\mathrm{C}$ or $\mathrm{C}=\mathrm{O}$ bonds of intermediate crotonaldehyde using $\mathrm{H}_{2}$ as a hydrogen source does not take place to any significant extent.
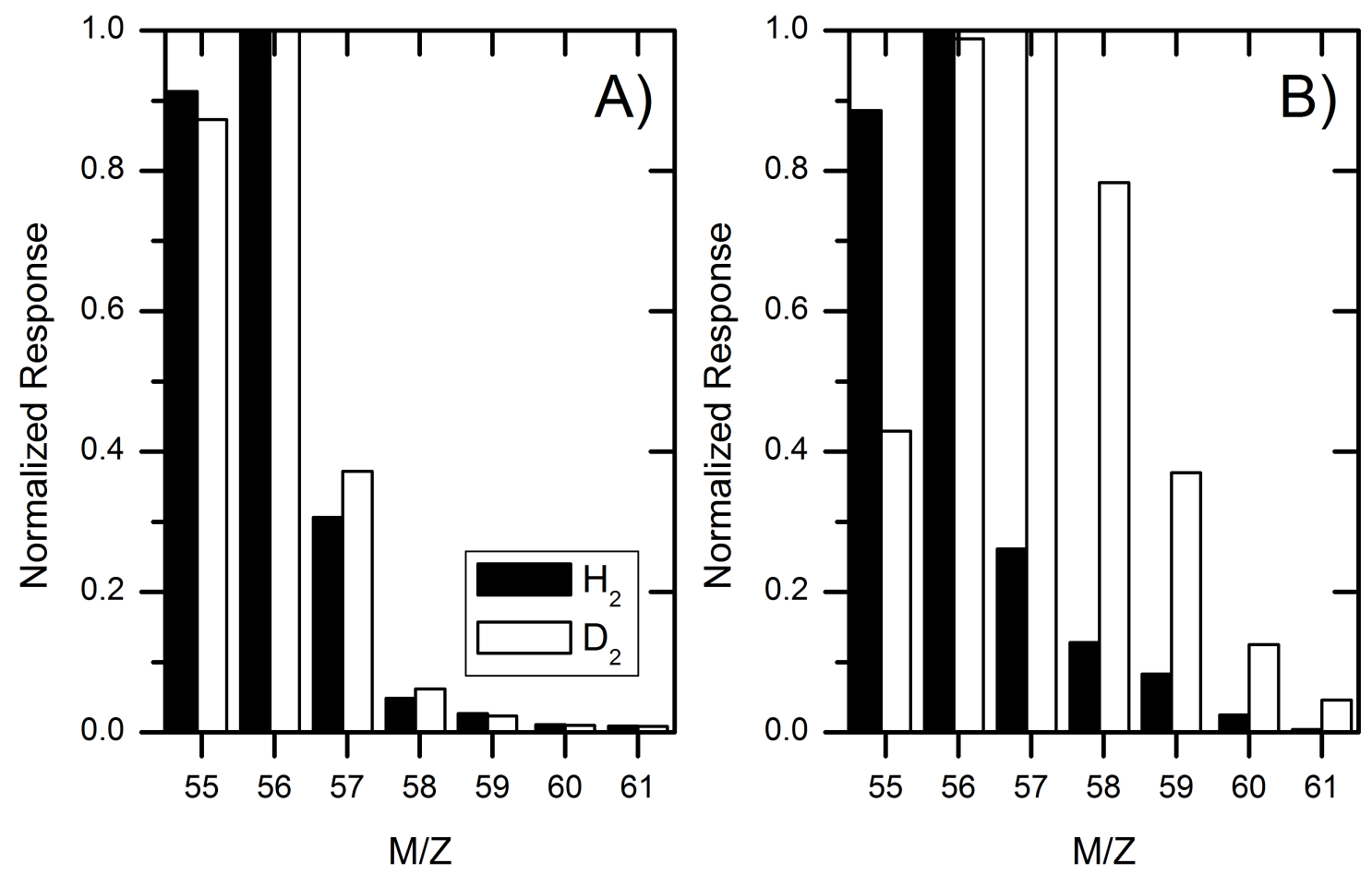

Figure 3.1: Mass Spectra of the butanol carbon backbone over A) HAP and B) MgO during the Guerbet coupling reaction in the presence of $\mathrm{H}_{2}$ or $\mathrm{D}_{2}$ carrier gas.

The significant difference in the isotopomer distribution of butanol produced over HAP and $\mathrm{MgO}$ motivated a study of the $\mathrm{H}_{2}-\mathrm{D}_{2}$ exchange reaction. The $\mathrm{MgO}$ catalyst is known to be very active for this reaction at low temperatures. ${ }^{33,67}$ Indeed, we observed the $\mathrm{H}_{2}-\mathrm{D}_{2}$ exchange reaction occurred readily at $298 \mathrm{~K}$ on $\mathrm{MgO}$ with a rate of $1.3 \times 10^{-5} \mathrm{~mol} \mathrm{~m}^{-2} \mathrm{~s}^{-1}$ when the $\mathrm{H}_{2}$ partial pressure was $2 \mathrm{kPa}$. The reaction was so rapid that conversion was $30 \%$ at all pressures tested, which is $83 \%$ of the calculated equilibrium conversion for the reaction $\left(f_{e q}=36 \%, K_{e q}=3.2\right) .{ }^{73}$ The 
rate of $\mathrm{H}_{2}-\mathrm{D}_{2}$ exchange reported by Boudart et al. ${ }^{67}$ measured at $78 \mathrm{~K}$ for an $\mathrm{MgO}$ sample calcined at $650 \mathrm{~K}$ can be extrapolated to $298 \mathrm{~K}$ and $2 \mathrm{kPa} \mathrm{H}_{2}$ using their reported activation energy. The extrapolated rate from Boudart et al. ${ }^{67}$ of $1.5 \times 10^{-5} \mathrm{~mol} \mathrm{~m}^{-2} \mathrm{~s}^{-1}$ is similar to our measured rate and this agreement suggests that the $\mathrm{MgO}$ catalyst used in the current study exposes similar active sites for $\mathrm{H}_{2}-\mathrm{D}_{2}$ exchange as the catalyst prepared by Boudart et al. ${ }^{67}$ They suggest the reaction proceeds through an Eley-Rideal like mechanism in which a proton on the catalyst surface reacts with a weakly adsorbed $D_{2}$ molecule through a triangular transition state ${ }^{67}$ to produce a surface deuteron and gas phase HD. For our work on Guerbet coupling of ethanol, we suggest the surface deuteron produced via surface exchange with the $D_{2}$ could then add to a carbanion that is formed during the coupling reaction sequence. In this way, deuterium can incorporate into product butanol. As no $\mathrm{H}_{2}-\mathrm{D}_{2}$ exchange was observed over the HAP catalyst at $298 \mathrm{~K}$, it is not surprising that no deuterium is incorporated into butanol during Guerbet coupling of ethanol.

\subsubsection{Hydrogenation Reaction}

Results described in the previous section indicate that neither HAP nor $\mathrm{MgO}$ are able to directly hydrogenate $\mathrm{C}=\mathrm{C}$ or $\mathrm{C}=\mathrm{O}$ bonds of reactive intermediates formed during Guerbet coupling using gas phase $\mathrm{H}_{2}$. Potential reactions of ethene and acetone in the presence of $\mathrm{H}_{2}$ were then examined to further probe the hydrogenating ability of the catalyst. No 2-propanol was formed when $\mathrm{H}_{2}$ and acetone were co-fed over either catalyst at $473 \mathrm{~K}$. However, $\mathrm{C}_{6}$ products were observed at $473 \mathrm{~K}$ due to the self-aldol condensation of acetone. When ethene and $\mathrm{H}_{2}$ were passed through a blank reactor at $473 \mathrm{~K}$ containing no catalyst, a small amount of ethane was observed ( $3 \%$ ethene conversion). This background hydrogenation reaction was most likely catalyzed by the stainless- 
steel reactor. When the reaction was carried out in the presence of $\mathrm{HAP}$ and $\mathrm{MgO}$, no conversion of ethene above the background was observed. The hydrogenation of ethene by $\mathrm{H}_{2}$ over $\mathrm{MgO}$ has been previously reported to occur over catalysts that had been pretreated at very high temperatures $(>1000 \mathrm{~K}) .^{24,65,72}$ Formation of strong basic sites that were capable of heterolytically dissociating $\mathrm{H}_{2}$ was proposed to account for the need of high temperature treatment. The hydride that was formed during the heterolytic dissociation then attacks the olefin resulting in a carbanion that would be subsequently protonated. ${ }^{66}$ The milder pretreatment condition used to activate the $\mathrm{MgO}$ in the current study is apparently unable to form sites that are active for olefin hydrogenation. It should be noted, however, the background hydrogenation rates that were observed in our reactor are an order of magnitude greater than the hydrogenation rates that were reported in the previous studies. ${ }^{65}$ As such, it is impossible for us to completely rule out the possibility that some $\mathrm{C}=\mathrm{C}$ bonds of reactive intermediates produced during Guerbet coupling are being hydrogenated by these catalysts. Based on the lack of deuterium incorporation into butanol over HAP (Figure 3.1), it seems unlikely that a $\mathrm{H}_{2} / \mathrm{D}_{2}$ heterolytic dissociation is kinetically relevant. Additionally, the presence of water was shown previously to destroy the strongly basic sites required for heterolytic $\mathrm{H}_{2}$ dissociation. Because water is a product of Guerbet coupling, it is unlikely that these sites would exist under Guerbet coupling conditions.

A commonly-proposed path for $\mathrm{C}=\mathrm{O}$ hydrogenation involves an MPV-like mechanism ${ }^{11,12}$ where hydrogen is transferred directly from a sacrificial alcohol to the $\mathrm{C}=\mathrm{O}$ bond as shown in Scheme 3.2. Therefore, hydrogenation of $\mathrm{C}=\mathrm{O}$ and $\mathrm{C}=\mathrm{C}$ bonds using ethanol as a hydrogen source was also tested. In the case of ethanol reacting with crotonaldehyde, this would result in the formation of acetaldehyde and crotyl alcohol. To explore this type of transfer hydrogenation, 


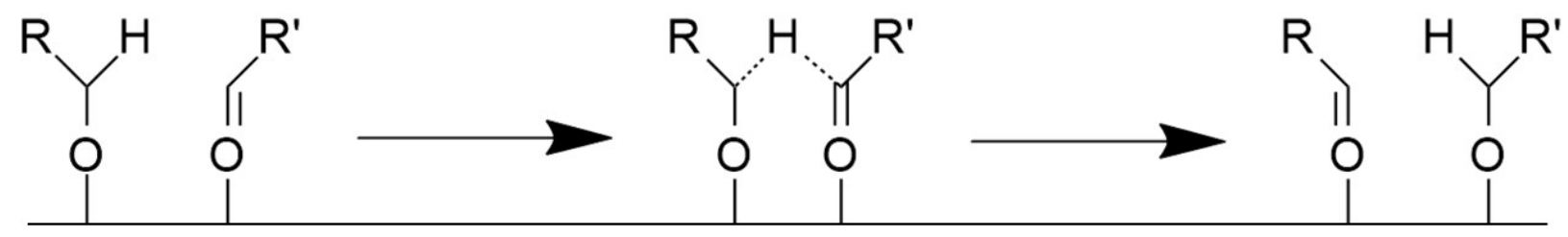

Scheme 3.2: MPV like reaction where hydrogen is transferred through a cyclic intermediate

the reaction of acetone to 2-propanol was performed over both $\mathrm{HAP}$ and $\mathrm{MgO}$ at $473 \mathrm{~K}$ using ethanol as the sacrificial alcohol. When excess ethanol was co-fed with acetone, the formation of 2-propanol was observed over both $\mathrm{HAP}$ and $\mathrm{MgO}$, and Figure 3.2 shows the rate of 2-propanol formation at a constant ratio of acetone to ethanol diluted in $\mathrm{N}_{2}$. Deactivation was observed over both HAP and $\mathrm{MgO}$, which makes a direct comparison of rates difficult, but it is clear that both catalysts are able to hydrogenate acetone using ethanol as a hydrogen source. Over $\mathrm{MgO}$, some $\mathrm{C}_{6}$ products were observed and more acetaldehyde was produced than 2-propanol over this catalyst. No $\mathrm{C}_{6}$ products were observed over HAP and a similar amount of acetaldehyde and 2-propanol were observed. It is possible that the excess acetaldehyde that was observed during the reaction over $\mathrm{MgO}$ is due to either background dehydrogenation of ethanol to acetaldehyde or to the transfer hydrogenation of $\mathrm{C}_{6}$ carbonyl compounds produced by aldol condensation of acetone. 


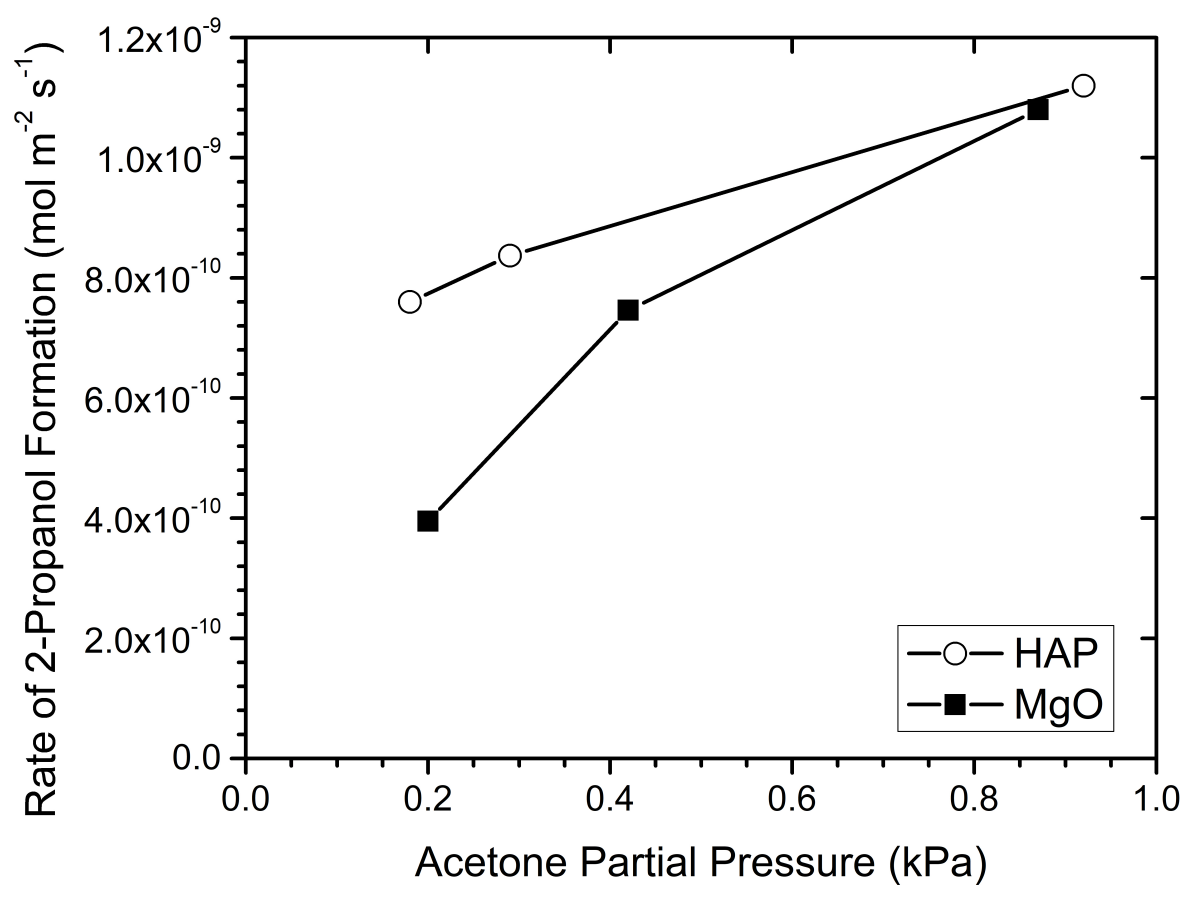

Figure 3.2: The rate of MPV-like hydrogenation over $\mathrm{HAP}$ and $\mathrm{MgO}$ at $473 \mathrm{~K}$. The reaction was carried out at atmospheric pressure with an acetone to ethanol molar ratio of 0.07 at all acetone partial pressures

When ethene and ethanol were passed over both HAP and $\mathrm{MgO}$ at $473 \mathrm{~K}$, no ethane formation was observed, indicating $\mathrm{C}=\mathrm{C}$ bonds were not readily hydrogenated by either ethanol or $\mathrm{H}_{2}$ under our reaction conditions. This observation suggests that the hydrogenation of intermediate crotonaldehyde proceeds through MPV-like alcohol transfer hydrogenation of the $\mathrm{C}=\mathrm{O}$ bond to form crotyl alcohol, followed by a double bond isomerization reaction and keto/enol tautomerization to form butanal, and final MPV-like $\mathrm{C}=\mathrm{O}$ bond hydrogenation to form the saturated alcohol 1-butanol. The double bond isomerization of butene will take place at water-ice temperatures over $\mathrm{MgO}^{74}$ and we have shown that enolate formation occurs rapidly during the aldol condensation of acetaldehyde ${ }^{69}$ indicating that both of these reactions will be very rapid for temperatures relevant to Guerbet coupling. This sequence of transfer hydrogenations from ethanol will produce two molecules of acetaldehyde that can undergo an aldol condensation step to regenerate the 
crotonaldehyde that was converted to butanol. The proposed reaction path is consistent with the autocatalytic mechanism that was proposed by Ho et al. ${ }^{11}$ While this is a possible mechanism for the hydrogenation of crotonaldehyde, it is also possible that a hydrogen transfer reaction is taking place to hydrogenate the $\mathrm{C}=\mathrm{C}$ bond of either crotonaldehyde or crotyl alcohol. A hydrogenation like this would not be observed during the ethene hydrogenation reaction experiments. If a transfer hydrogenation reaction is taking place in this way it would be kinetically indistinguishable from an MPV-like hydrogen transfer reaction that takes place at a $\mathrm{C}=\mathrm{O}$ bond.

The MPV-like $\mathrm{C}=\mathrm{O}$ bond hydrogen transfer reaction was also proposed by Ogo et al. ${ }^{10}$ and Moteki and Flaherty. ${ }^{12}$ In the study by Ogo et al. ${ }^{10}$ crotonaldehyde was reacted with both $\mathrm{H}_{2}$ and 2-butanol present as a hydrogen source, and the authors found that $\mathrm{H}_{2}$ was unable to hydrogenate crotonaldehyde at $573 \mathrm{~K}$ over a strontium substituted HAP, while the reaction between 2-butanol and crotonaldehyde lead to similar products as the overall Guerbet coupling of ethanol. Moteki and Flaherty ${ }^{12}$ studied butanal and crotyl alcohol hydrogenation in the presence of fully deuterated 2-propanol and t-butanol with three times as much t-butanol present as 2-propanol-d $\mathrm{d}_{8}$. In this way, the surface of the catalyst will be populated in both hydrogen and deuterium due to the decomposition of adsorbed alcohols into alkoxides. The three to one ratio of unlabeled t-butanol to fully deuterated 2-propanol will result in a surface that has a three to one ratio of hydrogen to deuterium. If the hydrogenation reaction takes place predominantly through direct hydrogen transfer from deuterated 2-propanol the mass spectrum of the product will be shifted $1 \mathrm{u}$. In contrast, if hydrogen originates from the surface, there will not be a shift in the mass spectrum. During the reaction of butanal under these conditions there was a $1 \mathrm{u}$ shift in the butanol mass spectrum indicating that a deuterium atom was transferred directly from 2-propanol- $\mathrm{d}_{8}$ to butanal. Inter- 
estingly, the hydrogenation of crotyl alcohol with 2-propanol- $\mathrm{d}_{8}$ did not shift the mass spectrum of the product butanol, which lead the authors to conclude that the $\mathrm{C}=\mathrm{C}$ bond of crotyl alcohol was hydrogenated by a surface hydrogen atom. The conclusion that $\mathrm{C}=\mathrm{C}$ is hydrogenated is not supported by the results of the current work and additional studies are underway to understand the nature of this inconsistency.

\subsubsection{Benzyl Alcohol Dehydrogenation}

Although an autocatalytic cycle that converts ethanol to butanol is consistent with Guerbet coupling kinetics, formation of acetaldehyde via dehydrogenation must also take place to initiate the autocatalytic sequence. To study this initiation reaction, the dehydrogenation of benzyl alcohol was performed. The dehydrogenation of benzyl alcohol occurred readily over both $\mathrm{HAP}$ and $\mathrm{MgO}$ with little deactivation and no observed side products. Figure 3.3 shows the rate of reaction over both $\mathrm{HAP}$ and $\mathrm{MgO}$ at $633 \mathrm{~K}$ and different alcohol partial pressures. The $\mathrm{MgO}$ catalyst was more active on an area basis for alcohol dehydrogenation than HAP. The rate of reaction is fit well by a two-step model consisting of equilibrated dissociative adsorption of the alcohol followed by a rate determining unimolecular surface reaction, which is most likely $\mathrm{C}-\mathrm{H}$ bond activation of the adsorbed alkoxide intermediate. This is consistent with an $E_{1 c B}$ mechanism that has been proposed elsewhere. ${ }^{71}$

Over $\mathrm{MgO}$, the rate of benzyl alcohol dehydrogenation is higher than the rate of Guerbet coupling of ethanol, despite the benzyl alcohol reaction being carried out $40 \mathrm{~K}$ lower, which may result from the presence of the aromatic ring. No Guerbet coupling of ethanol was observed over $\mathrm{MgO}$ 


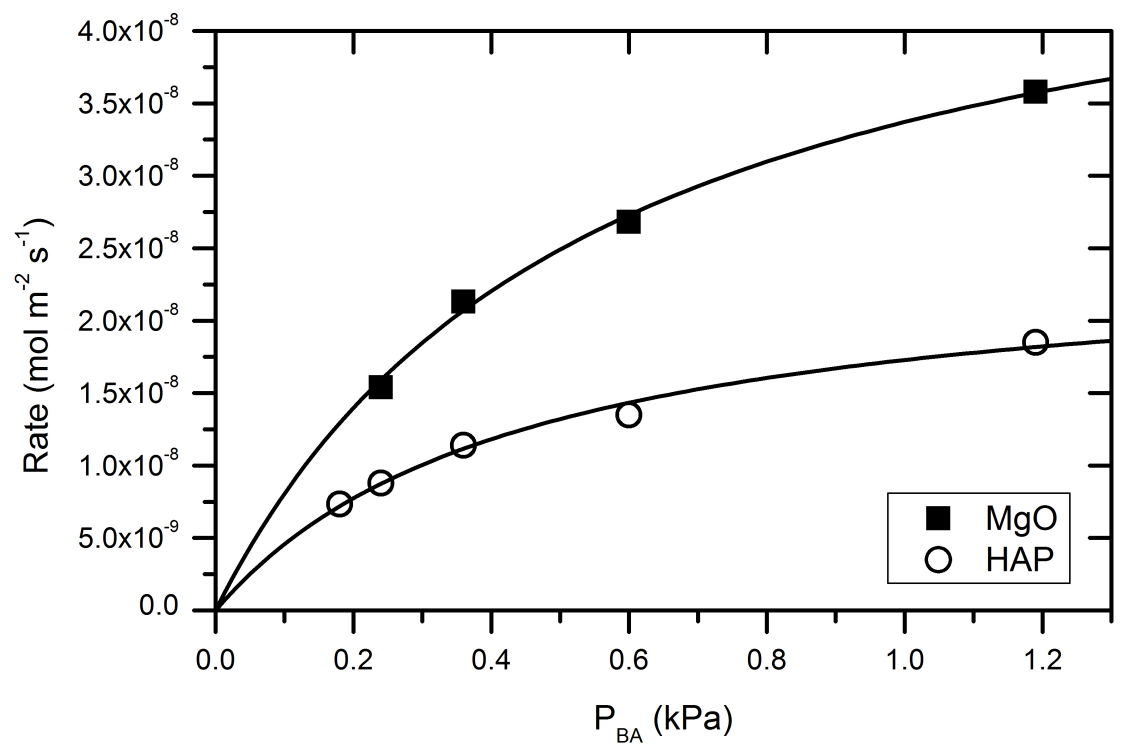

Figure 3.3: The rate of benzyl alcohol dehydrogenation over $\mathrm{HAP}$ and $\mathrm{MgO}$ at $633 \mathrm{~K}$. The reaction was carried out at atmospheric total pressure with $\mathrm{N}_{2}$ as a diluent gas.

at $633 \mathrm{~K}$ with similar contact times. Over HAP, the rate of benzyl alcohol dehydrogenation (Figure 3.3) is lower than the overall rate of ethanol Guerbet coupling shown in Table 3.1 despite the dehydrogenation reaction being carried out at a temperature $20 \mathrm{~K}$ higher and the higher reactivity of benzyl alcohol compared to ethanol. Both the dehydrogenation of benzyl alcohol and the Guerbet coupling of ethanol were carried out under conditions where the reaction is near zero order as shown in Figure 3.3 for benzyl alcohol dehydrogenation and the work of Hanspal et al. ${ }^{31}$ for the Guerbet coupling of ethanol. Evidently, a significant portion of intermediate acetaldehyde that proceeds to form butanol during Guerbet coupling of ethanol over HAP is not formed by direct dehydrogenation of ethanol to acetaldehyde and $\mathrm{H}_{2}$. Instead, the MPV-like transfer of hydrogen from ethanol to adsorbed intermediates must be responsible for production of most of the acetaldehyde. 


\subsection{Conclusions}

The addition of $\mathrm{H}_{2}$ or $\mathrm{D}_{2}$ to the Guerbet coupling of ethanol over $\mathrm{HAP}$ and $\mathrm{MgO}$ had no effect on rate or selectivity of the reaction toward butanol. The partial incorporation of deuterium into the product butanol produced over $\mathrm{MgO}$ is attributed to the deuteration of the hydroxyls of $\mathrm{MgO}$ through rapid exchange with $\mathrm{D}_{2}$. Indeed, rapid $\mathrm{H}_{2}-\mathrm{D}_{2}$ exchange occurred on $\mathrm{MgO}$ at room temperature but was not observed on HAP. Both $\mathrm{MgO}$ and HAP catalyzed the MPV-like hydrogen transfer from ethanol to acetone at $473 \mathrm{~K}$, but neither catalyst could hydrogenate acetone with $\mathrm{H}_{2}$. The hydrogenation of ethene to ethane was not observed above background conversion at $473 \mathrm{~K}$ using $\mathrm{H}_{2}$ and ethanol as hydrogen sources. It is possible that all of the hydrogen transfer reactions during Guerbet coupling involve MPV-like reactions between alcohols and carbonyls. No evidence for $\mathrm{C}=\mathrm{C}$ hydrogenation was observed, which suggests hydrogenation via MPV-hydrogen transfer steps likely undergo a double bond shift to form an enol, which is tautomerized to a carbonyl. Additionally, it is possible that a hydrogen transfer reaction from ethanol to the $\mathrm{C}=\mathrm{C}$ bond of crotnaldehyde or crotonalcohol could be taking place, but this would be kinetically indistinguishable from an MPV-like hydrogen transfer reaction. The rate of benzyl alcohol dehydrogenation was lower than the rate of ethanol coupling over HAP, consistent with MPV-like conversion of ethanol to acetaldehyde being a major source of the acetaldehyde needed to form butanol. 


\section{Chapter 4}

\section{Conclusions}

\subsection{Summary}

In this work the Guerbet coupling reaction network was broken down into its constituent steps that were analyzed independently of the overall reaction network. During aldol condensation of acetaldehyde, reaction kinetics and adsorption studies showed that adsorption and desorption steps were kinetically relevant while the surface reactions, including enolate formation, were rapid. Hydrogenation of $\mathrm{C}=\mathrm{O}$ bonds were shown to take place through an MPV-like mechanism using ethanol as a hydrogen source, while ethene hydrogenation showed negligible activity under similar conditions. Additionally, $\mathrm{H}_{2}$ was not an effective hydrogen source for the hydrogenation of either $\mathrm{C}=\mathrm{C}$ or $\mathrm{C}=\mathrm{O}$ bonds. Benzyl alcohol dehydrogenation occurred through an $E_{1 c B}$ mechanism at high temperatures relative to aldol condensation and hydrogenation reactions and $\alpha-\mathrm{H}$ abstraction was likely the kinetically relevant to the dehydrogenation step. 
For the aldol condensation work described in Chapter 2, reactions carried out at low acetaldehyde partial pressure over $\mathrm{HAP}$ and $\mathrm{TiO}_{2}$ were first order in acetaldehyde pressure. At higher partial pressures it was shown that the rate tended toward zero order with respect to acetaldehyde. Additionally, no kinetic isotope effect was observed when the reaction was carried out using fully deuterated acetaldehyde. Taken together, these results seems to suggest that both adsorption and desorption are kinetically relevant while surface reactions are very rapid. Infrared spectroscopy of adsorbed acetaldehyde showed that the formation of new surface species, likely acetate, occurred at room temperature and low aldehyde partial pressure, confirming that the surface reactions involving adsorbed acetaldehyde take place even under mild conditions.

Despite the fact that $\mathrm{TiO}_{2}$ was the most active catalyst for aldol condensation, it was unable to couple ethanol to butanol, instead favoring the acid-catalyzed product diethyl ether. This indicates that aldol condensation is not the only factor that is important to the overall Guerbet coupling reaction. The role that ethanol plays on aldol condensation was studied by measuring the rate of aldol condensation in the presence of ethanol. It was found that ethanol inhibited the rate of aldol condensation over $\mathrm{TiO}_{2}$, but not over HAP or MgO. Adsorption microcalorimitry of acetalehyde and ethanol showed that the acetaldehyde is more strongly adsorbed on the HAP and MgO surface than ethanol, while over $\mathrm{TiO}_{2}$ acetaldehyde and ethanol had similar heats of adsorption. Based on this, the inability of $\mathrm{TiO}_{2}$ to couple acetaldehyde is likely due to the inhibition of aldol condensation caused by ethanol.

After the aldol condensation reaction was analyzed, the dehydrogenation and hydrogenation reactions were studied in Chapter 3. Isotope experiments involving $\mathrm{D}_{2}$ were used to determine if gas phase $\mathrm{D}_{2}$ could incorporate into the product butanol. Over $\mathrm{MgO}$, some of the product butanol 
contained deuterium, but no deuterium incorporation into butanol was observed over HAP. The $\mathrm{H}_{2}-\mathrm{D}_{2}$ exchange reaction was also found to take place over $\mathrm{MgO}$, but not HAP. In addition to the $D_{2}$ incorporation experiments, we found gas phase $\mathrm{H}_{2}$ was unable to hydrogenate either $\mathrm{C}=\mathrm{C}$ or $\mathrm{C}=\mathrm{O}$ bonds. This reaction was carried out by passing either acetone and $\mathrm{H}_{2}$ or ethene and $\mathrm{H}_{2}$ over $\mathrm{HAP}$ and $\mathrm{MgO}$ at $473 \mathrm{~K}$. It was also found that ethanol could not hydrogenate ethene at the same temperature, indicating that $\mathrm{C}=\mathrm{C}$ bonds cannot be hydrogenated during the Guerbet coupling of ethanol. On the other hand, The reaction of ethanol and acetone resulted in the formation of 2propanol at $473 \mathrm{~K}$. This indicates that ethanol can be used as a hydrogen source for $\mathrm{C}=\mathrm{O}$ bond hydrogenation, likely through an MPV-like mechanism. During the Guerbet coupling of ethanol, the hydrogenation of the adsorbed intermediate crotonaldehyde likely proceeds through a $\mathrm{C}=\mathrm{O}$ bond hydrogenation resulting in the formation of crotyl alcohol. Crotyl alcohol then undergoes a fast double bond isomerization and keto/enol tautomerization to form butanal that is subsequently hydrogenated to the final product 1-butanol. The hydrogenation reactions result in the recovery the two molecules of acetaldehyde that were consumed during the aldol condensation step. In this way a small amount of acetaldehyde can result in a large amount of ethanol.

Benzyl alcohol dehydrogenation was also studied to measure the rate of the initial alcohol dehydrogenation reaction independent of the rest of the Guerbet coupling network. Both HAP and MgO catalyzed the dehydrogenation of benzyl alcohol at $633 \mathrm{~K}$. However, $\mathrm{MgO}$ was approximately a factor of two more active for the reaction on an area basis. The rate determining step is most likely $\alpha$-hydrogen abstraction from an adsorbed alkoxide intermediate. The rate of benzyl alcohol dehydrogenation was lower than the rate of the Guerbet coupling of ethanol over HAP suggesting that there should be another source of acetaldehyde produced during Guerbet coupling to account 
for the large amount of butanol produced. This is consistent with the MPV-like hydrogenation of crotonaldehyde using ethanol as a sacrificial alcohol.

The mechanism of Guerbet coupling can be updated using this new information. Scheme 4.1 shows the updated mechanism.

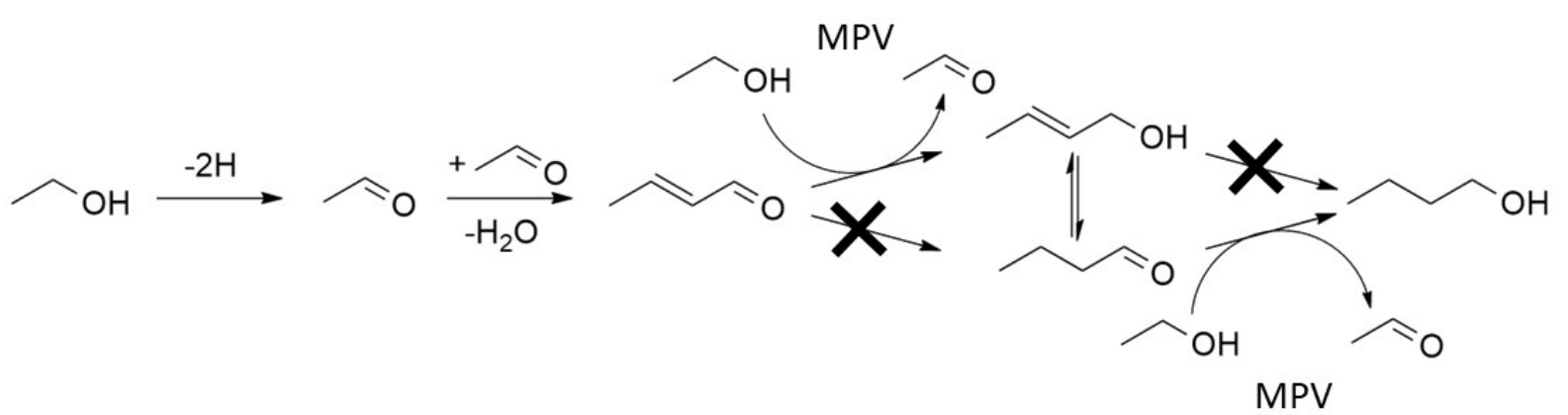

Scheme 4.1: Revised mechanism for Guerbet coupling

The initial dehydrogenation step is likely slow and initiates the relatively fast cascade of aldol condensation and MPV-like hydrogenation steps.

The fact that aldol condensation both occurs and is not kinetically relevant is not consistent with the previous work on the Guerbet coupling reaction. However, it was shown conclusively in Chapter 2 that aldol condensation can take place readily over these materials at a similar temperature to Guerbet coupling. Additionally, it was shown that the presence of ethanol does not inhibit the rate of aldol condensation over $\mathrm{HAP}$ and $\mathrm{MgO}$. Based on this, there is no reason to suspect that aldol condensation cannot take place under Guerbet coupling conditions.

The fact that ethanol and acetone react to form acetaldehyde and 2-propanol at relatively low 
temperatures (473 K for acetone hydrogenation versus $613 \mathrm{~K}$ to $673 \mathrm{~K}$ for Guerbet coupling) indicates that this reaction also occurrs rapidly. However, it is still unclear what role, if any, the surface plays during this hydrogen transfer reaction. The fact that $\mathrm{C}=\mathrm{O}$ bond hydrogenation takes place at such a low temperature relative to Guerbet coupling also indicates that it does not limit the overall rate of Guerbet coupling. Additionally, ethene hydrogenation is not catalyzed by either HAP or $\mathrm{MgO}$, which indicates that these catalysts do not hydrogenate $\mathrm{C}=\mathrm{C}$ bonds at coupling conditions. This means that the reaction must proceed through the double bond isomerization of crotyl alcohol to butanal. Butene isomerization has been shown to be very rapid over $\mathrm{MgO}$, even at dry ice temperature $^{74}$. Base on this, it is reasonable to assume that crotyl alcohol double bond isomerization is also very rapid. Taken together, this shows that crotonaldehyde hydrogenation likely does not limit the rate of Guerbet coupling.

Based on this work, it appears as though the rate of the initial dehydrogenation reaction plays an important role on the Guerbet coupling reaction. It is clear that at least a small amount of acetaldehyde needs to be formed in order for the autocatalytic cycle to begin. The fact that the dehydrogenation of benzyl alcohol required elevated temperature $(633 \mathrm{~K})$ relative to aldol condensation and hydrogenation, and that these temperatures are close to what is required for Guerbet coupling $(613 \mathrm{~K}$ to $673 \mathrm{~K})$ indicates that dehydrogenation determins what temperature the reaction will occur. This conclusion is in good agreement with the fact that adding a transition metal capable of dehydrogenation can greatly reduce the temperature that Guerbet coupling occurs. ${ }^{26}$ Once the reaction network is initiated, it is likely that the aldol condensation and MPV-like hydrogenation occur rapidly. The relative rates of the initial dehydrogenation of ethanol and the aldol condensation/crotonaldehyde hydrogenation cycle could be what determines the overall activity of 
the catalyst. The high rate of ethanol coupling and the high selectivity toward butanol observed over HAP is likely due to the fact that it is able to more efficiently catalyze the aldol condensation/crotonaldehyde hydrogenation cycle.

\subsection{Future Work}

At this point, the mechanism of the Guerbet coupling reaction is well known. It appears as though the overall rate and selectivity of the reaction network is base on subtle changes in the rates of very fast steps (i.e. aldol condensation, hydrogenation, double bond isomerization) that result in either more or less efficient propagation of the aldol condensation/crotonaldehyde hydrogenation cycle. No conclusive reason was found for the high activity and selectivity of HAP versus $\mathrm{MgO}$, likely due to the fact that large changes in activity and selectivity can be caused by small changes in the rates of the elementary steps. Further, measurement of these rates proved to be very difficult. Deactivation occurs when carbonyl compounds are present making it difficult to collect accurate kinetics of steps involving these compounds.

Because of this, future work on this topic should include the study of new reactions, or further characterization of acid-base properties. A very similar reaction to Guerbet coupling, known as the Lebedev reaction, could be studied using similar techniques and materials. The Lebedev reaction involves the coupling of two ethanol molecules to 1,3-butadiene. It is thought the reaction proceeds through a very similar mechanism to Guerbet coupling, consisting of dehydrogenation, aldol condensation, hydrogenation, and dehydration reactions. Studying this reaction, and the difference in acid-base properties of the catalyst that catalyze the Lebedev reaction versus the Guerbet 
reaction, could be interesting and provide useful insight into acid-base catalyst structure-function relationships.

Another direction the project could take is the investigation of new materials. Previous work showed that alkaline earth metal phosphates were able to catalyze the Guerbet coupling reaction. This group of catalysts present interesting opportunities to investigate acid-base catalysis. By changing the cation, the acid base properties can be subtly changes, which can result in large changes in activity and selectivity. 


\section{References}

(1) Guerbet, M. Action de l'alcool amylique de fermentation sur son dérivé iodé. C.R. Acad. Sci. Paris 1899, 1002.

(2) Kozlowski, J. T.; Davis, R. J. Heterogeneous Catalysts for the Guerbet Coupling of Alcohols. ACS Catalysis 2013, 3, 1588-1600.

(3) Savage, N. The Ideal Biofuel. Nature 2011, 474, S9-S11.

(4) Kozlowski, J. T.; Behrens, M.; Schlögl, R.; Davis, R. J. Influence of the precipitation method on acid-base-catalyzed reactions over Mg-Zr mixed oxides. ChemCatChem 2013, 5, 19891997.

(5) Di Cosimo, J.; Diez, V.; Xu, M.; Iglesia, E.; Apesteguia, C. Structure and Surface and Catalytic Properties of Mg-Al Basic Oxides. Journal of Catalysis 1998, 178, 499-510.

(6) Yang, C.; Meng, Z. Bimolecular Condensation of Ethanol to 1-Butanol Catalyzed by Alkali Cation Zeolites. Journal of Catalysis 1993, 142, 37-44.

(7) Tsuchida, T.; Sakuma, S.; Takeguchi, T.; Ueda, W. Direct Synthesis of n-Butanol from Ethanol over Nonstoichiometric Hydroxyapatite. Industrial \& Engineering Chemistry Research 2006, 45, 8634-8642. 
(8) Tsuchida, T.; Kubo, J.; Yoshioka, T.; Sakuma, S.; Takeguchi, T.; Ueda, W. Reaction of ethanol over hydroxyapatite affected by $\mathrm{Ca} / \mathrm{P}$ ratio of catalyst. Journal of Catalysis $\mathbf{2 0 0 8 ,}$ $259,183-189$.

(9) Ogo, S.; Onda, A.; Yanagisawa, K. Selective synthesis of 1-butanol from ethanol over strontium phosphate hydroxyapatite catalysts. Applied Catalysis A: General 2011, 402, 188-195.

(10) Ogo, S.; Onda, A.; Iwasa, Y.; Hara, K.; Fukuoka, A.; Yanagisawa, K. 1-Butanol synthesis from ethanol over strontium phosphate hydroxyapatite catalysts with various $\mathrm{Sr} / \mathrm{P}$ ratios. Journal of Catalysis 2012, 296, 24-30.

(11) Ho, C. R.; Shylesh, S.; Bell, A. T. Mechanism and Kinetics of Ethanol Coupling to Butanol over Hydroxyapatite. ACS Catalysis 2016, 6, 939-948.

(12) Moteki, T.; Flaherty, D. W. Mechanistic Insight to C-C Bond Formation and Predictive Models for Cascade Reactions among Alcohols on Ca- and Sr-Hydroxyapatites. ACS Catalysis 2016, 6, 4170-4183.

(13) Birky, T. W.; Kozlowski, J. T.; Davis, R. J. Isotopic transient analysis of the ethanol coupling reaction over magnesia. Journal of Catalysis 2013, 298, 130-137.

(14) Laurencin, D.; Almora-Barrios, N.; de Leeuw, N. H.; Gervais, C.; Bonhomme, C.; Mauri, F.; Chrzanowski, W.; Knowles, J. C.; Newport, R. J.; Wong, A.; Gan, Z.; Smith, M. E. Magnesium incorporation into hydroxyapatite. Biomaterials 2011, 32, 1826-37.

(15) Sugiyama, S.; Moffat, J. B. The conversion of methanol: A probe reaction for hydroxyapatite. Catalysis Letters 2001, 76, 75-80. 
(16) Flora, N. J.; Hamilton, K. W.; Schaeffer, R. W.; Yoder, C. H. A Comparative Study of the Synthesis of Calcium, Strontium, Barium, Cadmium, and Lead Apatites in Aqueous Solution. Synthesis and Reactivity in Inorganic and Metal-Organic Chemistry 2004, 34, 503521.

(17) Yasukawa, A.; Nakajima, M.; Kandori, K.; Ishikawa, T. Preparation and Characterization of Carbonated Barium Hydroxyapatites Effect of Washing. Journal of colloid and interface science 1999, 212, 220-227.

(18) Ramesh, K.; Ling, E. G. Y.; Gwie, C. G.; White, T. J.; Borgna, A. Structure and Surface Reactivity of WO42-, SO42-, PO43- Modified Ca-Hydroxyapatite Catalysts and Their Activity in Ethanol Conversion. Journal of Physical Chemistry C 2012, 116, 18736-18745.

(19) Zhu, Y.; Zhang, X.; Long, F.; Liu, H.; Qian, M.; He, N. Synthesis and characterization of arsenate/phosphate hydroxyapatite solid solution. Materials Letters 2009, 63, 1185-1188.

(20) Elliott, J. C., Structure and Chemistry of the Apatites and Other Calcium Orthophosphates; Stereochemistry of Organometallic and Inorganic Compounds; ELSEVIER SCIENCE \& TECHNOLOGY: 1994.

(21) McKenzie, A. L.; Fishel, C. T.; Davis, R. J. Investigation of the surface structure and basic properties of calcined hydrotalcites. Journal of Catalysis 1992, 138, 547-561.

(22) Rekoske, J. E.; Barteau, M. a. Kinetics, Selectivity, and Deactivation in the Aldol Condensation of Acetaldehyde on Anatase Titanium Dioxide. Industrial \& Engineering Chemistry Research 2011, 50, 41-51. 
(23) Ordomsky, V. V.; Sushkevich, V. L.; Ivanova, I. I. Study of acetaldehyde condensation chemistry over magnesia and zirconia supported on silica. Journal of Molecular Catalysis A: Chemical 2010, 333, 85-93.

(24) Hattori, H.; Tanaka, Y.; Tanabe, K. Hydrogenation of Olefins Catalyzed by Alkaline Earth Metal Oxides. Chemistry Letters 1975, 659-660.

(25) Tanaka, Y.; Hattori, H.; Tanabe, K. Selective Hydrogenation of 1, 3-Butadiene Over Alkaline Earth Metal Oxides. Chemistry Letters 1976, 37-38.

(26) Gines, M. J. L.; Iglesia, E. Bifunctional condensation reactions of alcohols on basic oxides modified by copper and potassium. Journal of Catalysis 1998, 176, 155-172.

(27) Ndou, A.; Plint, N.; Coville, N. Dimerisation of ethanol to butanol over solid-base catalysts. Applied Catalysis A: General 2003, 251, 337-345.

(28) Chieregato, A.; Velasquez Ochoa, J.; Bandinelli, C.; Fornasari, G.; Cavani, F.; Mella, M. On the chemistry of ethanol on basic oxides: revising mechanisms and intermediates in the Lebedev and Guerbet reactions. ChemSusChem 2015, 8, 377-88.

(29) A.S. Ndou; Coville, N. Self-condensation of propanol over solid-base catalysts. Applied Catalysis A: General 2004, 275, 103-110.

(30) Scalbert, J.; Thibault-Starzyk, F.; Jacquot, R.; Morvan, D.; Meunier, F. Ethanol condensation to butanol at high temperatures over a basic heterogeneous catalyst: How relevant is acetaldehyde self-aldolization? Journal of Catalysis 2014, 311, 28-32. 
(31) Hanspal, S.; Young, Z. D.; Prillaman, J. T.; Davis, R. J. Influence of surface acid and base sites on the Guerbet coupling of ethanol to butanol over metal phosphate catalysts. Journal of Catalysis 2017, 352, 182-190.

(32) Cardona-Martinez, N.; Dumesic, J. A. In, D.D. Eley, H. P., Weisz, P. B., Eds.; Advances in Catalysis, Vol. 38; Academic Press: 1992, pp 149-244.

(33) Di Cosimo, J.; Apesteguía, C.; Ginés, M.; Iglesia, E. Structural requirements and reaction pathways in condensation reactions of alcohols on MgyAlOx catalysts. Journal of Catalysis 2000, 190, 261-275.

(34) Bardin, B. B.; Bordawekar, S. V.; Neurock, M.; Davis, R. J. Acidity of Keggin-Type Heteropolycompounds Evaluated by Catalytic Probe Reactions, Sorption Microcalorimetry, and Density Functional Quantum Chemical Calculations. The Journal of Physical Chemistry B 1998, 102, 10817-10825.

(35) Emeis, C. Determination of Integrated Molar Extinction Coefficients for Infrared Absorption Bands of Pyridine Adsorbed on Solid Acid Catalysts. Journal of Catalysis 1993, 141, $347-354$.

(36) Bordawekar, S.; Doskocil, E.; Davis, R. Microcalorimetric study of CO2 and NH3 adsorption on Rb-and Sr-modified catalyst supports. Langmuir 1998, 14, 1734-1738.

(37) Bordawekar, S. V.; Davis, R. J. Probing the Basic Character of Alkali-Modified Zeolites by $\mathrm{CO} 2$ Adsorption Microcalorimetry, Butene Isomerization, and Toluene Alkylation with Ethylene. Journal of Catalysis 2000, 189, 79-90.

Auroux, A.; Gervasini, A. Microcalorimetric study of the acidity and basicity of metal oxide surfaces. J. Phys. Chem. 1990, 94, 6371-6379. 
(39) Hanspal, S.; Young, Z. D.; Shou, H.; Davis, R. J. Multiproduct Steady-State Isotopic Transient Kinetic Analysis of the Ethanol Coupling Reaction over Hydroxyapatite and Magnesia. ACS Catalysis 2015, 5, 1737-1746.

(40) Hill, I. M.; Hanspal, S.; Young, Z. D.; Davis, R. J. DRIFTS of Probe Molecules Adsorbed on Magnesia, Zirconia, and Hydroxyapatite Catalysts. Journal of Physical Chemistry C 2015, 119, 9186-9197.

(41) Ordóñez, S.; Díaz, E.; León, M.; Faba, L. Hydrotalcite-derived mixed oxides as catalysts for different $\mathrm{C}-\mathrm{C}$ bond formation reactions from bioorganic materials. Catalysis Today 2011, $167,71-76$.

(42) Tsuchida, T.; Kubo, J.; Yoshioka, T.; Sakuma, S.; Takeguchi, T.; Ueda, W. Influence of Preparation Factors on Ca/P Ratio and Surface Basicity of Hydroxyapatite Catalyst. Journal of the Japan Petroleum Institute 2009, 52, 51-59.

(43) Kibby, C. L.; Hall, W. K. Dehydrogenation of alcohols and hydrogen transfer from alcohols to ketones over hydroxyapatite catalysts. J. Catal. 1973, 31, 65-73.

(44) Biaglow, A. A 13C NMR Study of the Condensation Chemistry of Acetone and Acetaldehyde Adsorbed at the Brønsted Acid Sites in H-ZSM-5. Journal of Catalysis 1995, 151, $373-384$.

(45) Dumitriu, E.; Hulea, V.; Chelaru, C.; Catrinescu, C.; Tichit, D.; Durand, R. Influence of the acid-base properties of solid catalysts derived from hydrotalcite-like compounds on the condensation of formaldehyde and acetaldehyde. Applied Catalysis A: General 1999, 178, $145-157$. 
(46) Tichit, D.; Lutic, D.; Coq, B.; Durand, R.; Teissier, R. The aldol condensation of acetaldehyde and heptanal on hydrotalcite-type catalysts. Journal of Catalysis 2003, 219, 167-175.

(47) Abelló, S.; Medina, F.; Tichit, D.; Pérez-Ramírez, J.; Groen, J. C.; Sueiras, J. E.; Salagre, P.; Cesteros, Y. Aldol condensations over reconstructed Mg-Al hydrotalcites: structure-activity relationships related to the rehydration method. Chem. Eur. J. 2005, 11, 728-39.

(48) Sharma, S. K.; Parikh, P. a.; Jasra, R. V. Solvent free aldol condensation of propanal to 2-methylpentenal using solid base catalysts. Journal of Molecular Catalysis A: Chemical 2007, 278, 135-144.

(49) Reichle, W. Pulse microreactor examination of the vapor-phase aldol condensation of acetone. Journal of Catalysis 1980, 63, 295-306.

(50) Shen, W.; Tompsett, G. a.; Xing, R.; Curtis Conner, W.; Huber, G. W. Vapor phase butanal self-condensation over unsupported and supported alkaline earth metal oxides. Journal of Catalysis 2012, 286, 248-259.

(51) Raskó, J.; Kiss, J. Adsorption and surface reactions of acetaldehyde on $\mathrm{TiO} 2, \mathrm{CeO} 2$ and A12O3. Applied Catalysis A: General 2005, 287, 252-260.

(52) Di Cosimo, J.; Diez, V.; Apesteguia, C. Base catalysis for the synthesis of [alpha],[beta]unsaturated ketones from the vapor-phase aldol condensation of acetone. Applied Catalysis A: General 1996, 137, 149-166.

(53) Ai, M. Formation of Acrylaldehyde by Vapor-Phase Aldol Condensation I. Basic Oxide Catalysts. Bull. Chem. Soc. Jpn. 1991, 64, 1342-1345. 
(54) Luo, S.; Falconer, J. L. Acetone and Acetaldehyde Oligomerization on TiO2 Surfaces. Journal of Catalysis 1999, 185, 393-407.

(55) Idriss, H.; Diagne, C.; Hindermann, J.; Kiennemann, A.; Barteau, M. Reactions of Acetaldehyde on $\mathrm{CeO} 2$ and CeO2-Supported Catalysts. Journal of Catalysis 1995, 155, 219-237.

(56) Rodrigues, E. G.; Keller, T. C.; Mitchell, S.; Pérez-Ramírez, J. Hydroxyapatite, an exceptional catalyst for the gas-phase deoxygenation of bio-oil by aldol condensation. Green Chem. 2014, 16, 4870-4874.

(57) Kozlowski, J. T.; Aronson, M. T.; Davis, R. J. Transesterification of tributyrin with methanol over basic Mg:Zr mixed oxide catalysts. Applied Catalysis B: Environmental 2010, 96, 508515.

(58) Doskocil, E. J.; Bordawekar, S. V.; Davis, R. J. Alkali-Support Interactions on Rubidium Base Catalysts Determined by XANES, EXAFS, CO2Adsorption, and IR Spectroscopy. Journal of Catalysis 1997, 169, 327-337.

(59) Forzatti, P.; Lietti, L. Catalyst Deactivation. Catalysis Today 1999, 52, 165-181.

(60) Rekoske, J. E.; Barteau, M. A. Competition between acetaldehyde and crotonaldehyde during adsorption and reaction on anatase and rutile titanium dioxide. Langmuir 1999, 15, 2061-2070.

(61) Peng, X.; Barteau, M. Adsorption of formaldehyde on model magnesia surfaces: evidence for the Cannizzaro reaction. Langmuir 1989, 5, 1051-1056. 
(62) Tanaka, H.; Watanabe, T.; Masatoshi Chikazawa, A. FTIR and TPD studies on the adsorption of pyridine, n-butylamineand acetic acid on calcium hydroxyapatite. Journal of the Chemical Society, Faraday Transactions 1997, 93, 4377-4381.

(63) Hattori, H.; Tanaka, Y. A novel catalytic property of magnesium oxide for hydrogenation of 1, 3-butadiene. Journal of the American 1976, 4652, 4652-4653.

(64) Claus, P. Heterogeneously catalysed hydrogenation using gold catalysts. Applied Catalysis A: General 2005, 291, 222-229.

(65) Tezuka, M.; Inoue, Y.; Yasumori, I. Catalysis by Alkaline Earth Metal Oxides. II. The Mechanism of Ethylene Hydrogenation on Magnesium Oxides. Bull. Chem. Soc. Jpn. 1981, 54, 2515.

(66) Hattori, H. Heterogeneous Basic Catalysis. Chemical reviews 1995, 95, 537-558.

(67) Boudart, M.; Delbouille, A.; Derouane, E. Activation of hydrogen at 78. deg. K on paramagnetic centers of magnesium oxide. Journal of the American Chemical Society 1972, 2312, $6622-6630$.

(68) Augustine, R. L.; Yaghmaie, F.; Peppen, J. F. V. Heterogeneous Catalysis in Organic Chemistry. 2. A Mechanistic Comparitosn of Noble-Metal Catalysts in Olefin Hydrogenation. $J$ Org Chem 1984, 1865-1870.

(69) Young, Z. D.; Hanspal, S.; Davis, R. J. Aldol Condensation of Acetaldehyde over Titania, Hydroxyapatite, and Magnesia. ACS Catalysis 2016, 6, 3193-3202. 
(70) Wang, S.; Goulas, K.; Iglesia, E. Condensation and esterification reactions of alkanals, alkanones, and alkanols on TiO2: Elementary steps, site requirements, and synergistic effects of bifunctional strategies. Journal of Catalysis 2016, 340, 302-320.

(71) Diez, V.; Apesteguía, C.; Di Cosimo, J. Acid-base properties and active site requirements for elimination reactions on alkali-promoted $\mathrm{MgO}$ catalysts. Catalysis today 2000, 63, 53-62.

(72) Inoue, Y.; Yasumori, I. Catalysis by alkaline earth metal oxides. III. X-ray photoelectron spectroscopic study of catalytically active $\mathrm{MgO}, \mathrm{CaO}$, and $\mathrm{BaO}$ surfaces., 1981 .

(73) Woolley, H. W.; Scott, R. B.; Brickwedde, F. G. Compilation of thermal properties of hydrogen in its various isotopic and ortho-para modifications. Journal of research of the National Bureau of Standards 1948, 41, 379-475.

(74) Fishel, C. T.; Davis, R. J. Use of catalytic reactions to probe Mg-Al mixed oxide surfaces. Catalysis Letters 1994, 25, 87-95. 


\section{Appendix A}

\section{Adsorption Microcalorimeter Schematic}

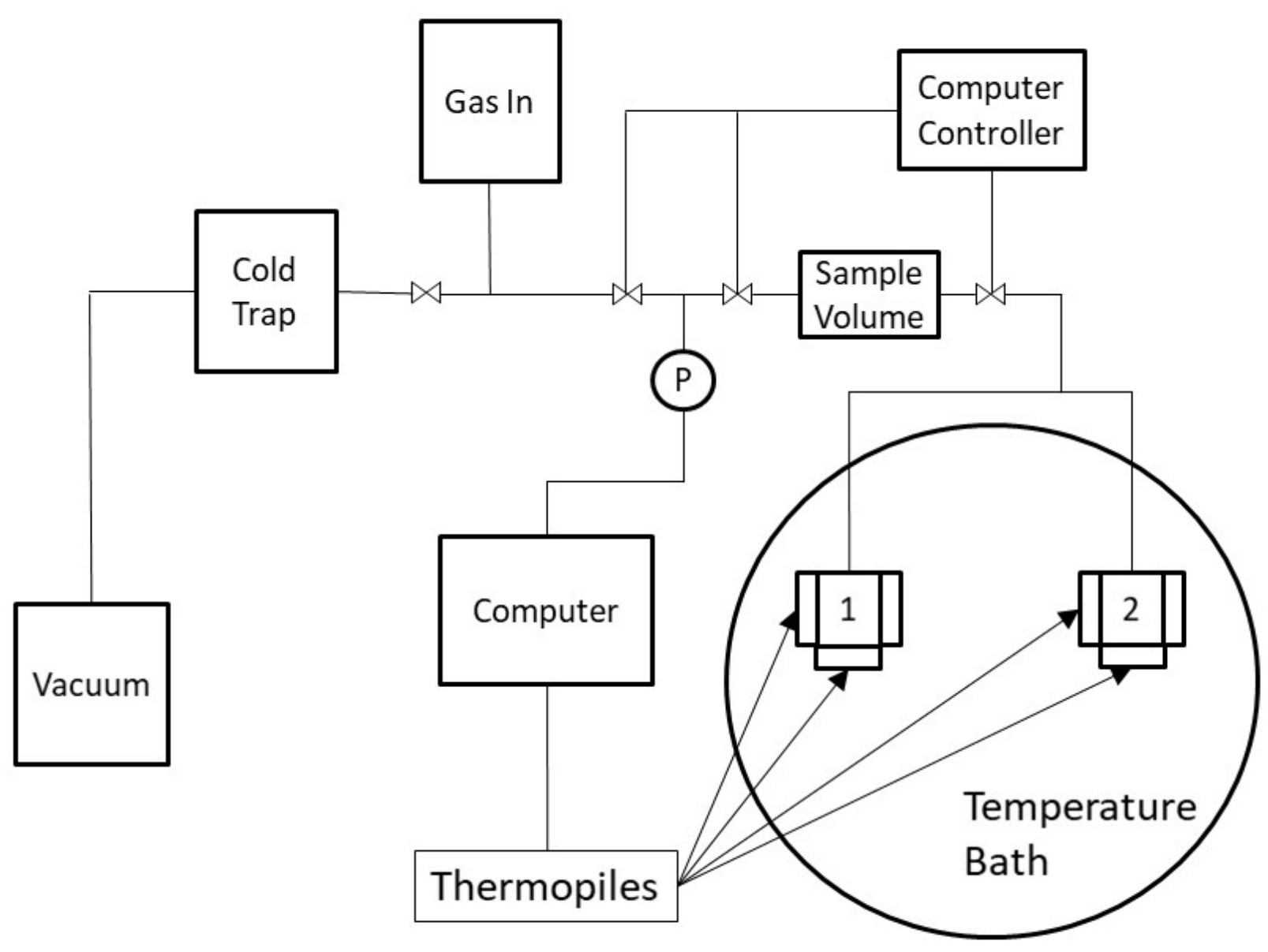




\section{Appendix B}

\section{Flow Reactor Schematic}

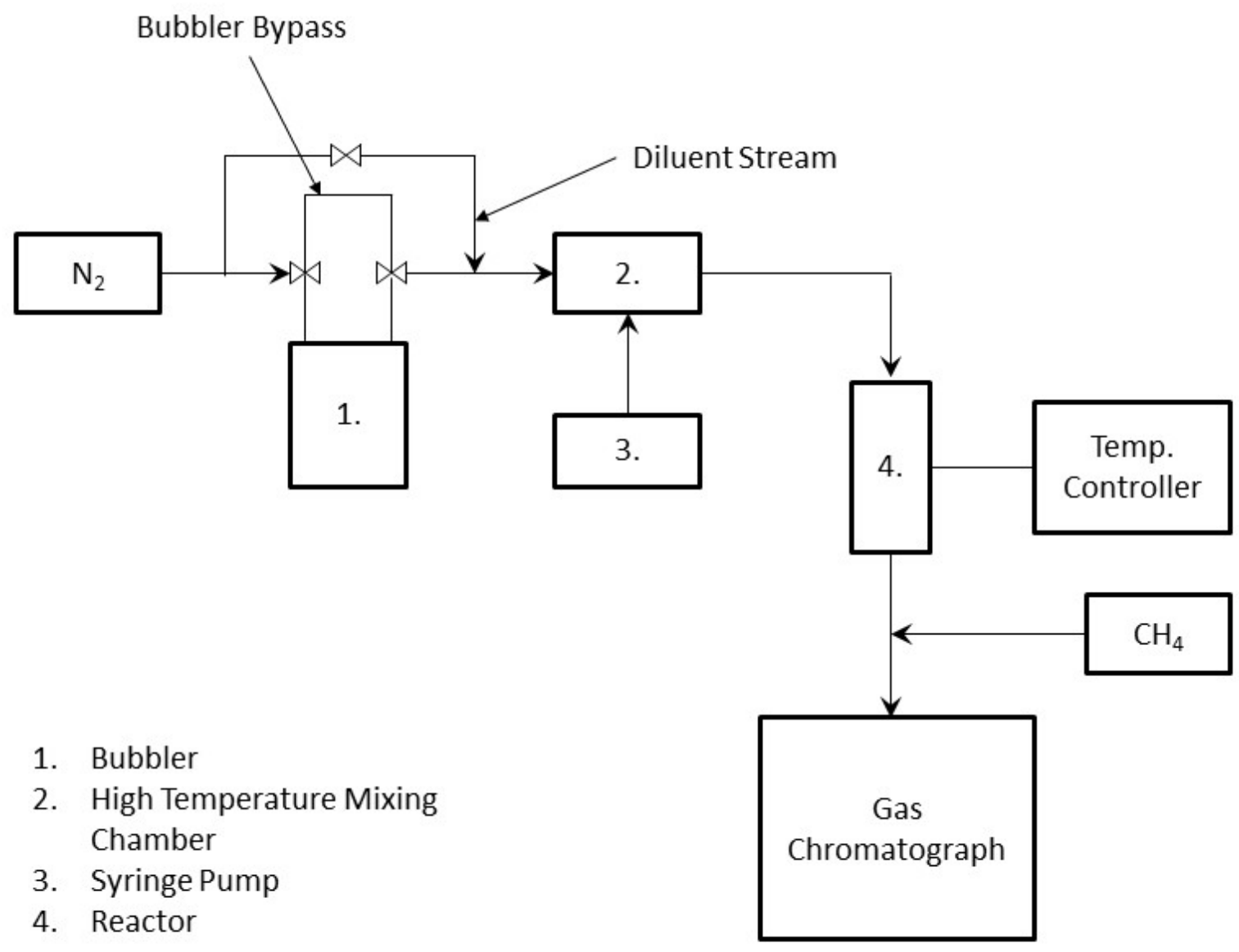




\title{
Appendix C
}

\section{The Effect of Hydroxyapatite Cation}

\section{Substitution on the Guerbet Coupling of}

\section{Ethanol}

\author{
Abstract \\ The effect of altering the cation of calcium hydroxyapatite $\left(\mathrm{Ca}_{10}\left(\mathrm{PO}_{4}\right)_{6}(\mathrm{OH})_{2}\right)$ on \\ the Guerbet coupling of ethanol to 1-butanol was studied by partially substituting $\mathrm{Mg}^{2+}$ \\ and fully substituting $\mathrm{Sr}^{2+}$ and $\mathrm{Ba}^{2+}$ for the $\mathrm{Ca}^{2+}$ ion. The substituted hydroxyap- \\ atites were characterized by dinitrogen physisorption, X-ray diffraction (XRD), X-ray \\ photoelectron spectroscopy (XPS), inductively coupled plasma optical emission spec- \\ troscopy (ICP-OES), and carbon dioxide $\left(\mathrm{CO}_{2}\right)$ and triethylamine (TEA) adsorption \\ microcalorimetry. The activity and selectivity of the substituted hydroxyapatites were
}


determined by flowing gaseous ethanol over the catalysts in a fixed bed reactor. Calcium hydroxyapatite (CaHAP) was the most active catalyst and had the highest selectivity to 1-butanol. Significant differences in activity and selectivity were observed between magnesium calcium hydroxyapatite (MgCaHAP) and $\mathrm{CaHAP}$ despite the low weight percentage of magnesium (0.6 wt.\%). Barium hydroxyapatite (BaHAP) was unstable at high temperatures and had lower activity and selectivity to 1-butanol than CaHAP. Strontium hydroxyapatite (SrHAP) had a similar rate of ethanol consumption and a much higher selectivity to acetaldehyde than CaHAP. The activity of strontium oxide ( $\mathrm{SrO}$ ) was tested and compared to magnesium oxide $(\mathrm{MgO})$, and calcium oxide $(\mathrm{CaO})$. Strontium oxide had a higher rate of ethanol consumption than $\mathrm{MgO}, \mathrm{CaO}$, or SrHAP and the only observed product was acetaldehyde. The difference in surface properties and reactivity between SrHAP and CaHAP could be due to the presence of SrO on the surface of SrHAP.

\section{C.1 Introduction}

Apatite can easily take on non-stoichiometric forms and is ammenable to cation and anion substitution. The hydroxyl, fluoride, and chloride anions, $\mathrm{Mg}^{2+}, \mathrm{Sr}^{2+}, \mathrm{Ba}^{2+}, \mathrm{Pb}^{2+}, \mathrm{Cd}^{2+}$, and other metal cations, as well as vanadate, arsenate, carbonate, and sulfate have all been observed in the apatite structure. ${ }^{1-8}$ Additionally HAP can take on a variety of non stoichiometric forms. Both calcium deficient hydroxyapatites with the chemical formula $\mathrm{Ca}_{10-z}\left(\mathrm{HPO}_{4}\right)_{z}\left(\mathrm{PO}_{4}\right)_{6-z}(\mathrm{OH})_{2-z}$ where $0<z \leq 1$ and calcium rich $(\mathrm{Ca} / \mathrm{P}>1.67)$ hydroxyapatites have been reported. ${ }^{8}$ The composition 
of the calcium rich hydroxyapatites is not well understood, but it is thought that these materials are mixtures of hydroxyapatite with $\mathrm{Ca}(\mathrm{OH})_{2}$ or $\mathrm{CaCO}_{3} .{ }^{8}$ Because HAP does not alywas take on a stoichiometric $\mathrm{Ca} / \mathrm{P}$, the surface composition of hydroxyapatite is often different from the bulk compositon. ${ }^{9}$ Typically, the surface calcium to phosphorus ratio of CaHAP is lower than the bulk calcium to phosphate ratio. ${ }^{10}$

Magnesium substituted hydroxyapatites have been studied because low amounts of magnesium are commonly found in hydroxyapatite isolated from bone and tooth. ${ }^{1,11}$ A fully substituted magnesium hydroxyapatite has been reported on two occasions, but this synthesis has never been repeated. ${ }^{11-14}$ Hydroxyapatites that have high amounts of magnesium are very unstable and phase separate into the mineral whitlockite at high temperature. ${ }^{14}$ This decomposition can take place with as little as $0.6 \mathrm{wt} . \%$ of magnesium at $1273 \mathrm{~K} .{ }^{14}$ Magnesium calcium HAP (MgCaHAP) with higher amounts of magnesium can be synthesized, but it typically has a much lower crystallinity than calcium containing HAP (CaHAP). The structure of MgCaHAP becomes completely amorphous with 8 wt.\% magnesium. ${ }^{15}$ The HAP structure has two non equivalent Ca sites (CaI and CaII). Both theoretical and experimental studies have shown that the magnesium ions that incorporate into the hydroxyapatite structure are preferentially found in the CaII site. ${ }^{1,16}$ The preference for the CaII site is likely due to the fact that $\mathrm{CaII}$ is bound to fewer oxygen atoms making it more favorable to the smaller ionic radius of $\mathrm{Mg}^{2+} \cdot{ }^{16}$ Changes in the basicity of hydroxyapatite have been observed when even a small weight percentage of magnesium is added. ${ }^{17}$

Unlike MgCaHAP, fully substituted barium hydroxyapatite (BaHAP, $\left.\mathrm{Ba}_{10}\left(\mathrm{PO}_{4}\right)_{6}(\mathrm{OH})_{2}\right)$ has been reported. ${ }^{4}$ Barium substituted hydroxyapatite has been used as a potential ion exchange material for waste water treatment as well as a catalyst for alkane oxidation. ${ }^{2,18,19}$ While BaHAP has 
been synthesized, tribarium phosphate $\left(\mathrm{Ba}_{3}\left(\mathrm{PO}_{4}\right)_{2}\right)$ is the preferred precipitation product below $\mathrm{pH}$ $12 .^{3}$

To our knowledge, as of this writing neither magnesium nor barium substituted hydroxyapatite has been tested for ethanol coupling, but this reaction has been studied with CaHAP and SrHAP. Guerbet coupling of ethanol over calcium hydroxyapatite was first studied by Tsuchida et al. ${ }^{20}$ who reported both high activity and high selectivity to 1-butanol over near stoichiometric hydroxyapatite $(\mathrm{Ca} / \mathrm{P}=1.67)$. Later, the same group reported that altering the stoichiometry of CaHAP had an effect on the rate and selectivity of ethanol coupling. ${ }^{10}$

Ogo et al. ${ }^{21}$ studied how changing the chemical makeup of hydroxyapatite could lead to changes in activity. They used both strontium and vanadate $\left(\mathrm{VO}_{4}{ }^{3-}\right)$ to compare CaHAP, calcium vanadate hydroxyapatite, strontium hydroxyapatite $\left(\operatorname{SrHAP},\left(\mathrm{Sr}_{10}\left(\mathrm{PO}_{4}\right)_{6}(\mathrm{OH})_{2}\right)\right)$, and strontium vanadate hydroxyapatite. Both calcium vanadate hydroxyapatite and strontium vanadate hydroxyapatite showed increased selectivity towards ethene while SrHAP showed increased selectivity to 1-butanol when compared to calcium hydroxyapatite. The effect of altering the stoichiometry of SrHAP was studied by Ogo et al. ${ }^{5}$ as well, and they found changes to the stoichiometry of SrHAP affected the activity of the catalyst.

Presumably, the reason hydroxyapatite is so effective at catalyzing Guerbet coupling of ethanol is because HAP contains a large number of moderate strength acid-base site pairs. Changing the stoichiometry as well as changing the ionic composition of hydroxyapatite can alter these properties. Surface properties and the kinetics of Guerbet coupling of ethanol were studied by comparing CaHAP to a set of cation substituted hydroxyapatites: MgCaHAP, SrHAP, and BaHAP. 
X-ray diffraction (XRD), X-ray photoelectron spectroscopy (XPS), nitrogen physisorption, and adsorption microcalorimetry were used to fully characterize the substituted hydroxyapatites. The characteristics of the substituted hydroxyapatites will then be compared to differences in activity for ethanol coupling.

\section{C.2 Materials and Methods}

\section{C.2.1 Catalyst Synthesis}

SrHAP was prepared using the same method as Tsuchida et al. ${ }^{20}$ replacing strontium nitrate for calcium nitrate. A copercipitation reaction was performed by cofeeding $0.5 \mathrm{M} \mathrm{Sr}\left(\mathrm{NO}_{3}\right)_{2}$ and $0.3 \mathrm{M}\left(\mathrm{NH}_{4}\right)_{2} \mathrm{HPO}_{4}$ to $100 \mathrm{~cm}^{3}$ of deionized water. Both solutions were $\mathrm{pH}$ adjusted to $10 \mathrm{using}$ $\mathrm{NH}_{4}(\mathrm{OH})$. The reaction mixture was held at a temperature of $358 \mathrm{~K}$ and the $\mathrm{pH}$ was maintained at 10 by adding $\mathrm{NH}_{4}(\mathrm{OH})$ throughout the reaction. The suspension was aged for $24 \mathrm{~h}$ while stirring at $358 \mathrm{~K}$. The resulting white powder was filtered and washed with deionized water three times. The washed precipitate was dried overnight at $393 \mathrm{~K}$ and then calcined at $873 \mathrm{~K}$ (ramp rate of $10 \mathrm{~K} \mathrm{~min}^{-1}$ ) under flowing air for $2 \mathrm{~h}$. The particles were then sieved to a size of $106 \mu \mathrm{m}$ to $180 \mu \mathrm{m}$.

MgCaHAP was synthesized in the same manner replacing the $0.5 \mathrm{M} \mathrm{Sr}\left(\mathrm{NO}_{3}\right)_{2}$ with a $0.5 \mathrm{M}$ solution of $\mathrm{Mg}\left(\mathrm{NO}_{3}\right)_{2}$ and $\mathrm{Ca}\left(\mathrm{NO}_{3}\right)_{2}$ with a molar $\mathrm{Mg} / \mathrm{Ca}$ ratio of 0.026 .

Barium substituted hydroxyapatite (BaHAP) was synthesized using the method described by Yasukawa et al. ${ }^{4}$ A neutralization reaction was carried out by adding 0.012 mol of $\mathrm{H}_{3} \mathrm{PO}_{4}$ diluted to 
approximately $1.5 \mathrm{wt} . \%$ in water to $0.04 \mathrm{~mol} \mathrm{Ba}(\mathrm{OH})_{2} \cdot 8 \mathrm{H}_{2} \mathrm{O}$ dissolved in $2000 \mathrm{~cm}^{3}$ of deionized water. The neutralization reaction was carried out at $373 \mathrm{~K}$ under flowing nitrogen. The $\mathrm{H}_{3} \mathrm{PO}_{4}$ solution was added very slowly to avoid a decrease in $\mathrm{pH}$. The suspension was aged for $16 \mathrm{~h}$ at $373 \mathrm{~K}$ under flowing nitrogen. The precipitate was then washed, calcined, and sized in the same manner as SrHAP.

\section{C.2.2 Characterization}

The surface areas of all catalysts were quantified by dinitrogen physisorption using a Micromeritics ASAP 2020 performed at liquid dinitrogen temperature. The surface area was calculated using the BET method. X-ray diffraction was carried out using a PANalytical X'Pert Pro MPD using $\mathrm{Cu}-\mathrm{K} \alpha$ radiation to determine if the synthesized catalysts were phase pure. X-ray photoelectron spectroscopy was performed to quantify the surface metal and phosphate concentration using a ThermoFisher ESCALab and Al-K $\alpha$ radiation. The calcium, magnesium, strontium, and barium concentrations were found by measuring the intensity and binding energy of $\mathrm{Ca} 2 \mathrm{p}, \mathrm{Mg} 1 \mathrm{~s}, \operatorname{Sr} 3 \mathrm{p}_{3 / 2}$, and $\mathrm{Ba}_{5 / 2}$. ICP-OES was used to determine the bulk molar metal to phosphorus $(\mathrm{M} / \mathrm{P})$ ratio of all the samples. ICP-OES was performed by Galbraith Laboratories (Knoxville, TN).

\section{C.2.3 Ethanol Coupling Reaction}

The reaction took place in a continuous flow fixed bed reactor at ambient pressure. The reactor was a stainless steel tube with an inner diameter of $0.58 \mathrm{~cm}$. A schematic of the reactor is shown in Appendix B. The catalyst was supported by a quartz wool bed. A liquid feed of 95 wt.\% ethanol 
and $5 \mathrm{wt} . \%$ octane (octane was used as an internal standard) was pumped to a mixing chamber with a syringe pump and diluted to a $7 \mathrm{~mol} \%$ ethanol vapor flow with $\mathrm{N}_{2}$. The products were analyzed with an Agilent 7890A GC with a Varian CP-Poraplot capillary column (25 m in length, $0.32 \mathrm{~mm}$ inner diameter) and a flame ionization detector. All catalysts were pretreated by heating to $773 \mathrm{~K}$ $\left(10 \mathrm{~K} \mathrm{~min}^{-1}\right.$ ramp rate) in flowing nitrogen for $2 \mathrm{~h}$ prior to reaction.

\section{C.2.4 Adsorption Microcalorimetry}

A custom built adsorption microcalorimeter described previously was used for adsorption microcalorimetry of $\mathrm{CO}_{2}$ and triethyl amine (TEA). ${ }^{22}$ A schematic of the adsorption microcalorimeter is shown in Appendix A. Each catalyst was heated to $773 \mathrm{~K}$ for $18 \mathrm{~h}$ under vacuum prior to adsorption. After cooling to room temperature, the sample cell was placed in a large aluminum block maintained at $303 \mathrm{~K}$. The sample was allowed to come to thermal equilibrium with the sample block for a $2 \mathrm{~h}$ period prior to adsorption. Each dose of probe molecule was allowed to equilibrate with the surface for $15 \mathrm{~min}$.

\section{C.3 Results and Discussion}

\section{C.3.1 Characterization}

The XRD patterns, shown in Figure C.1, of MgCaHAP and SrHAP were found to be identical to

those reported in literature. ${ }^{4,5,20}$ There is little difference between XRD patters of MgCaHAP and 
the CaHAP because very little magnesium is incorporated into the solid.

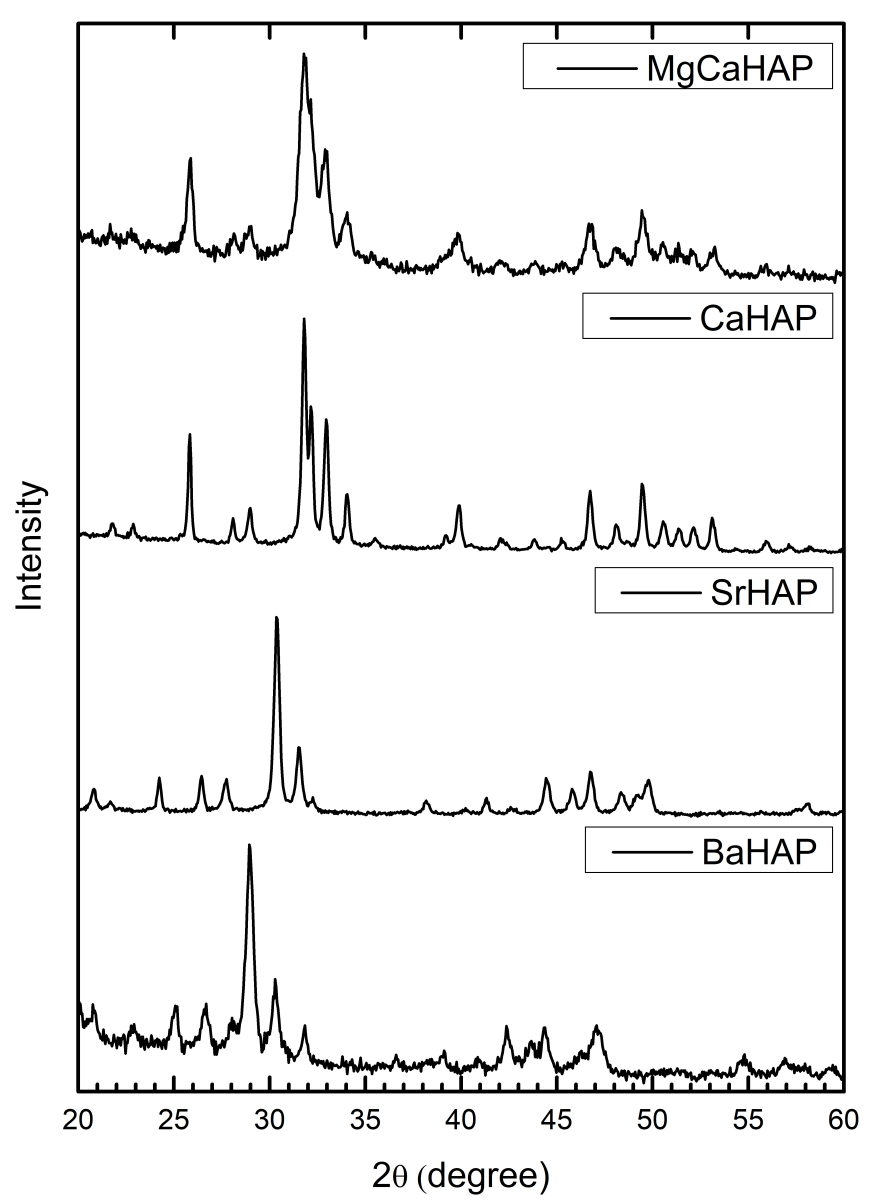

Figure C.1: The XRD patters of MgCaHAP, CaHAP, SrHAP, and BaHAP.

Originally, the synthesis of BaHAP was attempted using the same method as the other hydroxyapatites by substituting $\mathrm{Ba}\left(\mathrm{NO}_{3}\right)_{2}$ for $\mathrm{Ca}\left(\mathrm{NO}_{3}\right)_{2}$, but the resulting product was $\mathrm{Ba}_{3}\left(\mathrm{PO}_{4}\right)_{2}$ as determined by XRD (data not shown). To overcome this, a method developed by Yasukawa et al. ${ }^{4}$ described in the materials and methods section was used, and the resulting solid was thermally treated at $873 \mathrm{~K}$ for $1 \mathrm{~h}$. The resulting XRD pattern shown in Figure C. 1 contained the features of BaHAP, but there were two peaks at a $2 \theta$ of $29^{\circ}$ and $31^{\circ}$ that are attributed to $\mathrm{Ba}_{3}\left(\mathrm{PO}_{4}\right)_{2}$. To determine the source of $\mathrm{Ba}_{3}\left(\mathrm{PO}_{4}\right)_{2}$, $\mathrm{BaHAP}$ was synthesized using the same method without the 
thermal treatment. An XRD pattern of the solid was taken and no peaks associated with $\mathrm{Ba}_{3}\left(\mathrm{PO}_{4}\right)_{2}$ were observed. This implied that the BaHAP was partially converted to $\mathrm{Ba}_{3}\left(\mathrm{PO}_{4}\right)_{2}$ during the high temperature treatment. To determine if the BaHAP would be thermally stable under reaction conditions, the phase pure BaHAP was heated to $623 \mathrm{~K}$ for $18 \mathrm{~h}$ in flowing air. The XRD pattern of the heated sample contained the $\mathrm{Ba}_{3}\left(\mathrm{PO}_{4}\right)_{2}$ peaks, as shown in Figure C.2, indicating that the pure BaHAP is not stable at the temperature used for Guerbet coupling. Because the BaHAP was not stable under reaction temperatures, the BaHAP that was treated at $873 \mathrm{~K}$ and contained peaks associated with $\mathrm{Ba}_{3}\left(\mathrm{PO}_{4}\right)_{2}$ was used for the ethanol coupling reaction.

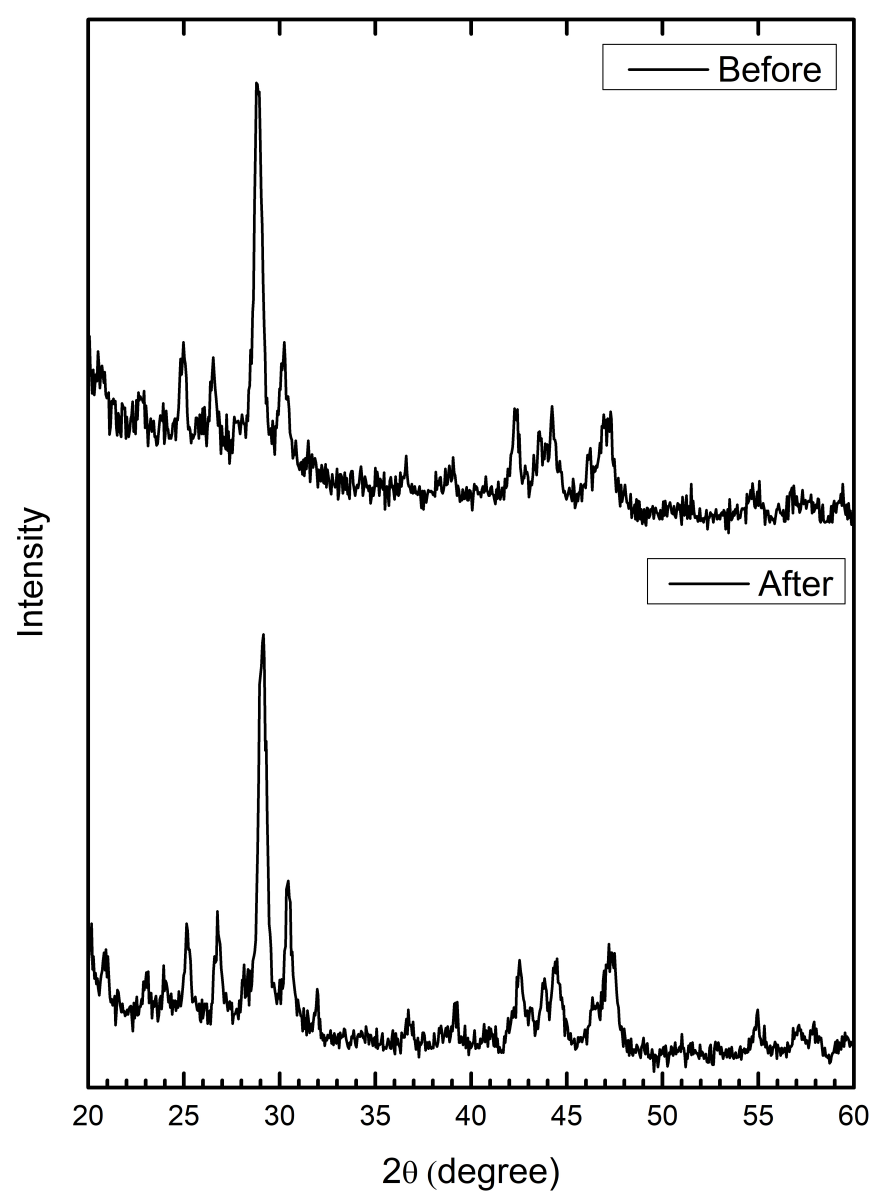

Figure C.2: The XRD patterns of BaHAP before (top) and after (bottom) heating at $623 \mathrm{~K}$. 
The bulk metal and phosphorus concentrations of SrHAP, MgCaHAP, and BaHAP were measured using ICP-OES and can be found in Table C.1. It can be seen that the MgCaHAP is stoichiometric with a molar $(\mathrm{Mg}+\mathrm{Ca}) / \mathrm{P}$ ratio of 1.67 . The magnesium to phosphorus ratio is much lower than the calcium to phosphorus ratio as expected based on the small amount of magnesium nitrate used in the synthesis. The synthesized MgCaHAP has a chemical formula of $\mathrm{Mg}_{0.24} \mathrm{Ca}_{9.76}\left(\mathrm{PO}_{4}\right)_{6}(\mathrm{OH})_{2}$ with a molar $\mathrm{Mg} / \mathrm{Ca}$ ratio of 0.025 . The SrHAP has a metal rich bulk phase with a molar Sr/P ratio of 1.75 as shown in Table C.1. The bulk ratio of BaHAP as measured by ICP-OES was 1.84 as shown in Table C.1. Like SrHAP, BaHAP is metal rich. The BaHAP has been shown to contain $\mathrm{Ba}_{3}\left(\mathrm{PO}_{4}\right)_{2}$ which has a fixed $\mathrm{Ba} / \mathrm{P}$ ratio of 1.50 . Large amounts of $\mathrm{Ba}_{3}\left(\mathrm{PO}_{4}\right)_{2}$ contamination would lead to barium hydroxyapatites with a $\mathrm{Ba} / \mathrm{P}$ near 1.5 , indicating that there is only a small amount of $\mathrm{Ba}_{3}\left(\mathrm{PO}_{4}\right)_{2}$ present in the sample.

Table C.1: M/P stands for the metal to phosphorous ratio, where the metal is indicated by the type of hydroxyapatite. $\mathrm{MgCaHAP}$ requires the full molar $\mathrm{M} / \mathrm{P}$ ratio and the molar $\mathrm{Mg} / \mathrm{P}$ ratio to be fully characterized because it has two metal ions.

\begin{tabular}{cccccc}
\hline Catalyst & $\begin{array}{c}\text { Surface } \\
\text { Area }^{\mathrm{a}} \\
\left(\mathrm{m}^{2} \mathrm{~g}^{-1}\right)\end{array}$ & $\begin{array}{c}\mathrm{Bulk} \\
\mathrm{M} / \mathrm{Pb}^{\mathrm{b}} \\
(\mathrm{Mg} / \mathrm{P})\end{array}$ & $\begin{array}{c}\text { Surface } \\
\mathrm{M} / \mathrm{P}^{\mathrm{c}} \\
(\mathrm{Mg} / \mathrm{P})\end{array}$ & $\begin{array}{c}\mathrm{CO}_{2} \\
\text { uptakes } \\
\left(\mu \mathrm{mol} \mathrm{m}^{-2}\right)\end{array}$ & $\begin{array}{c}\text { TEA } \\
\text { uptakes } \\
\left(\mu \mathrm{mol} \mathrm{m}^{-2}\right)\end{array}$ \\
\hline MgCaHAP & 35.6 & $\begin{array}{c}1.67 \\
(0.041)\end{array}$ & $\begin{array}{c}1.51 \\
(0.096)\end{array}$ & 1.1 & 0.50 \\
CaHAP & 34.9 & 1.67 & 1.46 & 2.4 & 1.6 \\
SrHAP & 32.2 & 1.75 & 1.90 & 0.67 & 1.8 \\
BaHAP & 15.8 & 1.84 & 1.32 & 0.97 & 2.1 \\
\hline
\end{tabular}

a: collected using BET

b: ICP-OES

c: XPS

The results from XPS of the different hydroxyapatites are also shown in Table C.1. The surface metal concentration of the MgCaHAP is lower than the bulk concentration with a molar M/P ratio of 1.51. This result is expected because it has been observed that the surface calcium con- 
centration of CaHAP tends to be lower than the bulk concentration. ${ }^{23}$ It would be expected that MgCaHAP would follow the same trend. The surface magnesium concentration is higher than the bulk magnesium concentration meaning that magnesium preferentially incorporated into surface sites. The SrHAP sample shows a surface molar Sr/P ratio of 1.90 as measured by XPS. The surface concentration of SrHAP is higher than both the bulk concentration of SrHAP and is above the stoichiometric value of 1.67 . This result is consistent with other observations of the surface concentration of SrHAP. ${ }^{5}$ The increased molar Sr/P ratio could indicate the SrHAP surface is significantly different from the CaHAP surface. A higher molar Sr/P ratio could be due to the presence of surface strontium oxide $(\mathrm{SrO})$. BaHAP showed a molar $\mathrm{Ba} / \mathrm{P}$ ratio of 1.32 which is both less than stoichiometric and less than the molar $\mathrm{Ca} / \mathrm{P}$ ratio of $\mathrm{CaHAP}$. The fact that the ratio is not 1.50 implies that the $\mathrm{Ba}_{3}\left(\mathrm{PO}_{4}\right)_{2}$ contamination is not a major component of the surface.

Both the surface coverage and the heats of adsorption of $\mathrm{CO}_{2}$ and triethylamine (TEA) were measured using microcalorimetry for the different hydroxyapatites. The coverage and heat of adsorption of these molecules are shown in Figure C.3. It is clear that there is chemical adsorption of both $\mathrm{CO}_{2}$ and TEA on all of the hydroxyapatites as indicated by a large change in coverage at very low pressures and large heats of adsorption at low coverage. Chemical adsorption of both probe molecules confirms that the surface has both acidic and basic sites. The amount of chemically adsorbed probe molecules (uptake) is given in Table C.1. The uptake was calculated by extrapolating the linear section of the isotherm at high pressure back to zero pressure.

The results of the $\mathrm{CO}_{2}$ adsorption microcalorimetry show some differences between the substituted hydroxyapatites. It is clear from Figure C.3 that $\mathrm{CaHAP}$ has the largest $\mathrm{CO}_{2}$ uptake, MgCaHAP and BaHAP have similar uptakes, and SrHAP has the lowest uptake. The heats of 

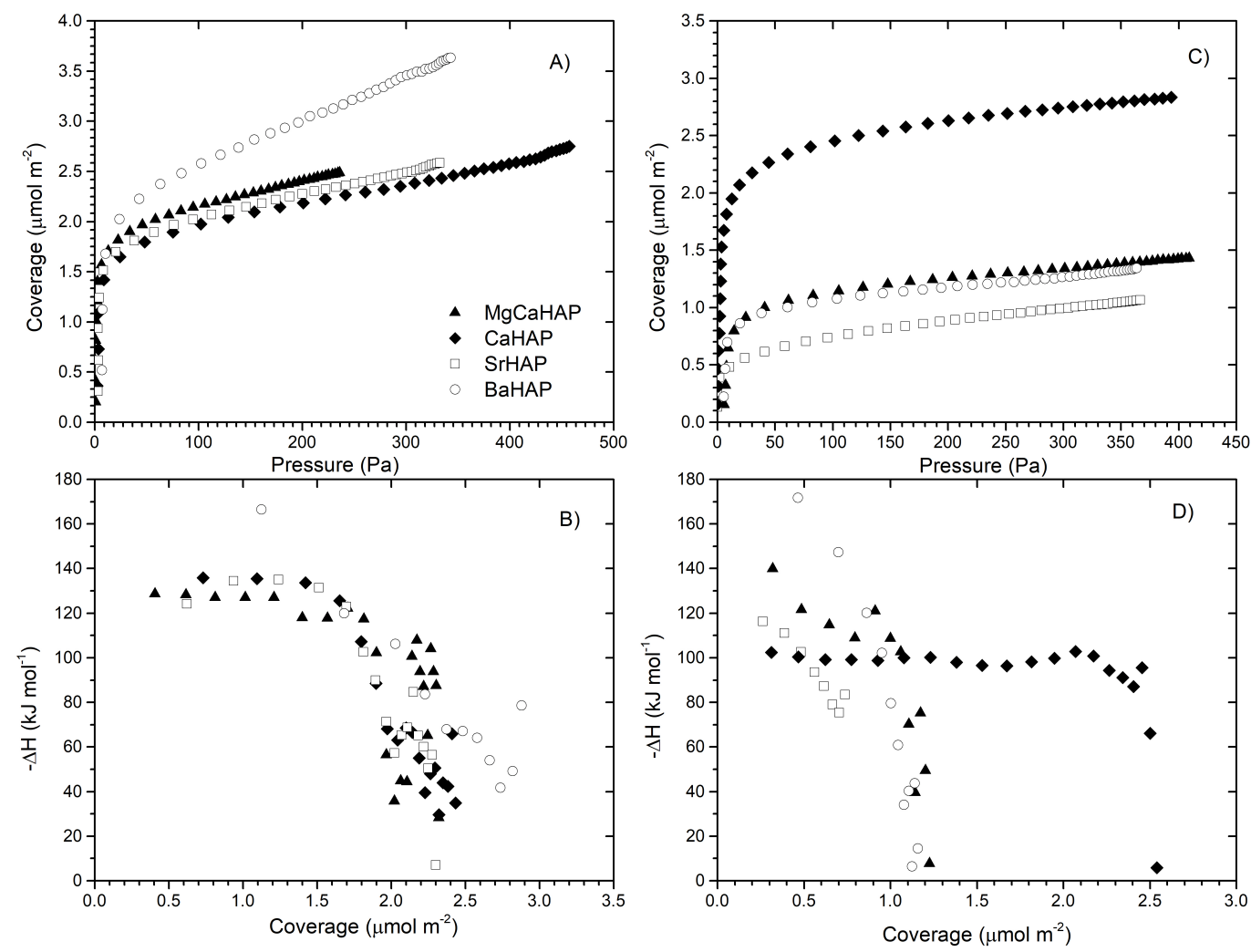

Figure C.3: The adsorption isotherms of the heat of adsorption for MgCaHAP, CaHAP, SrHAP, and BaHAP. A) Shows the TEA uptake. B) is the TEA heat of adsorption. C) is the $\mathrm{CO}_{2}$ uptake. D) is the $\mathrm{CO}_{2}$ heat of adsorption.

adsorption of the different samples also vary. The BaHAP has the highest heat of adsorption while the other hydroxyapatites have similar heats of adsorption. The MgCaHAP also had a relatively high initial heat of adsorption compared to CaHAP. The MgCaHAP sample also has a significantly lower $\mathrm{CO}_{2}$ uptake than the pure CaHAP despite the very low magnesium incorporation. Structurally, the MgCaHAP and the CaHAP are the most similar. Both MgCaHAP and CaHAP have identical bulk molar $\mathrm{M} / \mathrm{P}$ ratios and very similar surface molar M/P ratios. The XRD pattern of MgCaHAP and CaHAP has been shown to be identical to one another indicating that the structures are very similar. This could be due to the partitioning of the magnesium ions to the surface (Table 
C.1) resulting in a small number of strong base sites. The initial heat of adsorption of the SrHAP and CaHAP are similar, but SrHAP contains fewer $\mathrm{CO}_{2}$ adsorption sites.

Compared to CaHAP, SrHAP has a much lower $\mathrm{CO}_{2}$ uptake as shown in Figure C.3. This could be related to the increased surface metal content of SrHAP. BaHAP also has a $\mathrm{CO}_{2}$ uptake that is lower than CaHAP as shown in Figure C.3. Like SrHAP, BaHAP has a bulk molar M/P ratio that is above stoichiometric. Unlike SrHAP, this increased bulk molar M/P ratio does not lead to an increased surface molar $\mathrm{M} / \mathrm{P}$ ratio. In fact, the molar $\mathrm{M} / \mathrm{P}$ ratio of $\mathrm{BaHAP}$ is even lower than CaHAP. The decreased uptake is likely due to changes in the surface caused by the cation substitution leading to fewer $\mathrm{CO}_{2}$ binding sites.

The TEA microcalorimetry experiments also show differences between the hydroxyapatite uptakes, but very little difference between the heats of adsorption. The similarity between the heats of adsorption indicates that the cation does not affect the strength of the TEA binding site, only the number the sites with BaHAP containing the largest number of sites.

\section{C.3.2 Guerbet Coupling of Ethanol}

The rate of ethanol coupling of the substituted hydroxyapatites at $613 \mathrm{~K}$ are shown in Table C.2. CaHAP had both the highest rate of ethanol consumption and the highest selectivity to 1-butanol, making it the most effective catalysts for the Guerbet coupling of ethanol to 1-butanol. The major product over MgCaHAP is 1-butanol, but MgCaHAP has much less activity than CaHAP. For both SrHAP and BaHAP the major product is acetaldehyde with BaHAP having higher selective to 1butanol than SrHAP. The reactivity of SrHAP is greater than BaHAP and MgCaHAP but lower 
Table C.2: The reaction data for the different hydroxyapatites at $613 \mathrm{~K}$.

\begin{tabular}{ccccc}
\hline \multirow{2}{*}{ Catalyst } & $\begin{array}{c}\text { Ethanol } \\
\text { conversion }(\%)\end{array}$ & $\begin{array}{c}\text { Rate of ethanol } \\
\text { conversion } \\
\left.\text { (nmol m }{ }^{-2} \mathrm{~s}^{-1}\right)\end{array}$ & \multicolumn{2}{c}{ Selectivity (C\%) } \\
\cline { 4 - 6 } & 3.1 & 15 & Acetaldehyde & Butanol \\
\hline MgCaHAP & 3.3 & 32 & 23 & 63 \\
CaHAP & 3.1 & 20 & 64 & 37 \\
SrHAP & 2.7 & 2.0 & 57 & 43 \\
BaHAP & &
\end{tabular}

than CaHAP. Of the tested hydroxyapatites, BaHAP had the lowest activity.

There is a significant decrease in activity over MgCaHAP compared to CaHAP. This difference is likely due to subtle changes in the rate of the aldol condensation/hydrogenation cycle caused by the incorporation of $\mathrm{Mg}^{2+}$. The activity of SrHAP is the most similar to CaHAP, but the selectivities are drastically different. The rate of acetaldehyde production of SrHAP is almost twice the rate of ethanal production of CaHAP. Additionally, the rate of 1-butanol formation is a third that of CaHAP despite the higher rate of acetaldehyde formation. SrHAP is unique in the fact that the surface metal to phosphorus ratio is above the stoichiometric value of 1.67. This increased molar $\mathrm{Sr} / \mathrm{P}$ ratio could be explained by the presence of $\mathrm{SrO}$ on the surface.

The rate of ethanol conversion over $\mathrm{SrO}$ at $673 \mathrm{~K}$ is shown in Table C.3. Table C.3 shows that $\mathrm{SrO}$ is able to dehydrogenate ethanol to acetaldehyde with $100 \%$ selectivity. The other metal oxides, $\mathrm{MgO}$ and $\mathrm{CaO}$, produce high amounts of ethene under the same conditions. The high selectivity of $\mathrm{SrO}$ to acetaldehyde corroborates the idea that the SrHAP surface may have $\mathrm{SrO}$ present. 
Table C.3: The reaction data of metal oxides and SrHAP at $673 \mathrm{~K}$.

\begin{tabular}{cccccc}
\hline Catalyst & $\begin{array}{c}\text { Ethanol } \\
\text { conversion } \\
(\%)\end{array}$ & $\begin{array}{c}\text { Rate of ethanol } \\
\text { conversion } \\
\left(\mathrm{nmol} \mathrm{m}^{-2} \mathrm{~s}^{-1}\right)\end{array}$ & Ethene & Acetaldehyde & Butanol \\
\cline { 4 - 6 } & 4 & 16 & 27 & 60 & 14 \\
$\mathrm{MgO}$ & 5 & 8.4 & 27 & 73 & 0 \\
$\mathrm{CaO}$ & 4 & 173 & 0 & 100 & 0 \\
$\mathrm{SrO}$ & & &
\end{tabular}

\section{C.4 Conclusion}

CaHAP had the highest activity and selectivity to 1-butanol compared to MgCaHAP, SrHAP, and BaHAP for Guerbet coupling of ethanol. Despite the low amount of magnesium in the MgCaHAP the catalyst had a much lower selectivity towards butanol. The SrHAP and BaHAP were less active and had higher selectivity to acetaldehyde. The high selectivity to acetaldehyde over SrHAP could be due to the presence of $\mathrm{SrO}$ on the surface. Based on TEA adsorption microcalorimetry all the catalysts had a similar number of TEA adsorption sites and all these sites were a similar strength. Based on $\mathrm{CO}_{2}$ adsorption microcalorimetry CaHAP had the greatest number of $\mathrm{CO}_{2}$ adsorption sites by a factor of two. Additionally, CaHAP had the weakest $\mathrm{CO}_{2}$ adsorption sites. It appears as though subtle changes in acid-base properties can have a large effect on the overall rate and selectivity of ethanol coupling to butanol over apatite catalysts, likely because these subtle changes can have a large effect on the aldol condensation/crotonaldehyde hydrogenation reaction cycle. 


\section{References}

(1) Laurencin, D.; Almora-Barrios, N.; de Leeuw, N. H.; Gervais, C.; Bonhomme, C.; Mauri, F.; Chrzanowski, W.; Knowles, J. C.; Newport, R. J.; Wong, A.; Gan, Z.; Smith, M. E. Magnesium incorporation into hydroxyapatite. Biomaterials 2011, 32, 1826-37.

(2) Sugiyama, S.; Moffat, J. B. The conversion of methanol: A probe reaction for hydroxyapatite. Catalysis Letters 2001, 76, 75-80.

(3) Flora, N. J.; Hamilton, K. W.; Schaeffer, R. W.; Yoder, C. H. A Comparative Study of the Synthesis of Calcium, Strontium, Barium, Cadmium, and Lead Apatites in Aqueous Solution. Synthesis and Reactivity in Inorganic and Metal-Organic Chemistry 2004, 34, 503521.

(4) Yasukawa, A.; Nakajima, M.; Kandori, K.; Ishikawa, T. Preparation and Characterization of Carbonated Barium Hydroxyapatites Effect of Washing. Journal of colloid and interface science 1999, 212, 220-227.

(5) Ogo, S.; Onda, A.; Iwasa, Y.; Hara, K.; Fukuoka, A.; Yanagisawa, K. 1-Butanol synthesis from ethanol over strontium phosphate hydroxyapatite catalysts with various Sr/P ratios. Journal of Catalysis 2012, 296, 24-30.

(6) Ramesh, K.; Ling, E. G. Y.; Gwie, C. G.; White, T. J.; Borgna, A. Structure and Surface Reactivity of WO42-, SO42-, PO43- Modified Ca-Hydroxyapatite Catalysts and Their Activity in Ethanol Conversion. Journal of Physical Chemistry C 2012, 116, 18736-18745.

(7) Zhu, Y.; Zhang, X.; Long, F.; Liu, H.; Qian, M.; He, N. Synthesis and characterization of arsenate/phosphate hydroxyapatite solid solution. Materials Letters 2009, 63, 1185-1188. 
(8) Elliott, J. C., Structure and Chemistry of the Apatites and Other Calcium Orthophosphates; Stereochemistry of Organometallic and Inorganic Compounds; ELSEVIER SCIENCE \& TECHNOLOGY: 1994.

(9) Sugiyama, S.; Miyamoto, T.; Hayashi, H.; Moffat, J. B. Effects of non-stoichiometry of calcium and strontium hydroxyapatites on the oxidation of ethane in the presence of tetrachloromethane. Journal of Molecular Catalysis A: Chemical 1998, 135, 199-208.

(10) Tsuchida, T.; Kubo, J.; Yoshioka, T.; Sakuma, S.; Takeguchi, T.; Ueda, W. Reaction of ethanol over hydroxyapatite affected by $\mathrm{Ca} / \mathrm{P}$ ratio of catalyst. Journal of Catalysis $\mathbf{2 0 0 8}$, $259,183-189$.

(11) Terpstra, R. A.; Driessens, F. C. M. Magnesium in tooth enamel and synthetic apatites. Calcified Tissue International 1986, 39, 348-354 LA -English.

(12) Patel, P. N. Mangnesium calcium hydroxylapatite solid solutions. Journal of Inorganic and Nuclear Chemistry 1980, 42, 1129-1132.

(13) Chiranjeevirao, S. V.; Hemmerle, J.; Voegel, J. C.; Frank, R. A Method of Preparation and Characterization of Magnesium-Apatites. Inorganica Chimica Acta 1982, 67, 183-187.

(14) Fadeev, I. V.; Shvorneva, L. I.; Barinov, S. M.; Orlovskii, V. P. Synthesis and Structure of Magnesium-Substituted Hydroxyapatite. Inorganic Materials 2003, 39, 947-950.

(15) Yasukawa, A.; Kandori, K.; Ishikawa, T. Preperation and characterization of magnesiumcalcium hydroxyapatites. J. Mater. Chem. 1996, 6, 1401-1405. 
(16) Almora-Barrios, N.; Grau-Crespo, R.; Leeuw, N. H. D. A computational study of magnesium incorporation in the bulk and surfaces of hydroxyapatite. Langmuir : the ACS journal of surfaces and colloids 2013, 29, 5851-6.

(17) Diallo-Garcia, S.; Laurencin, D.; Krafft, J.-M.; Casale, S.; Smith, M. E.; Lauron-Pernot, H.; Costentin, G. Influence of Magnesium Substitution on the Basic Properties of Hydroxyapatites. The Journal of Physical Chemistry C 2011, 115, 24317-24327.

(18) Sugiyama, S.; Matsumoto, H.; Hayashi, H.; Moffat, J. B. Sorption and ion-exchange properties of barium hydroxyapatite with divalent cations. Colloids and Surfaces A: Physicochemical and Engineering Aspects 2000, 169, 17-26.

(19) Sugiyama, S.; Mo, J. B. Cation effects in the conversion of methanol on calcium, strontium , barium and lead hydroxyapatites. Catalysis letters 2002, 81, 77-81.

(20) Tsuchida, T.; Sakuma, S.; Takeguchi, T.; Ueda, W. Direct Synthesis of n-Butanol from Ethanol over Nonstoichiometric Hydroxyapatite. Industrial \& Engineering Chemistry Research 2006, 45, 8634-8642.

(21) Ogo, S.; Onda, A.; Yanagisawa, K. Selective synthesis of 1-butanol from ethanol over strontium phosphate hydroxyapatite catalysts. Applied Catalysis A: General 2011, 402, 188-195.

(22) Bordawekar, S.; Doskocil, E.; Davis, R. Microcalorimetric study of CO2 and NH3 adsorption on Rb-and Sr-modified catalyst supports. Langmuir 1998, 14, 1734-1738.

(23) Tsuchida, T.; Kubo, J.; Yoshioka, T.; Sakuma, S.; Takeguchi, T.; Ueda, W. Influence of Preparation Factors on Ca/P Ratio and Surface Basicity of Hydroxyapatite Catalyst. Journal of the Japan Petroleum Institute 2009, 52, 51-59. 


\section{Appendix D}

\section{Multiproduct Steady-State Isotopic}

\section{Transient Kinetic Analysis of the Ethanol}

\section{Coupling Reaction over Hydroxyapatite and}

\section{Magnesia}

This chapter was adapted from: Hanspal et al., "Multiproduct Steady-State Isotopic Transient Kinetic Analysis of the Ethanol Coupling Reaction over Hydroxyapatite and Magnesia." Published in ACS Catalysis. DOI:10.1021/cs502023g 
The Guerbet coupling of ethanol into butanol was investigated using multi-product steady-state isotopic transient kinetic analysis (SSITKA) in a comparative study between stoichiometric hydroxyapatite (HAP) and magnesia (MgO) catalysts at $613 \mathrm{~K}$ and $653 \mathrm{~K}$, respectively. The steady-state catalytic reactions were conducted in a gasphase, fixed-bed, differential rector at 1.3 atm total system pressure. Multi-product SSITKA results showed that the mean surface residence time of reactive intermediates leading to acetaldehyde was significantly shorter than that of intermediates leading to butanol on both HAP and $\mathrm{MgO}$. This finding may suggest that the dehydrogenation of ethanol to acetaldehyde is fast on these surfaces compared to $\mathrm{C}-\mathrm{C}$ bond formation, however significant re-adsorption of butanol was observed. If adsorbed acetaldehyde is a key reaction intermediate in the Guerbet coupling of ethanol into butanol, then SSITKA revealed that the majority of adsorbed acetaldehyde produced on the surface of $\mathrm{MgO}$ desorbs into the gas-phase, while the majority of adsorbed acetaldehyde on HAP likely undergoes sequential aldol-type reactions required for butanol formation. Adsorption microcalorimetry of triethylamine and $\mathrm{CO}_{2}$ showed a significantly higher number of acid and base sites on the surface of HAP compared to on MgO. Diffuse reflectance infrared Fourier transform spectroscopy (DRIFTS) of adsorbed ethanol followed by stepwise temperature-programmed desorption (STPD) revealed that ethoxide is more weakly bound to the HAP surface compared to $\mathrm{MgO}$. A high surface density of acid-base site pairs along with a weak binding affinity for ethanol on HAP may provide a possible explanation for the increased activity and high butanol selectivity observed with HAP compared to $\mathrm{MgO}$ catalysts in the ethanol coupling reaction. 


\section{D.1 Introduction}

Steady state isotopic transient kinetic analysis (SSITKA) is a well-established and powerful method that allows quantification of important kinetic parameters such as surface coverages of adsorbed reactant species and surface reaction intermediates, average surface lifetimes of those intermediates, and an upper bound of the turnover frequency. ${ }^{1-3}$ For additional details regarding the SSITKA technique, see the comprehensive review by Shannon and Goodwin. ${ }^{4}$ Recently, our group studied the gas-phase conversion of ethanol to butanol over $\mathrm{MgO}$ at $673 \mathrm{~K}$ using SSITKA; however acetaldehyde could not be followed as an intermediate with the reaction system. ${ }^{5}$ In the present work, we have performed a comparative study between stoichiometric hydroxyapatite (HAP) and $\mathrm{MgO}$, using a modified SSITKA reactor system that allows the monitoring of multiple products formed during the reaction.

To relate reactivity results to catalyst properties, adsorption sites on the catalysts were characterized using diffuse reflectance FT-IR spectroscopy (DRIFTS) during stepwise temperature programmed desorption (STPD) of adsorbed ethanol, as well as adsorption microcalorimetry of carbon dioxide, triethylamine, and ethanol. Results from surface characterization, reactivity testing, and isotopic transient studies were used to propose key structural and compositional properties that facilitate the Guerbet coupling reaction. 


\section{D.2 Materials and Methods}

\section{D.2.1 Catalyst Preparation}

The calcium hydroxyapatite catalyst was prepared using a controlled co-precipitation method, based on the procedure described by Tsuchida et al. ${ }^{6}$ First, two aqueous solutions were prepared: $200 \mathrm{~cm}^{3}$ of $0.5 \mathrm{M}$ calcium nitrate tetrahydrate $\left(\mathrm{Ca}\left(\mathrm{NO}_{3}\right)_{2} \cdot 4 \mathrm{H}_{2} \mathrm{O}\right.$, Acros Organics) and $200 \mathrm{~cm}^{3}$ of $0.3 \mathrm{M}$ diammonium phosphate $\left(\left(\mathrm{NH}_{4}\right)_{2} \mathrm{HPO}_{4}\right.$, Aldrich, $\left.>99.99 \%\right)$. These compositions corresponded to a stoichiometric molar ratio of $\mathrm{Ca} / \mathrm{P}(1.67)$ in the resulting mixed solution. Both solutions, previously adjusted with aqueous ammonia to $\mathrm{pH}=10.5$, were simultaneously added drop-wise to $100 \mathrm{~cm}^{3}$ of distilled deionized water (DDI) at $353 \mathrm{~K}$. Sufficient aqueous ammonia was added continuously during precipitation to maintain a $\mathrm{pH}$ of 10.5 . The resulting suspension was stirred for $24 \mathrm{~h}$ at $353 \mathrm{~K}$. The precipitate was recovered by vacuum filtration, washed 3 times with DDI water, and dried in air at $400 \mathrm{~K}$ overnight.

High purity and ultrafine ( $500 \AA) \mathrm{MgO}$ was obtained commercially (Ube Material Industries, Ltd.). The $\mathrm{MgO}$ and $\mathrm{HAP}$ powders were calcined at $873 \mathrm{~K}$ for $2 \mathrm{~h}$ in flowing air, using a $10 \mathrm{~K} \mathrm{~min}^{-1}$ ramp rate, then pressed, crushed and sieved into pellets between $106 \mu \mathrm{m}$ to $180 \mu \mathrm{m}$.

\section{D.2.2 Catalyst Characterization}

Crystalline phases of the catalysts were confirmed by powder X-ray diffraction (XRD) on a PANalytical X'Pert Pro diffractometer using monochromatic $\mathrm{Cu}-\mathrm{K} \alpha$ radiation $(\lambda=1.54 \AA)$. Scans were 
collected from $2 \theta=20^{\circ}$ to $90^{\circ}$ with a $0.05^{\circ}$ step size.

Specific surfaces areas were obtained by $\mathrm{N}_{2}$ adsorption measured at $77 \mathrm{~K}$ using the BET method on a Micromeritics ASAP 2020 automated analyzer.

Elemental analysis of the HAP catalyst was performed by Galbraith Laboratories (Knoxville, TN) using inductively coupled plasma optical emission spectroscopy (ICP-OES) for calcium and phosphorous content in the bulk material. The chemical composition on the surface of the HAP sample was analyzed by X-ray photoelectron spectroscopy (XPS) using a ThermoFisher ESCALab 250 apparatus. The signals were referenced to adventitious carbon $(C(1 s))$ at a binding energy of $285.09 \mathrm{eV}$.

\section{D.2.3 Ethanol Coupling Reactions}

Guerbet coupling of ethanol was performed in a downward flow, fixed-bed, stainless steel tubular reactor (ID: $0.46 \mathrm{~cm})$ at $1.3 \mathrm{~atm}$ total system pressure. The catalyst pellets $(0.2 \mathrm{~g}$ of $\mathrm{MgO}$ or $0.063 \mathrm{~g}$ of HAP) rested upon a packed region of quartz wool in the reactor tube with a thermocouple positioned at the center of the catalytic bed. Prior to reaction, the catalysts were heated in situ to $773 \mathrm{~K}$ at $10 \mathrm{~K} \mathrm{~min}^{-1}$ in flowing $\mathrm{He}\left(50 \mathrm{~cm}^{3} \mathrm{~min}^{-1}\right)$ and held at $773 \mathrm{~K}$ for $1 \mathrm{~h}$. The reactor effluent was analyzed by an online SRI 8610C gas chromatograph equipped with a flame ionization detector (FID). Reactants and products were quantified using a Restek MXT-Q-Bond column $(0.53 \mathrm{~mm}$ I.D., $30 \mathrm{~m}$ length) connected to the FID.

The peak areas of reactants and products identified by GC were used to determine the ethanol 
conversion and selectivity of products. The conversion of ethanol was calculated as follows:

$$
\text { Conversion }(\mathrm{C} \%)=\left(\frac{\sum_{i} n_{i} M_{i}}{2}\right) \times 100
$$

where $n_{i}$ is the number of carbon atoms in product $i$ and $M_{i}$ is the molar ratio of product $i$ detected to the initial moles of ethanol. The selectivity towards product $i$ was calculated based on the total number of carbon atoms in the product and is therefore defined as:

$$
\text { Selectivity }(\mathrm{C} \%)=\frac{n_{i} M_{i}}{\sum_{i} n_{i} M_{i}} \times 100
$$

\section{D.2.4 Multi-product SSITKA}

A schematic of the reactor system used for the multi-product SSITKA experiments is shown in Figure D.1. Details regarding the system were described in previous work from our group ${ }^{7}$ so only a brief description is provided here. After achieving steady-state conversion (minimum of $16 \mathrm{~h}$ on stream), an isotopic switch was performed using a Valco 2-position pneumatic valve, from unlabeled ${ }^{12} \mathrm{C}$ ethanol (anhydrous, Sigma Aldrich, $99.5 \%$ ) to doubly labeled ${ }^{13} \mathrm{C}$ ethanol (Cambridge Isotopes Laboratories, Inc.; $\left.1,2-{ }^{13} \mathrm{C}, 99 \%\right)$. The unlabeled/labeled ethanol were each contained in two identical saturators that were submerged in a heated water bath maintained at $299 \mathrm{~K}$. The

${ }^{13} \mathrm{C}$-labeled ethanol was received with a substantial amount of water $(5.89 \mathrm{wt} . \%)$, therefore $3 \mathrm{~A}$ molecular sieves (Sigma Aldrich) that were previously treated at $523 \mathrm{~K}$ for several hours in flowing He, were added to the saturator to dehydrate the ethanol. Molecular sieves were also added to the unlabeled ethanol so that the liquid level in both saturators was the same. 


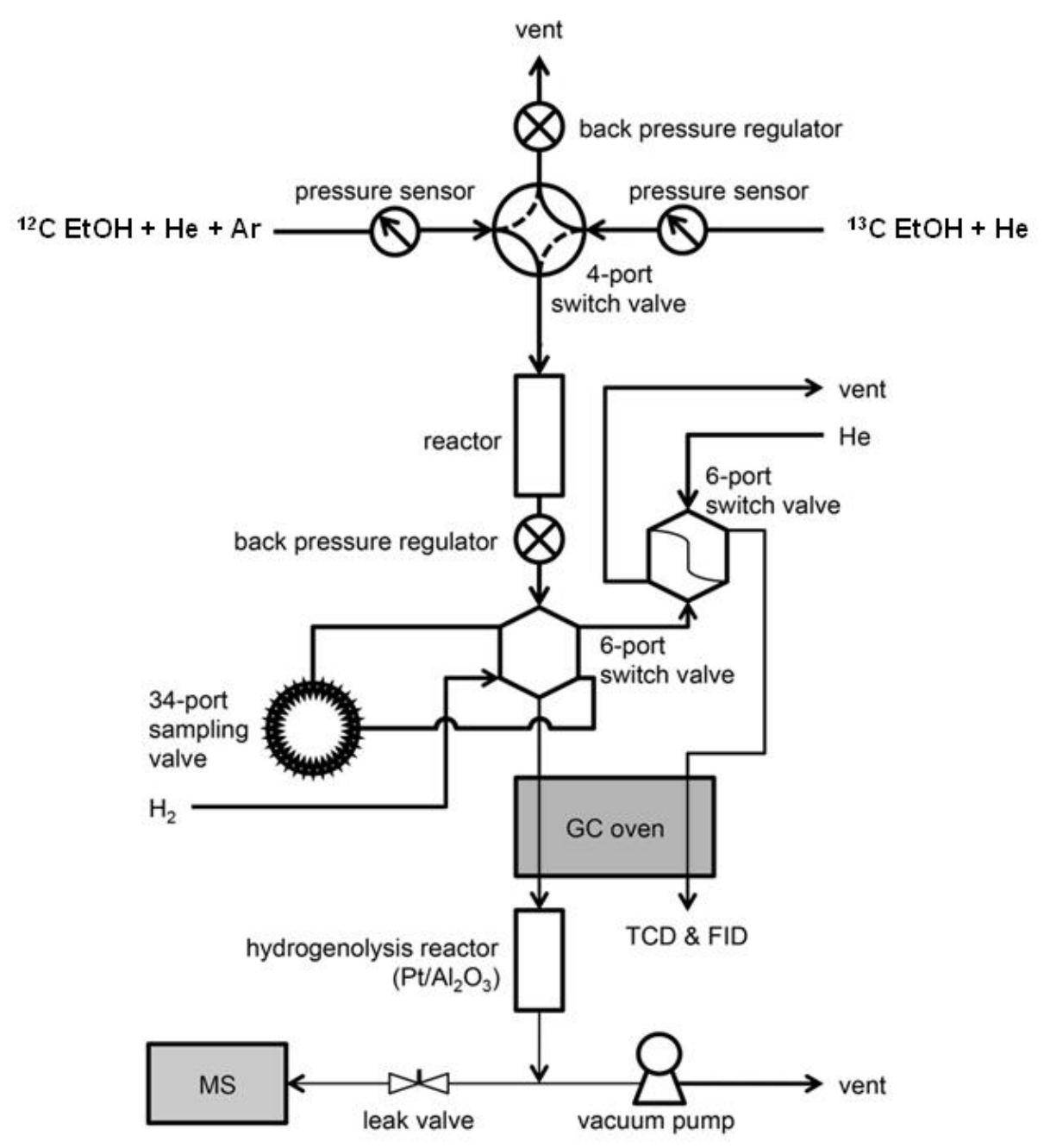

Figure D.1: Reaction system for multi-product SSITKA. This figure is adapted from Shou and Davis. ${ }^{7}$

Helium (GTS-Welco, 99.999\%) was used as the carrier gas and flowed through the saturators with a mole fraction of ethanol in the gas phase equal to $6.2 \%$. The ${ }^{12} \mathrm{C}$ ethanol gas feed was mixed with an inert argon (GTS-Welco, 99.999\%) tracer (2 vol.\% of the total flow rate) that was used to correct for the gas-phase holdup in the reactor. The SSITKA experiments were conducted at 3 different total gas flow rates $\left(30 \mathrm{~cm}^{3} \mathrm{~min}^{-1}, 50 \mathrm{~cm}^{3} \mathrm{~min}^{-1}\right.$ and $\left.75 \mathrm{~cm}^{3} \mathrm{~min}^{-1}\right)$ to investigate reactant and product re-adsorption effects.

The ${ }^{12} \mathrm{C} /{ }^{13} \mathrm{C}$ ethanol switch was achieved without disrupting the steady-state of the reaction by 
maintaining the reaction temperature as well as the total system pressure at $1.3 \mathrm{~atm}$, with the use of two back pressure regulators positioned at the end of the reactor and the vent line. Following the isotope switch, 16 gas samples of the reactor effluent were collected at various time intervals throughout the transient, using an automated Valco 34-port sampling valve. The samples were injected and separated by gas chromatography (GC). To avoid fragmentation and overlapping issues that are often associated with mass spectrometric (MS) analysis of higher alcohols, the gas samples were passed to a hydrogenolysis reactor held at $673 \mathrm{~K}$ and converted into methane over $5 \mathrm{wt} . \%$ $\mathrm{Pt} / \mathrm{Al}_{2} \mathrm{O}_{3}$ (Sigma Aldrich) after separation by GC and prior to entering the MS (Pfeiffer Vacuum). In the MS, the ion signals for $\mathrm{m} / \mathrm{z}=16\left({ }^{12} \mathrm{CH}_{4}\right)$ and $17\left({ }^{13} \mathrm{CH}_{4}\right)$ were continuously monitored to determine the isotope content of the original gas sample. Based on the fragmentation pattern for methane, a portion of the ${ }^{12} \mathrm{CH}_{4}$ signal is attributed to ${ }^{13} \mathrm{CH}_{4}$, therefore the MS ${ }^{12} \mathrm{CH}_{4}$ responses were all corrected by subtracting the ${ }^{13} \mathrm{CH}_{4}$ contribution. Figure D.2 shows an example set of normalized transient response curves for Ar, acetaldehyde, butanol, and ethanol that were obtained following the isotopic switch from ${ }^{12} \mathrm{C}$ ethanol to ${ }^{13} \mathrm{C}$ ethanol during the steady-state reaction of ethanol over HAP at $613 \mathrm{~K}$ at a total flow rate of $50 \mathrm{~cm}^{3} \mathrm{~min}^{-1}$. The argon decay curve was used to determine the gas phase holdup of the reactor system since we assumed that the inert gas did not adsorb or react on the surface of the catalyst. Therefore, the difference in area under the normalized transient response of each species $\left(F_{i}\right)$ from that of the inert $\operatorname{Ar} \operatorname{tracer}\left(F_{A r}\right)$ is equal to the overall mean surface residence time associated with that species $\left(\tau_{i}\right)$ :

$$
\tau_{i}=\int_{0}^{\infty}\left(F_{i}-F_{A r}\right) d t
$$

The surface coverage of reactant or reactive intermediates that lead to a specific product $\left(N_{i}\right)$ can 
then be determined as follows:

$$
N_{i}=R_{i} \tau_{i}
$$

where $R_{i}$ refers to the steady-state flow rate of reactant or the reaction rate to form product $i$.

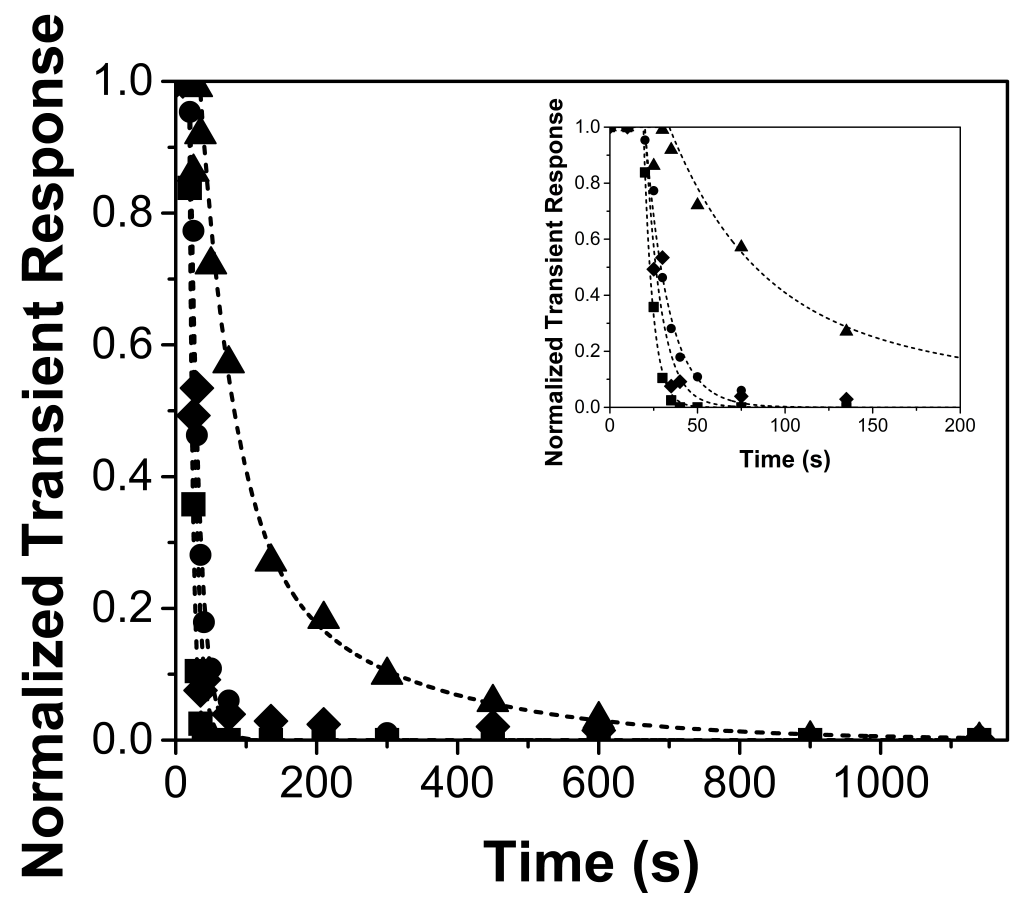

Figure D.2: Normalized isotopic transient response curves following the switch from unlabeled ethanol to doubly labeled ${ }^{13} \mathrm{C}$-labeled ethanol with a total flow of $50 \mathrm{~cm}^{3} \mathrm{~min}^{-1}$ at $613 \mathrm{~K}$ during the coupling of ethanol

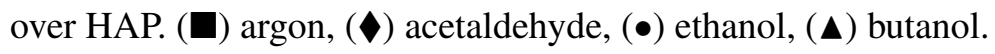

\section{D.2.5 Adsorption Microcalorimetry}

Adsorption sites on HAP and $\mathrm{MgO}$ were characterized using adsorption microcalorimetry of carbon dioxide, triethylamine (TEA), and ethanol. The experiments were conducted at $303 \mathrm{~K}$ using a heat-flow microcalorimeter. Experimental procedures ${ }^{5}$ as well as a detailed description of the apparatus, ${ }^{8}$ used for the calorimetry measurements have been reported in previous work. A schematic of the adsorption microcalrimeter is shown in Appendix A. 
In summary, samples were first outgassed at $773 \mathrm{~K}$ for $16 \mathrm{~h}$ under vacuum to a pressure below $10^{-3}$ Torr then cooled to room temperature. Prior to adsorption, the pretreated sample cell was inserted into an isothermal heat block (maintained at $303 \mathrm{~K}$ ) for $2 \mathrm{~h}$ and allowed to thermally equilibrate with the system. Incremental doses of the gas probe molecule (carbon dioxide, triethylamine, ethanol) were introduced to the catalyst via a volumetric dosing system. Liquid TEA and ethanol were purified by several freeze-pump-thaw cycles prior to use. Adsorption isotherms and differential enthalpies of adsorption were obtained by measuring the amount of adsorbed species on the catalytic surface and the heats evolved for each dose.

\section{D.2.6 Diffuse Reflectance Infrared Fourier Transform Spectroscopy (DRIFTS)}

Stepwise temperature-programmed desorption (STPD) of adsorbed ethanol was investigated in the diffuse reflectance mode on a Bio-Rad (FTS-60A) FTIR spectrometer, equipped with a liquid nitrogen cooled MCT detector. The DRIFTS experiments were conducted using a high-temperature gas reaction chamber (Harrick Scientific) positioned onto a Praying Mantis diffuse reflectance sample accessory. All spectra were obtained by co-adding and averaging 100 scans at a spectral resolution of $4 \mathrm{~cm}^{-1}$.

The STPD measurements were carried out according to the experimental procedure described in detail in previous work by Birky et al. ${ }^{5}$ Catalyst samples, diluted in $\mathrm{KBr}$ powder at 1 wt. $\%$ HAP and $5 \mathrm{wt} . \% \mathrm{MgO}$, were loaded into the DRIFTS cell and pretreated in situ at $773 \mathrm{~K}$ for $1 \mathrm{~h}$ in flowing $\mathrm{He}\left(30 \mathrm{~cm}^{3} \mathrm{~min}^{-1}\right)$. The DRIFTS cell was exposed to anhydrous ethanol (Sigma Aldrich) at $303 \mathrm{~K}$ for $15 \mathrm{~min}$ by passing $\mathrm{He}\left(30 \mathrm{~cm}^{3} \mathrm{~min}^{-1}\right)$ through an ethanol saturator followed by purging 
under He flow $\left(30 \mathrm{~cm}^{3} \mathrm{~min}^{-1}\right)$ for $15 \mathrm{~min}$. The catalyst sample was then heated stepwise to $673 \mathrm{~K}$ at $10 \mathrm{~K} \mathrm{~min}^{-1}$ with IR spectra collected after waiting $15 \mathrm{~min}$ at each temperature. The DRIFTS spectrum of the catalyst sample taken at each temperature prior to ethanol adsorption was used as background for each measurement.

\section{D.3 Results}

\section{D.3.1 Catalyst Characterization}

Powder X-ray diffraction patterns of the investigated materials are shown in Figure D.3. The magnesia catalyst (Figure D.3a) had an XRD pattern that is characteristic of periclase $\mathrm{MgO}$, the cubic form of magnesium oxide. The XRD pattern of the stoichiometric HAP material, prepared via coprecipitation (Figure D.3b), confirmed that the sample was composed of crystalline hydroxyapatite and that no other phases were present.

The BET surface areas of the HAP and $\mathrm{MgO}$ catalysts used for this work are summarized in Table D.1. Surface analysis by XPS revealed that the HAP material had a lower $\mathrm{Ca} / \mathrm{P}$ surface molar ratio (1.46) than that measured in the bulk by ICP-OES (1.66). The surface deficiency in calcium is consistent with prior works and is likely due to its susceptibility to lattice substitutions and an ability to assemble in non-stoichiometric forms. ${ }^{9-11}$

Table D.1: Specific surface areas of stoichiometric hydroxyapatite and magnesia catalysts.

\begin{tabular}{cc}
\hline Catalyst & BET Surface Area $\left(\mathrm{m}^{2} \mathrm{~g}^{-1}\right)$ \\
\hline $\mathrm{HAP}$ & 35 \\
$\mathrm{MgO}$ & 35 \\
\hline
\end{tabular}




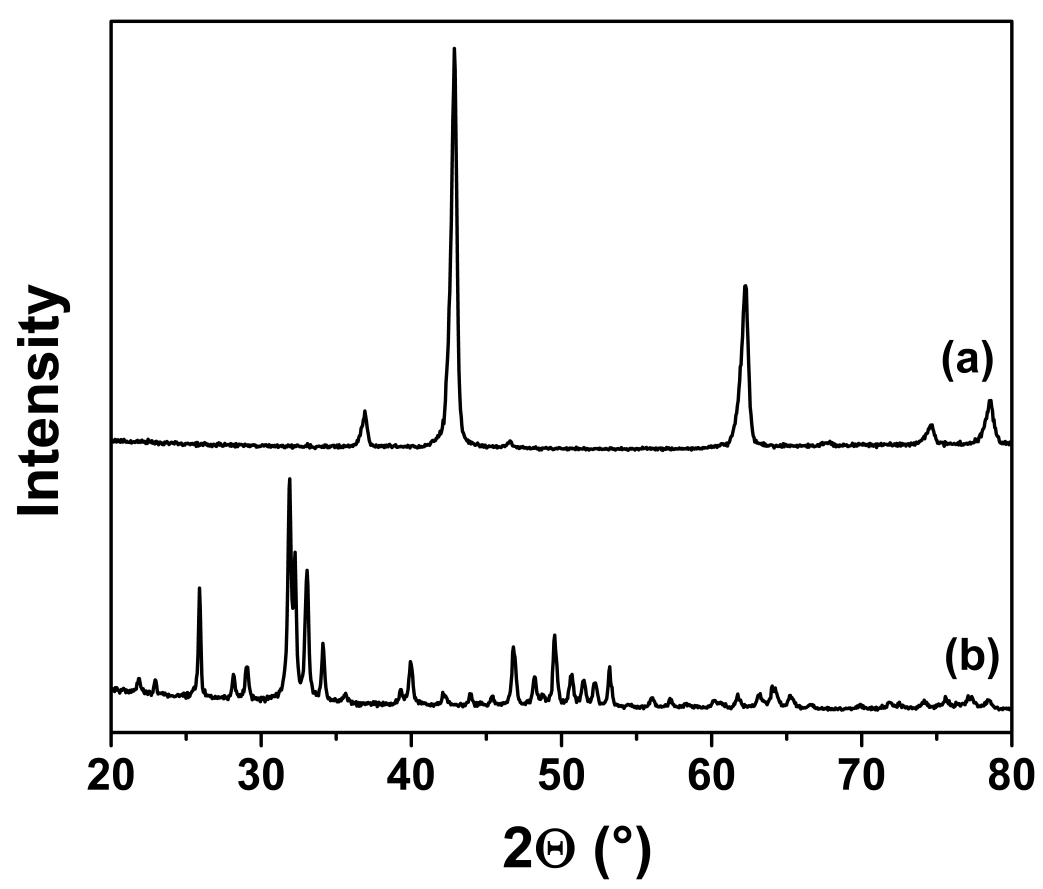

Figure D.3: X-ray diffraction patterns of (a) $\mathrm{MgO}$ and (b) stoichiometric $\mathrm{HAP}$ (catalysts were calcined at $873 \mathrm{~K}$ for $2 \mathrm{~h}$ in air). Patterns are offset for clarity.

\section{D.3.2 Steady-State Conversion of Ethanol}

The reactivity results obtained during the steady-state conversion of ethanol over $\mathrm{MgO}$ at $653 \mathrm{~K}$ at three different total gas flow rates are presented in Table D.2. Acetaldehyde, formed via dehydrogenation of ethanol, was the primary product at low ethanol conversion $(<5 \%)$. As conversion increased, the product distribution shifted towards the coupled product, butanol, as expected for a sequential reaction network in which acetaldehyde is a reaction intermediate in the conversion of ethanol into butanol. The dehydration reaction of ethanol to ethene, which is an undesired side reaction, was also observed over $\mathrm{MgO}$ at $653 \mathrm{~K}$. The ethene selectivity remained constant $(\sim 10 \%)$ at the reaction conditions tested. Constant ethene selectivity was also observed in previous work by Birky et al. over $\mathrm{MgO}$ at $673 \mathrm{~K}$ over a wide range of ethanol conversions ( $7 \%$ to $23 \%$ ). ${ }^{5}$ 
Table D.2: Product distribution during the catalytic conversion of ethanol over $\mathrm{MgO}$ at $653 \mathrm{~K}$.

\begin{tabular}{|c|c|c|c|c|c|}
\hline \multirow{2}{*}{$\begin{array}{l}\text { Total flow rate } \\
\left(\mathrm{cm}^{3} \mathrm{~min}^{-1}\right)\end{array}$} & \multirow{2}{*}{$\begin{array}{l}\text { Ethanol } \\
\text { conversion } \\
(\%)\end{array}$} & \multirow{2}{*}{$\begin{array}{l}\text { Rate of ethanol } \\
\text { conversion } \\
\left(\mathrm{mol} \mathrm{m}^{-2} \mathrm{~s}^{-1}\right)\end{array}$} & \multicolumn{3}{|c|}{ Selectivity (C\%) } \\
\hline & & & Ethene & Acetaldehyde & Butanol \\
\hline 30 & 7.9 & $1.5 \times 10^{-8}$ & 11 & 49 & 40 \\
\hline 50 & 4.5 & $1.4 \times 10^{-8}$ & 12 & 67 & 21 \\
\hline 75 & 3.7 & $1.7 \times 10^{-8}$ & 13 & 67 & 20 \\
\hline
\end{tabular}
Catalyst loading: $0.2 \mathrm{~g} ; T=653 \mathrm{~K}$; total system pressure $=1.3 \mathrm{~atm}$.

Table D.3: Product distribution during the catalytic conversion of ethanol over stoichiometric HAP at 613 K.

\begin{tabular}{cccccc}
\hline \multirow{2}{*}{$\begin{array}{c}\text { Total flow rate } \\
\left(\mathrm{cm}^{3} \mathrm{~min}^{-1}\right)\end{array}$} & $\begin{array}{c}\text { Ethanol } \\
\text { conversion }\end{array}$ & $\begin{array}{c}\text { Rate of ethanol } \\
\text { conversion } \\
(\%)\end{array}$ & \multicolumn{3}{c}{ Selectivity (C\%) } \\
\cline { 4 - 6 } & 6.6 & $4.1 \times 10^{-8}$ & Ethene & Acetaldehyde & Butanol \\
\hline 30 & 4.3 & $4.4 \times 10^{-8}$ & 1 & 24 & 75 \\
50 & 3.2 & $5.0 \times 10^{-8}$ & 1 & 36 & 67 \\
75 & &
\end{tabular}

Catalyst loading: $0.06 \mathrm{~g} ; T=613 \mathrm{~K}$; total system pressure $=1.3 \mathrm{~atm}$.

Table D.3 presents the analogous results obtained from the steady-state reaction of ethanol over stoichiometric hydroxyapatite at $613 \mathrm{~K}$ at three different total flow rates. Butanol was the major product observed at all three conditions with selectivities towards the coupled product greater than $60 \%$ even at conversions as low as $3.2 \%$. The dehydrated side product ethene was a minor product observed during the coupling of ethanol over HAP with a selectivity of only $1 \%$ at the reaction conditions investigated. It should also be noted that the temperature of the reaction over HAP $(613 \mathrm{~K})$ was $40 \mathrm{~K}$ lower than that over $\mathrm{MgO}$ and even at the lower temperature, the HAP catalyst was about $300 \%$ more active in the ethanol coupling reaction than $\mathrm{MgO}$ on a surface area basis (Tables D.2, D.3).

Ethanol conversions obtained during the steady-state Guerbet coupling of ethanol over HAP and $\mathrm{MgO}$ are plotted in Figure D.4 as a function of inverse volumetric flow rate, which is pro- 
portional to reactor space time. Linearity of the results confirms that the reactor was operated differentially with respect to ethanol conversion.

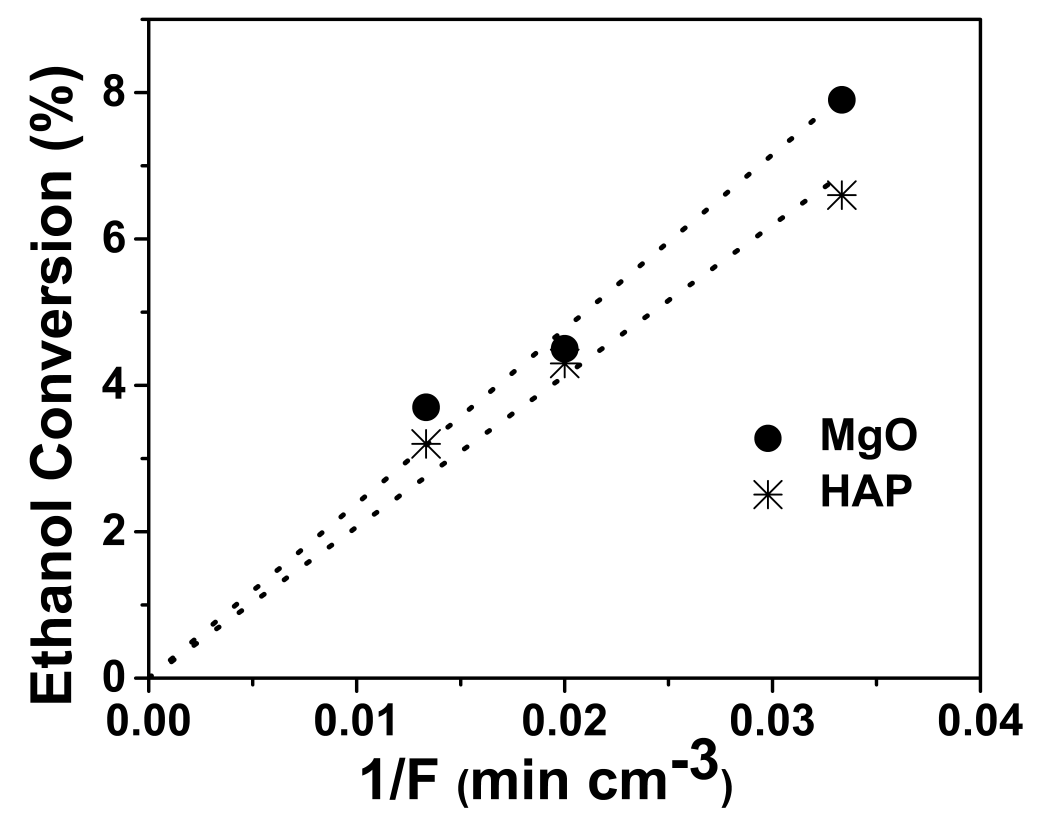

Figure D.4: The conversion of ethanol as a function of inverse reactant flow rate during the coupling of ethanol over $\mathrm{MgO}$ and stoichiometric HAP at $653 \mathrm{~K}$ and $613 \mathrm{~K}$, respectively. The observed linear dependence confirms differential reactor conditions.

\section{D.3.3 Multi-Product SSITKA}

Multi-product SSITKA measurements during the Guerbet coupling of ethanol over MgO and HAP allowed for the quantification of important kinetic parameters of the reaction such as surface concentrations of reaction intermediates $\left(N_{i}\right)$, mean surface residence times of adsorbed species $(\tau)$, and an approximation for the intrinsic turnover frequencies of the catalytic cycle. The average surface residence time and surface coverage of ethanol on $\mathrm{MgO}$ and $\mathrm{HAP}$ with varying flow rate are summarized in Table D.4. The surface coverage of ethanol on $\mathrm{MgO}$ was about $5.0 \times 10^{-6} \mathrm{~mol} \mathrm{~m}^{-2}$ 
Table D.4: Time constants and surface coverages of ethanol $\left(N_{\mathrm{EtOH}}\right)$ during the steady-state Guerbet coupling of ethanol over $\mathrm{MgO}$ and $\mathrm{HAP}$ at $653 \mathrm{~K}$ and $613 \mathrm{~K}$, respectively.

\begin{tabular}{ccccccc}
\hline \multirow{2}{*}{$\begin{array}{c}\text { Total Flow } \\
\text { Rate } \\
\left(\mathrm{cm}^{3} \mathrm{~min}^{-1}\right)\end{array}$} & \multicolumn{2}{c}{$\tau_{\text {EtOH }}(\mathrm{s})$} & & \multicolumn{2}{c}{ Coverage of Ethanol $N_{\text {EtOH }}\left(\mathrm{mol} \mathrm{m}^{-2}\right)$} \\
\cline { 2 - 3 } \cline { 6 - 7 } & $\begin{array}{c}\mathrm{MgO} \\
(653 \mathrm{~K})\end{array}$ & $\begin{array}{c}\mathrm{HAP} \\
(613 \mathrm{~K})\end{array}$ & & $\begin{array}{c}\mathrm{MgO} \\
(653 \mathrm{~K})\end{array}$ & $\begin{array}{c}\mathrm{HAP} \\
(613 \mathrm{~K})\end{array}$ & $\begin{array}{c}\text { HAP } \\
(\text { corrected }) \\
(613 \mathrm{~K})\end{array}$ \\
\hline 30 & 25 & 43 & & $4.8 \times 10^{-6}$ & $2.7 \times 10^{-5}$ & -- \\
50 & 18 & 8.8 & & $5.7 \times 10^{-6}$ & $9.1 \times 10^{-6}$ & $3.9 \times 10^{-6}$ \\
75 & 10 & 7.1 & & $4.5 \times 10^{-6}$ & $1.1 \times 10^{-5}$ & $5.0 \times 10^{-6}$ \\
\hline
\end{tabular}

(between $4.5 \times 10^{-6} \mathrm{~mol} \mathrm{~m}^{-2}$ to $5.7 \times 10^{-6} \mathrm{~mol} \mathrm{~m}^{-2}$ ) regardless of total flow rate, which agrees well with results obtained previously in our lab on $\mathrm{MgO}$ at $673 \mathrm{~K} .{ }^{5}$ Significantly higher surface coverages of ethanol were observed on HAP at $613 \mathrm{~K}$. Since a lower temperature and a smaller HAP sample mass loading relative to $\mathrm{MgO}$ were required to maintain low conversion, the interaction of ethanol with the reactor system walls and quartz wool plug would be relatively more important in the HAP experiments. A blank SSITKA experiment was thus performed at the two highest flowrates $\left(50 \mathrm{~cm}^{3} \mathrm{~min}^{-1}\right.$ and $\left.75 \mathrm{~cm}^{3} \mathrm{~min}^{-1}\right)$ to determine the surface residence time of the ethanol in the system. Table D.4 presents the "corrected" value of ethanol surface coverage after accounting for ethanol adsorption in the reactor system. Evidently, the surface coverage of ethanol was similar on both $\mathrm{MgO}$ and $\mathrm{HAP}$, at $5.0 \times 10^{-6} \mathrm{~mol} \mathrm{~m}^{-2}$.

Figure D.5 compares the normalized transient decays for ${ }^{12} \mathrm{C}$-unlabeled butanol obtained over HAP to that obtained over $\mathrm{MgO}$, during the steady-state reaction of ethanol following a switch from ${ }^{12} \mathrm{C}$-labeled ethanol to ${ }^{13} \mathrm{C}$-labeled ethanol. The butanol response curves presented in Figure D.5 were fit with a two-term exponential decay function. The ${ }^{12} \mathrm{C}$ butanol signal observed with the HAP catalyst exhibited a slow decay which did not fully reach background level until after $900 \mathrm{~s}$. The butanol transient over $\mathrm{MgO}$, on the other hand, was completed after only $300 \mathrm{~s}$. 


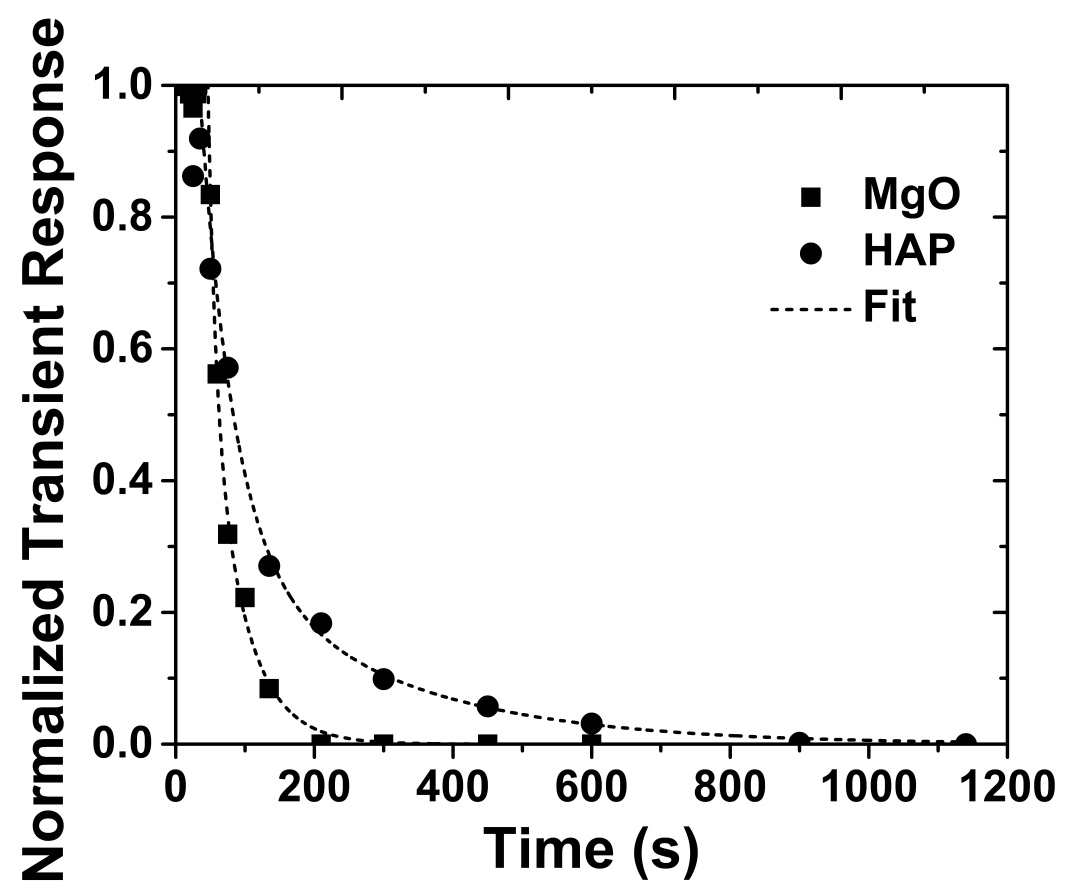

Figure D.5: Normalized isotopic transient response curves for butanol following the switch from unlabeled ethanol to doubly labeled ${ }^{13} \mathrm{C}$-labeled ethanol with a total flow of $50 \mathrm{~cm}^{3} \mathrm{~min}^{-1}$ during the coupling of ethanol over $\mathrm{MgO}$ at $653 \mathrm{~K}$ and $613 \mathrm{~K}$. Curves have been fit using a two-term exponential decay function.

Mean surface residence times as well as coverages of surface intermediates that led to acetaldehyde and butanol are summarized in Tables D.5 and D.6, respectively. For both $\mathrm{MgO}$ and HAP, the average surface lifetime of reactive intermediates leading to acetaldehyde was much shorter than that leading to butanol. Stated another way, it took a significantly longer time for butanol to desorb from the surface compared to acetaldehyde. The surface coverage of reaction intermediates leading to acetaldehyde relative to butanol on the two catalysts also provides valuable information. On $\mathrm{MgO}$, there was a higher number of intermediates that led to acetaldehyde compared to those that lead to butanol $\left(N_{\mathrm{AcH}}>N_{\mathrm{BuOH}}\right)$, whereas the opposite trend was observed over HAP $\left(N_{\mathrm{BuOH}} \gg N_{\mathrm{AcH}}\right)$. Moreover, Table D.6 indicates the surface density of adsorbed intermediates leading to butanol was orders of magnitude greater on HAP than on $\mathrm{MgO}$ at all three flowrates investigated. 
Table D.5: Time constants and surface coverages of reactive intermediates leading to acetaldehyde $\left(N_{\mathrm{AcH}}\right)$ during the steady-state Guerbet coupling of ethanol over $\mathrm{MgO}$ and $\mathrm{HAP}$ at $653 \mathrm{~K}$ and $613 \mathrm{~K}$, respectively.

\begin{tabular}{|c|c|c|c|c|}
\hline \multirow{2}{*}{$\begin{array}{l}\text { Total Flow } \\
\text { Rate } \\
\left(\mathrm{cm}^{3} \mathrm{~min}^{-1}\right)\end{array}$} & \multicolumn{2}{|c|}{$\tau_{\mathrm{AcH}}(\mathrm{s})$} & \multicolumn{2}{|c|}{$\begin{array}{l}\text { Coverage of intermediates to } \\
\text { acetaldehyde } N_{\mathrm{AcH}}\left(\mathrm{mol} \mathrm{m}^{-2}\right)\end{array}$} \\
\hline & $\mathrm{MgO}(653 \mathrm{~K})$ & HAP (613 K) & $\mathrm{MgO}(653 \mathrm{~K})$ & $\operatorname{HAP}(613 \mathrm{~K})$ \\
\hline 30 & 15 & 4.4 & $1.1 \times 10^{-7}$ & $4.3 \times 10^{-8}$ \\
\hline 50 & 13 & 4.6 & $1.2 \times 10^{-7}$ & $6.5 \times 10^{-8}$ \\
\hline 75 & 11 & 4.6 & $1.2 \times 10^{-7}$ & $8.2 \times 10^{-8}$ \\
\hline
\end{tabular}

Table D.6: Time constants and surface coverages of reactive intermediates leading to butanol $\left(N_{\mathrm{BuOH}}\right)$ during the steady-state Guerbet coupling of ethanol over $\mathrm{MgO}$ and $\mathrm{HAP}$ at $653 \mathrm{~K}$ and $613 \mathrm{~K}$, respectively.

\begin{tabular}{|c|c|c|c|c|}
\hline \multirow{2}{*}{$\begin{array}{l}\text { Total Flow } \\
\text { Rate } \\
\left(\mathrm{cm}^{3} \mathrm{~min}^{-1}\right)\end{array}$} & \multicolumn{2}{|c|}{$\tau_{\mathrm{BuOH}}(\mathrm{s})$} & \multicolumn{2}{|c|}{$\begin{array}{l}\text { Coverage of intermediates to } \\
\text { acetaldehyde } N_{\mathrm{BuOH}} \\
\left(\mathrm{mol} \mathrm{m}^{-2}\right)\end{array}$} \\
\hline & $\mathrm{MgO}(653 \mathrm{~K})$ & HAP $(613 \mathrm{~K})$ & $\mathrm{MgO}(653 \mathrm{~K})$ & HAP $(613 \mathrm{~K})$ \\
\hline 30 & 93 & 310 & $2.8 \times 10^{-7}$ & $4.8 \times 10^{-6}$ \\
\hline 50 & 53 & 117 & $8.1 \times 10^{-8}$ & $1.7 \times 10^{-6}$ \\
\hline 75 & 27 & 69 & $4.6 \times 10^{-8}$ & $1.1 \times 10^{-6}$ \\
\hline
\end{tabular}

The re-adsorption of reactants or products in the reaction can have a significant influence on the time constant measured by SSITKA. This effect of re-adsorption can be seen in the variation of $\tau$ for ethanol and butanol with respect to flowrate listed in Tables D.4 and D.6, respectively. The mean surface residence times of adsorbed intermediates to acetaldehyde $\left(\tau_{\mathrm{AcH}}\right)$ (Table D.5), however were relatively independent of total flow rate, which suggests acetaldehyde re-adsorption was negligible.

\section{D.3.4 STPD of Adsorbed Ethanol Monitored by DRIFTS}

To probe the interaction of ethanol on the catalytic surfaces, DRIFTS of pre-adsorbed ethanol on $\mathrm{MgO}$ and HAP followed by stepwise temperature-programmed desorption (STPD) was performed. 
The spectra obtained from these experiments are presented in Figure D.6.

The left plot in Figure D.6 shows IR bands observed in the $3200 \mathrm{~cm}^{-1}$ to $2600 \mathrm{~cm}^{-1}$ and $1300 \mathrm{~cm}^{-1}$ to $1000 \mathrm{~cm}^{-1}$ regions after ethanol adsorption on $\mathrm{MgO}$ at $303 \mathrm{~K}$ at various temperatures. The bands are characteristic of adsorbed ethoxide species formed on the surface of the catalyst. The peaks at $2954\left(\nu \mathrm{CH}_{3}\right), 2917\left(\nu \mathrm{CH}_{3}\right)$, and $2847\left(\nu \mathrm{CH}_{2}\right) \mathrm{cm}^{-1}$ are attributed to $\mathrm{C}-\mathrm{H}$ stretches of ethoxide and the bands observed at $1125 \mathrm{~cm}^{-1}$ and $1063 \mathrm{~cm}^{-1}$ correspond to the two $\mathrm{C}-\mathrm{C}-\mathrm{O}$ stretching modes of the adsorbed ethoxide species. ${ }^{5}$ Features of the surface ethoxide intermediate in the $\mathrm{C}-\mathrm{H}$ stretching region remain evident on the $\mathrm{MgO}$ surface up to $673 \mathrm{~K}$.
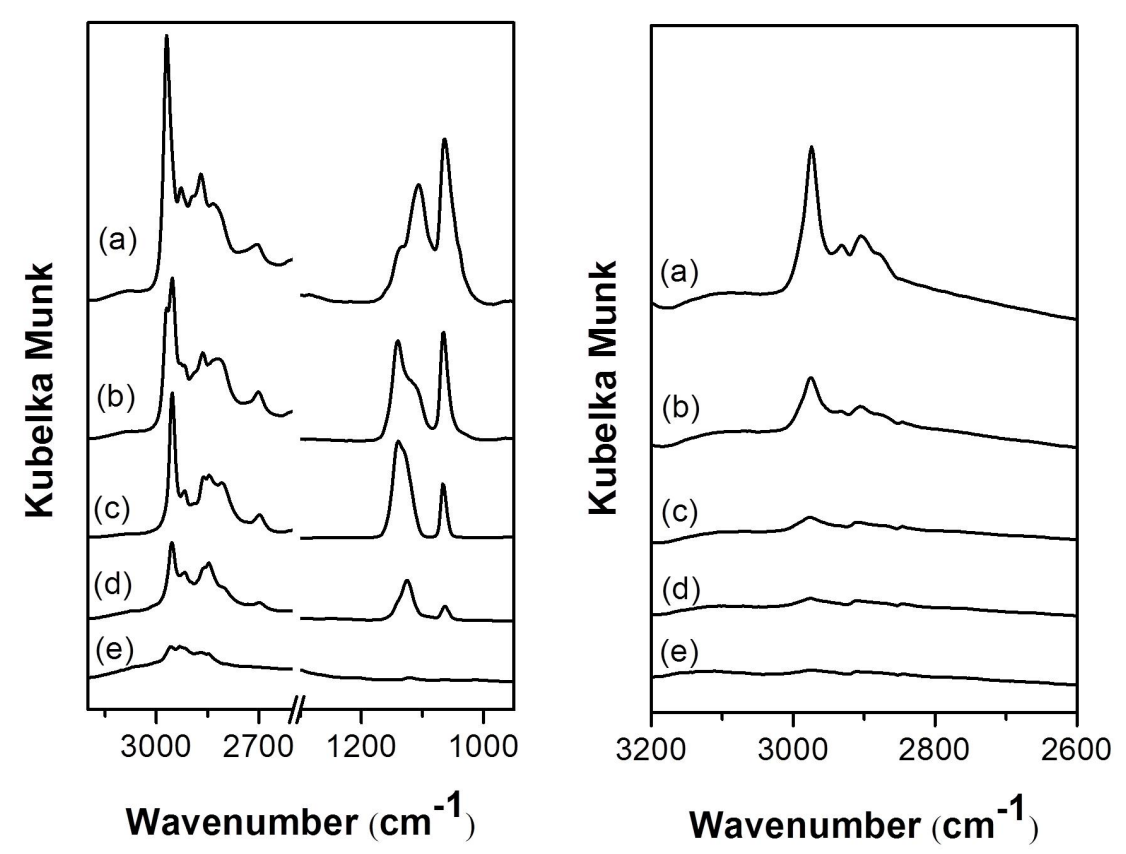

Figure D.6: DRIFTS spectra of adsorbed ethanol at $303 \mathrm{~K}$ on $\mathrm{MgO}$ (left) and HAP (right) collected after heating to various temperatures: (a) $303 \mathrm{~K}$, (b) $373 \mathrm{~K}$, (c) $473 \mathrm{~K}$, (d) $573 \mathrm{~K}$, (e) $673 \mathrm{~K}$. Spectra are offset for clarity.

The DRIFTS spectra collected of adsorbed ethanol on HAP at $303 \mathrm{~K}$ followed by stepwise heating to $673 \mathrm{~K}$ are displayed in Figure D.6 (right). The adsorption of ethanol revealed 3 peaks in the $3100 \mathrm{~cm}^{-1}$ to $2800 \mathrm{~cm}^{-1}$ region that can be assigned to the $\mathrm{C}-\mathrm{H}$ stretches of a surface ethoxide 
species: $2975\left(\nu \mathrm{CH}_{3}\right), 2932\left(\nu \mathrm{CH}_{2}\right)$, and $2904 \mathrm{~cm}^{-1}\left(\nu \mathrm{CH}_{3}\right)$. Lower wavenumber bands associated with ethoxide could not be detected because of strong absorption by the HAP material in this region. The intensity of the $\mathrm{C}-\mathrm{H}$ bands attributed to ethoxide significantly decreased after heating the sample to $473 \mathrm{~K}$. Upon further heating to $573 \mathrm{~K}$ the bands were not observed, indicating ethoxide had completely desorbed from HAP at this temperature. This result is consistent with previous reports on hydroxyapatite materials that also showed the disappearance of $\mathrm{C}-\mathrm{H}$ ethoxide bands by $573 \mathrm{~K} .^{12}$

\section{D.3.5 Adsorption Microcalorimetry of $\mathrm{CO}_{2}$, TEA, and Ethanol}

Adsorption sites on the catalytic materials were also characterized by adsorption microcalorimetry at $303 \mathrm{~K}$. The experimental results, obtained from the adsorption of carbon dioxide, triethylamine, and ethanol, are summarized in Figures D.7, D.8, and D.9, respectively.

Carbon dioxide was used to probe the surface base properties of the catalysts. Isotherms obtained from the adsorption microcalorimetry of $\mathrm{CO}_{2}$ on $\mathrm{MgO}$ and $\mathrm{HAP}$ are given in Figure D.7. The total adsorption capacity or uptake of each probe molecule on the catalytic surface, was determined by extrapolating the high pressure, horizontal portion of the isotherm (corresponds to saturation) to zero pressure. For $\mathrm{CO}_{2}$ on $\mathrm{MgO}$ and $\mathrm{HAP}$ the capacity was $1.0 \mu \mathrm{mol} \mathrm{m}{ }^{-2}$ and $2.5 \mu \mathrm{mol} \mathrm{m}^{-2}$, respectively, suggesting a significantly higher base site density on the surface of stoichiometric hydroxyapatite compared to that observed on $\mathrm{MgO}$.

Figure D.7b presents the differential heats of $\mathrm{CO}_{2}$ adsorption on $\mathrm{MgO}$ and $\mathrm{HAP}$ as a function of surface coverage. The initial differential heat of $\mathrm{CO}_{2}$ adsorption on $\mathrm{MgO}$ was $20 \mathrm{~kJ} \mathrm{~mol}^{-1}$ higher 

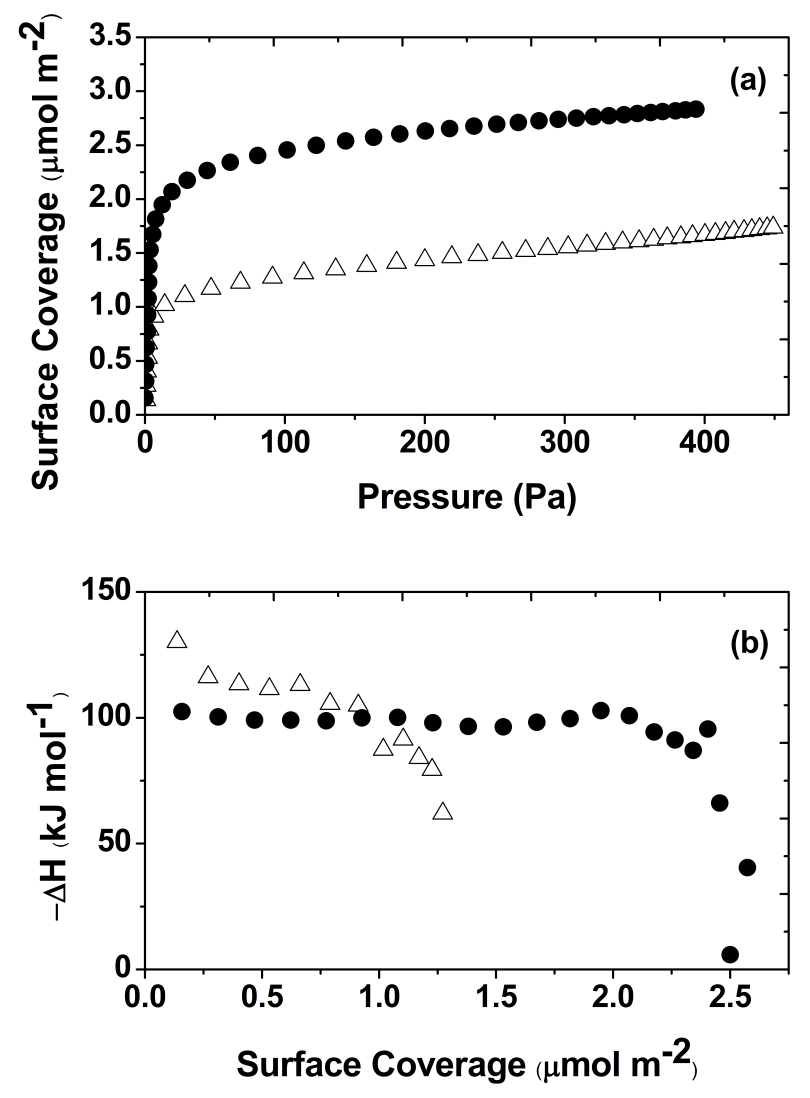

Figure D.7: Adsorption microcalorimetry of carbon dioxide on $(\triangle) \mathrm{MgO}$ and $(\bullet)$ stoichiometric hydroxyapatite (HAP) catalysts at $303 \mathrm{~K}$; (a) adsorption isotherms of carbon dioxide (b) differential heats of adsorption as a function of coverage.

than that on $\mathrm{HAP}$, which implies $\mathrm{MgO}$ exposes stronger base sites that interact with $\mathrm{CO}_{2}$ compared to those on HAP.

Adsorption microcalorimetry of ammonia has been employed extensively as a probe of surface acidity, however there can be multiple interactions with ammonia and solid surfaces. These additional adsorption states include weak hydrogen bonding interactions with the surface as well as deprotonation of ammonia by strong base sites to form surface $\mathrm{NH}_{2}$ species. ${ }^{13}$

Triethylamine (TEA) is harder to deprotonate and is therefore less susceptible to dissociation 

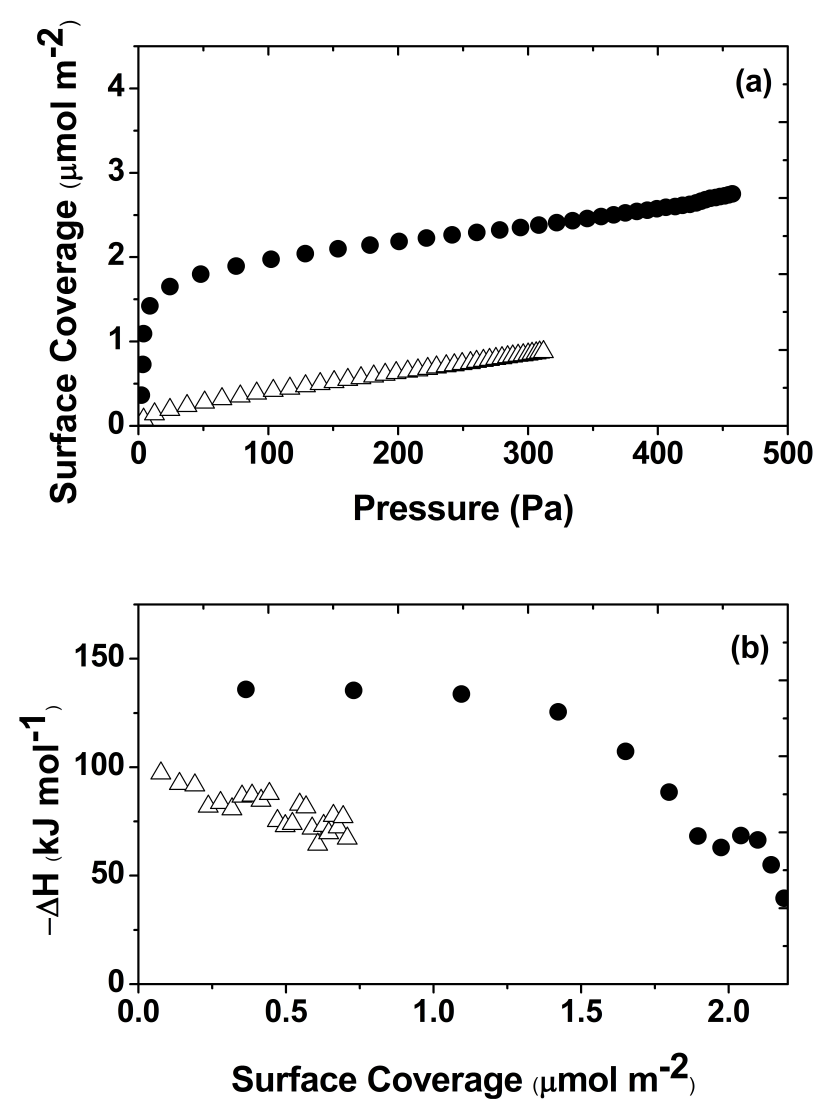

Figure D.8: Adsorption microcalorimetry of triethylamine (TEA) on $(\triangle) \mathrm{MgO}$ and $(\bullet)$ stoichiometric hydroxyapatite (HAP) catalysts at $303 \mathrm{~K}$; (a) adsorption isotherms of triethylamine (b) differential heats of adsorption as a function of coverage.

on the surface. It also has a stronger proton affinity than ammonia suggesting it is a stronger gas-phase base and should therefore be more selective in probing surface acid sites. ${ }^{14}$

Adsorption isotherms of TEA obtained on $\mathrm{MgO}$ and $\mathrm{HAP}$ at $303 \mathrm{~K}$ are presented in Figure D.8a. The low observed uptake and linear variation of TEA surface coverage with pressure on $\mathrm{MgO}$ indicate a very weak interaction with the surface. In contrast, TEA was chemisorbed onto the HAP catalytic surface with an overall uptake of $1.7 \mu \mathrm{mol} \mathrm{m}^{-2}$, which is illustrated by its Langmuirian adsorption isotherm. A weak surface interaction between TEA and $\mathrm{MgO}$ is confirmed by the 
relatively low differential heats of TEA adsorption on $\mathrm{MgO}$ compared to those observed on HAP (Figure D.8b). Evidently, HAP exposes a considerably higher acid site density than $\mathrm{MgO}$.

Figure D.9 shows the results from adsorption microcalorimetry of ethanol on $\mathrm{MgO}$ and $\mathrm{HAP}$ at $303 \mathrm{~K}$. The adsorption isotherms for the two catalysts in Figure D.9a were nearly identical, resulting in an overall ethanol uptake of $5.1 \mu \mathrm{mol} \mathrm{m}{ }^{-2}$ on $\mathrm{MgO}$ and $5.2 \mu \mathrm{mol} \mathrm{m}^{-2}$ on HAP. These results are consistent with the surface coverages of ethanol on $\mathrm{MgO}$ and HAP determined by SSITKA (Table D.4).
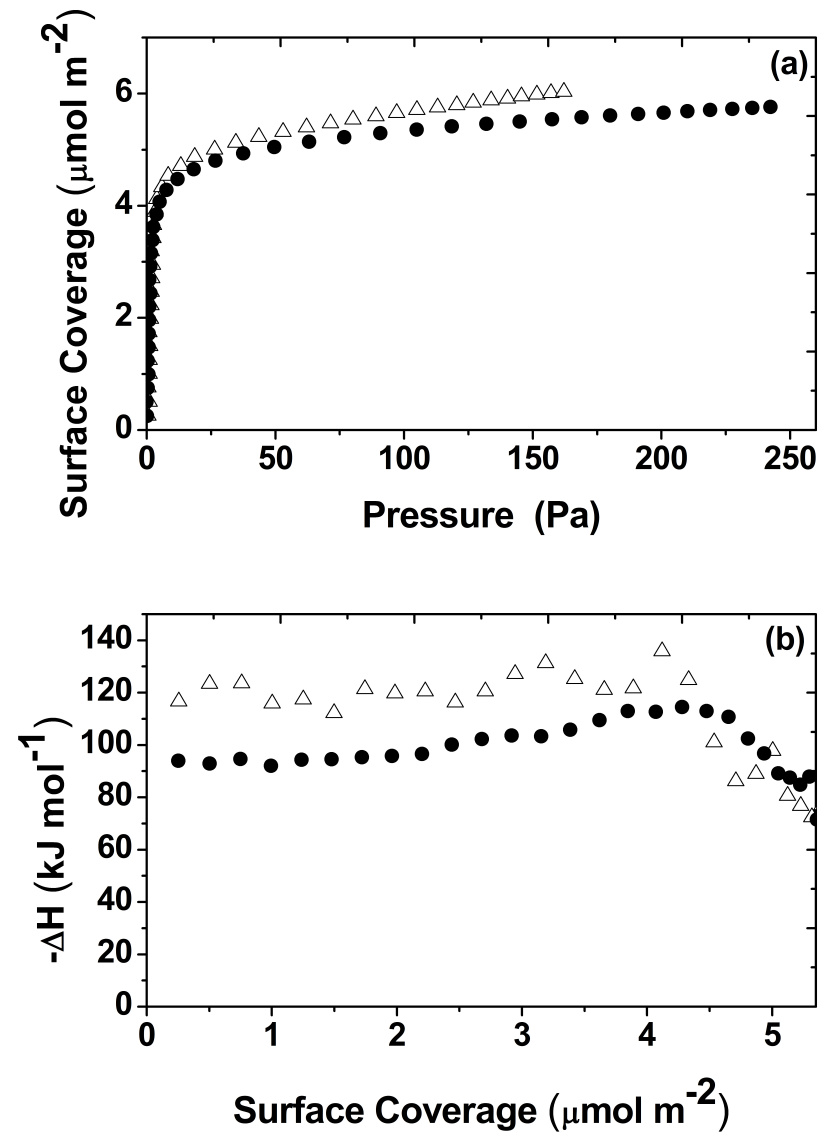

Figure D.9: Adsorption microcalorimetry of ethanol on $(\triangle) \mathrm{MgO}$ and (•) stoichiometric hydroxyapatite (HAP) catalysts at $303 \mathrm{~K}$; (a) adsorption isotherms of ethanol (b) differential heats of adsorption as a function of coverage. 
Differential heats of ethanol adsorption as a function of surface coverage for the catalysts are provided in Figure D.9b. The initial differential heats observed on $\mathrm{MgO}$ and HAP were 118 and $90 \mathrm{~kJ} \mathrm{~mol}^{-1}$, respectively. This $30 \mathrm{~kJ} \mathrm{~mol}^{-1}$ difference in adsorption energy suggests that the ethanol interacts more weakly with HAP compared to $\mathrm{MgO}$, which is consistent with the results obtained from STPD of pre-adsorbed ethanol (Figure D.6) that reveal desorption of ethanol from $\mathrm{HAP}$ at a significantly lower temperature than from $\mathrm{MgO}$. It is also worth mentioning that the ethanol adsorption sites on both $\mathrm{MgO}$ and HAP appear to be fairly uniform in strength, indicated by the invariance in $\Delta H_{\text {ads }}$ as a function of coverage up to about $4 \mu \mathrm{mol} \mathrm{m}{ }^{-2}$.

\section{D.4 Discussion}

The SSITKA measurements allowed for the direct quantification of critical kinetic parameters such as mean surface residence times as well as surface coverages of intermediates leading to products formed in the reaction. Transient results revealed that, for both $\mathrm{MgO}$ and HAP, the residence time for intermediates leading to acetaldehyde $\left(\tau_{\mathrm{AcH}}\right)$, was much shorter than the residence time of reaction intermediates leading to butanol $\left(\tau_{\mathrm{BuOH}}\right)$ at all three flowrates investigated. Moreover, the residence times of ethanol and butanol depended strongly on flow rate, which is strong evidence that the alcohols were readsorbing and desorbing as they passed through the reactor. There is not an adequate way to determine the intrinsic residence time, i.e. the residence time at infinite flow rate, from the limited results reported here. Nevertheless, we can still discuss limits on the values.

A commonly-hypothesized reaction path for the Guerbet coupling of ethanol involves the aldol condensation of intermediate acetaldehyde which likely proceeds through a surface enolate species 
that produces coupled products that desorb as butanol. In this coupling path, surface acetaldehyde produced from ethanol dehydrogenation may desorb or undergo base-catalyzed abstraction of the $\alpha-\mathrm{H}$ to form an adsorbed enolate species. The isotopic transient results obtained during the steadystate conversion of ethanol over $\mathrm{MgO}$ revealed a significantly higher surface coverage of reactive intermediates leading to acetaldehyde than to butanol (Tables D.5, D.6 $N_{\mathrm{AcH}}>N_{\mathrm{BuOH}}$ ) at all flow rates. These results suggest a higher fraction of surface acetaldehyde produced during the reaction of ethanol on $\mathrm{MgO}$ desorbed rather than coupled form butanol. The coverages $N_{\mathrm{AcH}}$ and $N_{\mathrm{BuOH}}$ are consistent with the higher selectivity to acetaldehyde compared to butanol observed over $\mathrm{MgO}$.

In contrast, the coverage of intermediates that led to butanol on HAP was higher than that leading to acetaldehyde by roughly 1-2 orders of magnitude $\left(N_{\mathrm{BuOH}} \gg N_{\mathrm{AcH}}\right)$, regardless of flowrate (Tables D.5, D.6). Evidently, the majority of acetaldehyde formed from ethanol dehydrogenation on HAP remained on the surface to undergo sequential reactions leading to butanol formation.

A previous study from our group on ethanol coupling over $\mathrm{MgO}$, investigated the relationship between butanol rate and acetaldehyde concentration over a broad range of ethanol conversions ( $7 \%$ to $23 \%$ ) and observed a first-order dependence of butanol formation on gas-phase acetaldehyde concentration. ${ }^{5}$ In the current work on $\mathrm{MgO}$, a $36 \%$ decrease in gas-phase acetaldehyde concentration at the reactor exit (from $57.8 \mu \mathrm{mol} \mathrm{L}^{-1}$ to $37.2 \mu \mathrm{mol} \mathrm{L}-1$ at $7.9 \%$ and $3.7 \%$ ethanol conversion, respectively) corresponded with a $44 \%$ decrease in butanol production rate $\left(3.0 \times 10^{-9} \mathrm{~mol} \mathrm{~m}^{-2} \mathrm{~s}^{-1}\right.$ to $\left.1.7 \times 10^{-9} \mathrm{~mol} \mathrm{~m}^{-2} \mathrm{~s}^{-1}\right)$, which is consistent with earlier work and confirms a strong dependence of butanol formation on acetaldehyde concentration. Interestingly, a $28 \%$ decrease in gas-phase acetaldehyde concentration at the reactor exit during ethanol coupling over HAP was not accompanied by a measurable change in the production rate of butanol. These 
results suggest that most of the butanol formed over HAP did not involve the participation of gasphase acetaldehyde whereas the butanol formation over $\mathrm{MgO}$ might involve a surface that is more equilibrated with gas-phase acetaldehyde.

Adsorption microcalorimetry of $\mathrm{CO}_{2}$ was performed to investigate the number and nature of base sites on the catalytic surfaces. Microcalorimetry results revealed that the coverage of $\mathrm{CO}_{2}$ on the HAP surface was 2.5 times that of $\mathrm{MgO}$. However, differential heats of $\mathrm{CO}_{2}$ adsorption on HAP were lower than on $\mathrm{MgO}$. Recent IR studies on HAP have shown that $\mathrm{CO}_{2}$ interacts with the $\mathrm{OH}^{-}$groups and the $\mathrm{O}^{2-}$ atoms of surface $\mathrm{PO}_{4}{ }^{3-}$ groups. ${ }^{15}$ Adsorption microcalorimetry suggests that relative to $\mathrm{MgO}$, HAP exposed a higher number density of base sites but that the sites were weaker in adsorption binding energy. Adsorption microcalorimetry of TEA also revealed a higher acid site density on the surface of HAP compared to MgO. Since the Guerbet coupling of ethanol likely occurs on acid-base site pairs, the high reactivity of ethanol on HAP compared to $\mathrm{MgO}$ appears to be related to high number of acid-base site pairs with appropriate binding affinity on HAP. The higher density of these preferred site pairs may also explain why a significantly higher surface coverage of intermediates leading to butanol was observed on HAP relative to $\mathrm{MgO}$.

Stepwise temperature-programmed desorption of pre-adsorbed ethanol at $303 \mathrm{~K}$ on $\mathrm{MgO}$ and HAP was studied using DRIFTS. The IR spectra revealed the formation of a surface ethoxide intermediate on both of the catalytic materials. Ethanol dissociatively adsorbs on the surface forming ethoxide coordinated to a Lewis acid site $\left(\mathrm{Ca}^{2+}\right.$ on $\mathrm{HAP}, \mathrm{Mg}^{2+}$ for $\left.\mathrm{MgO}\right)$ and proton-like hydrogen coordinated to a Brønsted base site. The STPD results show that the ethoxide species on HAP completely desorbed from the surface by $473 \mathrm{~K}$, whereas a temperature of $673 \mathrm{~K}$ was required on $\mathrm{MgO}$. This $200 \mathrm{~K}$ difference in desorption temperature indicates that the dissociated ethanol is 
much more weakly held to HAP relative to $\mathrm{MgO}$, which is consistent with the results obtained from adsorption microcalorimetry of ethanol where the initial differential heat of ethanol adsorption on HAP was $30 \mathrm{~kJ} \mathrm{~mol}^{-1}$ lower than that on $\mathrm{MgO}$.

The TOF based on ethanol adsorption is a lower bound because not all of the adsorbed ethanol proceeds to product. A better estimate of the TOF can be derived from the isotopic transient results as the reciprocal of the mean surface residence time $\left(\mathrm{TOF}=\tau^{-1}\right)$. Unfortunately, the readsorption of alcohols during the transient increased the measured surface residence time. If we try to minimize the effects of readsorption by using the surface residence time of intermediates to butanol at the highest flow rate in the study $\left(75 \mathrm{~cm}^{3} \mathrm{~min}^{-1}\right)$, we have $\tau_{\mathrm{BuOH}}=27 \mathrm{~s}$ and $69 \mathrm{~s}$ for $\mathrm{MgO}$ $(653 \mathrm{~K})$ and HAP $(613 \mathrm{~K})$. Moreover, if we assume that the $\tau_{\mathrm{EtOH}}$ at high flow rate is a reasonable approximation of the effect of readsorption then we can simply subtract the value for $\tau_{\mathrm{EtOH}}$ (Table D.4) from $\tau_{\mathrm{BuOH}}$ (Table D.6) as reported by Birky et al. to get a "corrected" $\tau_{\mathrm{BuOH}} \cdot{ }^{5}$ The inverse of the "corrected" $\tau_{\text {BuOH }}$ provides a better estimate of the TOF associated with intermediates that form

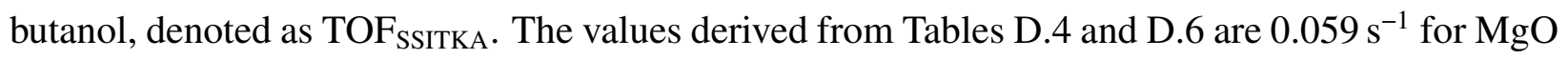
$(653 \mathrm{~K})$ and $0.016 \mathrm{~s}^{-1}$ for HAP $(613 \mathrm{~K})$. The values of $\mathrm{TOF}_{\text {SSITKA }}$ for acetaldehyde production can be estimated as the inverse of the $\tau_{\mathrm{AcH}}$ at the highest flow rate because readsorption appears to be significant. Thus the $\mathrm{TOF}_{\mathrm{SSITKA}}$ for $\mathrm{AcH}$ is $0.091 \mathrm{~s}^{-1}$ for $\mathrm{MgO}$ at $653 \mathrm{~K}$ and $0.22 \mathrm{~s}^{-1}$ for $\mathrm{HAP}$ at $613 \mathrm{~K}$. The higher coverage and TOF of intermediates leading to acetaldehyde on $\mathrm{MgO}$ explain the high observed selectivity to acetaldehyde over $\mathrm{MgO}$. Because the selectivity to butanol was much higher over HAP, the high TOF of acetaldehyde formation must be overwhelmed by a much larger coverage of intermediates that lead to butanol.

Ogo et al. ${ }^{16}$ used isotopic exchange reactions to show that ethanol dehydrogenation occurs 
rapidly on strontium-substituted hydroxyapatite catalysts and that aldol condensation is the rate determining step. The very short residence time of intermediates leading to acetaldehyde $\left(\tau_{\mathrm{AcH}}\right)$ relative to $\tau_{\text {BuOH }}$ observed here by SSITKA, would support this proposal. Based on this proposal it is possible that the kinetically relevant step of the reaction is related to enolate formation via $\alpha-\mathrm{H}$ abstraction of adsorbed acetaldehyde which may be facilitated over HAP compared to on $\mathrm{MgO}$ due to more available base sites on the surface of HAP which would lead to a higher number of coupled products.

\section{D.5 Conclusions}

Isotopic transient studies were performed during the steady-state Guerbet coupling of ethanol to butanol over stoichiometric hydroxyapatite and $\mathrm{MgO}$ at $613 \mathrm{~K}$ and $653 \mathrm{~K}$, respectively. The HAP catalyst was about 3 times more active in the reaction than $\mathrm{MgO}$ on a surface area basis even at the lower TOF. The selectivity over HAP was as high as $75 \%$ to butanol.

The surface coverage of reactive intermediates leading to butanol $\left(N_{\mathrm{BuOH}}\right)$ relative to that leading to acetaldehyde $\left(N_{\mathrm{AcH}}\right)$ was very high on $\mathrm{HAP}\left(N_{\mathrm{BuOH}} \gg N_{\mathrm{AcH}}\right)$ whereas on $\mathrm{MgO}$, $N_{\mathrm{AcH}}>N_{\mathrm{BuOH}}$. Given the generally understood accepted mechanism for Guerbet coupling that involves aldol condensation of acetaldehyde, it appears that a greater fraction of the acetaldehyde produced during the reaction proceeds toward coupling products on HAP relative to $\mathrm{MgO}$. Adsorption microcalorimetry of $\mathrm{CO}_{2}$ showed a higher surface density of base sites on HAP compared to that on $\mathrm{MgO}$, but the $\mathrm{CO}_{2}$ adsorption binding energy was weaker on HAP. Moreover, adsorption of triethylamine revealed significant Lewis acidity on HAP and negligible acidity on $\mathrm{MgO}$. 
It is likely that the high activity and selectivity observed during the Guerbet coupling of ethanol over HAP involves the proper balance of acid-base site pairs to facilitate all of the steps in the sequence, including alcohol dehydrogenation, aldol condensation and aldehyde hydrogenation. The relatively strong basicity of $\mathrm{MgO}$ retains adsorbed ethanol at higher temperatures compared to HAP, which is consistent with the idea that Guerbet coupling is facilitated by weak acid-base bifunctional catalysts.

\section{D.6 Acknowledgments}

This work was supported by the Chemical Sciences, Geosciences and Biosciences Division, Office of Basic Energy Sciences, Office of Science, U.S. Department of Energy, grant no. DE-FG0295ER14549. The authors would like to thank Dmitry Pestov at Virginia Commonwealth University for assistance with XPS.

\section{References}

(1) McClaine, B. C.; Davis, R. J. Importance of Product Readsorption during Isotopic Transient Analysis of Ammonia Synthesis on Ba-Promoted Ru/BaX Catalyst. J. Catal. 2002, 211, 379-386.

(2) Gao, J.; Mo, X.; Goodwin, J. G. Relationships between oxygenate and hydrocarbon formation during $\mathrm{CO}$ hydrogenation on $\mathrm{Rh} / \mathrm{SiO} 2$ : Use of multiproduct SSITKA. Journal of Catalysis 2010, 275, 211-217. 
(3) Ledesma, C.; Yang, J.; Chen, D.; Holmen, A. Recent approaches in mechanistic and kinetic studies of catalytic reactions using SSITKA technique. ACS Catalysis 2014, 4, 4527-4547.

(4) Shannon, S. L.; Goodwin, J. G. Characterization of Catalytic Surfaces. Chemical Reviews 1995, 95, 677-695.

(5) Birky, T. W.; Kozlowski, J. T.; Davis, R. J. Isotopic transient analysis of the ethanol coupling reaction over magnesia. Journal of Catalysis 2013, 298, 130-137.

(6) Tsuchida, T.; Kubo, J.; Yoshioka, T.; Sakuma, S.; Takeguchi, T.; Ueda, W. Influence of Preparation Factors on Ca/P Ratio and Surface Basicity of Hydroxyapatite Catalyst. Journal of the Japan Petroleum Institute 2009, 52, 51-59.

(7) Shou, H.; Davis, R. J. Multi-product steady-state isotopic transient kinetic analysis of CO hydrogenation over supported molybdenum carbide. Journal of Catalysis 2013, 306, 91-99.

(8) Bordawekar, S.; Doskocil, E.; Davis, R. Microcalorimetric study of CO2 and NH3 adsorption on Rb-and Sr-modified catalyst supports. Langmuir 1998, 14, 1734-1738.

(9) Stošić, D.; Bennici, S.; Sirotin, S.; Calais, C.; Couturier, J. L.; Dubois, J. L.; Travert, A.; Auroux, A. Glycerol dehydration over calcium phosphate catalysts: Effect of acidic-basic features on catalytic performance. Applied Catalysis A: General 2012, 447-448, 124-134.

(10) Tsuchida, T.; Kubo, J.; Yoshioka, T.; Sakuma, S.; Takeguchi, T.; Ueda, W. Reaction of ethanol over hydroxyapatite affected by $\mathrm{Ca} / \mathrm{P}$ ratio of catalyst. Journal of Catalysis $\mathbf{2 0 0 8}$, $259,183-189$. 
(11) Tanaka, H.; Watanabe, T.; Masatoshi Chikazawa, A. FTIR and TPD studies on the adsorption of pyridine, n-butylamineand acetic acid on calcium hydroxyapatite. Journal of the Chemical Society, Faraday Transactions 1997, 93, 4377-4381.

(12) Faria, R. M.; César, D. V.; Salim, V. M. Surface reactivity of zinc-modified hydroxyapatite. Catalysis Today 2008, 133-135, 168-173.

(13) Auroux, A.; Gervasini, A. Microcalorimetric study of the acidity and basicity of metal oxide surfaces. J. Phys. Chem. 1990, 94, 6371-6379.

(14) Cardona-Martinez, N.; Dumesic, J. A. In, D.D. Eley, H. P., Weisz, P. B., Eds.; Advances in Catalysis, Vol. 38; Academic Press: 1992, pp 149-244.

(15) Diallo-Garcia, S.; Osman, M. B.; Krafft, J. M.; Casale, S.; Thomas, C.; Kubo, J.; Costentin, G. Identification of surface basic sites and acid-base pairs of hydroxyapatite. Journal of Physical Chemistry C 2014, 118, 12744-12757.

(16) Ogo, S.; Onda, A.; Iwasa, Y.; Hara, K.; Fukuoka, A.; Yanagisawa, K. 1-Butanol synthesis from ethanol over strontium phosphate hydroxyapatite catalysts with various $\mathrm{Sr} / \mathrm{P}$ ratios. Journal of Catalysis 2012, 296, 24-30. 


\section{Appendix E}

\section{Rate Equation Derivation}

\section{Aldol Condensation: Kinetically Relevant Adsorption and Des- orption}

A potential kinetic model that fits the results presented in the paper assumes that both adsorption of acetaldehyde and desorption of crotonaldehyde are kinetically relevant and that crotonaldehyde is the most abundant reactive intermediate. In this case, the kinetically-significant elementary steps are 


$$
\begin{gathered}
\mathrm{AcH}+* \stackrel{\mathrm{k}_{1}}{\longrightarrow} \mathrm{AcH} * \\
\cdots \\
\mathrm{CrH} * \stackrel{\mathrm{k}_{2}}{\longrightarrow} \mathrm{CrH}+*
\end{gathered}
$$

where step E.1 occurs twice for every occurrence of step E.2.

A derivation of the rate equation in which the desorption of water is kinetically relevant gives the same result. It seems more likely that desorption of crotonaldehyde is more kinetically relevant than desorption of water because of the poly-condensation products that are formed at higher pressures of acetaldehyde and are responsible for deactivation.

The overall rate of reaction must be equal to the rate of these two elementary steps

$$
r=\frac{r_{1}}{2}=r_{2}
$$

where $r_{1}=k_{1} P_{\mathrm{AcH}}[*]$ and $r_{2}=k_{2}[\mathrm{CrH} *]$. Substituting into Equation E.3 and rearranging

$$
[\mathrm{CrH} *]=\frac{k_{1}}{2 k_{2}} P_{\mathrm{AcH}}[*]
$$

A site balance can be used to solve for $[*]$. Assuming crotonaldehyde is the most abundant reactive intermediate 


$$
[*]_{0}=[*]+[\mathrm{CrH} *]
$$

Substituting Equation E.4 into Equation E.5 and rearranging gives

$$
[*]=\frac{[*]_{0}}{1+\left(k_{1} / 2 k_{2}\right) P_{\mathrm{AcH}}}
$$

Plugging Equation E.6 into the expression for $r_{1}$ gives

$$
r=\frac{\left(k_{1} / 2\right)[*]_{0} P_{\mathrm{AcH}}}{1+\left(k_{1} / 2 k_{2}\right) P_{\mathrm{AcH}}}
$$

